UNIVERSIDADE DE SÃO PAULO

DANIEL COSTA DE PAIVA

\title{
MODELAGEM E SIMULAÇÃO DE AGENTES COM ASPECTOS COGNITIVOS PARA AVALIAÇÃO DE COMPORTAMENTO SOCIAL
}


DANIEL COSTA DE PAIVA

\section{MODELAGEM E SIMULAÇÃO DE AGENTES COM ASPECTOS COGNITIVOS PARA AVALIAÇÃO DE COMPORTAMENTO SOCIAL}

Tese apresentada à Escola Politécnica da Universidade de São Paulo para obtenção do Título de Doutor em Engenharia Elétrica. 
DANIEL COSTA DE PAIVA

\section{MODELAGEM E SIMULAÇÃO DE AGENTES COM ASPECTOS COGNITIVOS PARA AVALIAÇÃO DE COMPORTAMENTO SOCIAL}

Tese apresentada à Escola Politécnica da Universidade de São Paulo para obtenção do Título de Doutor em Engenharia Elétrica.

Área de Concentração:

Engenharia de Sistemas Eletrônicos

Orientador: Prof. Dr. Marcio Lobo Netto 
Este exemplar foi revisado e alterado em relação à versão original, sob responsabilidade única do autor e com a anuência do orientador.

São Paulo, 27 de Maio de 2011.

Daniel Costa de Paiva

Marcio Lobo Netto

Paiva, Daniel Costa de

Modelagem e simulação de agentes com aspectos cognitivos para avaliação de comportamento social / D. C. de Paiva. - ed. rev. -- São Paulo, 2011.

$144 \mathrm{p}$.

Tese (Doutorado) - Escola Politécnica da Universidade de São Paulo. Departamento de Engenharia de Sistemas Eletrônicos.

1. Simulação 2. Sistemas multiagentes 3. Comportamento social t. Ontologia 5. Fluxos de informação I. Universidade de São Paulo. Escola Politécnica. Departamento de Engenharia de Sistemas Eletrônicos II. t. 


\section{DEDICATÓRIA}

Este trabalho é dedicado a todos os amigos, colegas do Cognitio e da Universidade, professores e familiares que direta ou indiretamente contribuíram para que esteja concluído. 


\section{AGRADECIMENTOS}

Primeiramente ao Pai Celestial por me dar forças todos os dias para o cumprimento das tarefas;

Aos amigos do Cognitio e do LSI pela troca de informações e o aprendizado constante;

Aos amigos, João Henrique Ranhel Ribeiro, Luciene Cristina Alves Rinaldi, Marcos Cavalhieri, César Gomes Miguel, Carolina Zanqueta e Fábio da Silva Gomes pelas conversas, discussões científicas e ajudas;

Aos professores, em especial, Marcos Luiz Mucheroni, Hélcio Domingues e Maria Cristina Vidal Borba, pela atenção, dedicação e troca de conhecimento;

Aos colegas da Faculdade Cásper Líbero e da Escola de Comunicação e Artes da USP pelas oportunidades;

Ao professor Dr. Henrique Schützer Del Nero (in memorian) e sua esposa Dra. Lúcia Maria Argollo Maciel pela iniciação na Ciência Cognitiva, o conhecimento adquirido e por terem cuidado de mim, sendo efetivos quando mais precisei;

Ao meu orientador, Marcio Lobo Netto, pelas discussões e contribuições, por me ajudar nesta árdua jornada de um dia almejar um posto que nunca imaginei, ser doutor, e por mostrar-me que posso cumprir tarefas bem maiores que imaginava poder;

A todas as pessoas que conheci após o ingresso no Curso pelo companheirismo;

Aos meus familiares pelo apoio constante e por entenderem minha ausência em muitos momentos pelas tarefas e, principalmente pela distância;

Aos meus pais pelas cobranças, apoios e incentivos, sempre contribuindo;

À Vanessa que participou de toda a jornada, sendo decisiva nos momentos em que eu mais precisei;

A todas as pessoas que participaram destes mais de quatro anos, nos momentos de distração ou nos períodos de trabalho e dedicação, pois mesmo com o tempo, muitas vezes curto, conseguimos realizar nossas atividades.

À Fundação de Amparo à Pesquisa do Estado de São Paulo (FAPESP) pelo suporte financeiro e por acreditar no meu potencial. 
"Um trabalho que temos a graça e a oportunidade de fazer, é nossa realização. Dedicar a alguém é demonstrar, reconhecer que eles também ajudaram de algum modo".

Retirado do livro: A Casa do Escritor, por Vera Lúcia Marinzeck de Carvalho, publicado em 1995. 


\section{RESUMO}

Este trabalho foi elaborado considerando conceitos de quatro áreas de pesquisa: ciência da computação, ciência cognitiva, ciência da informação e comunicação social. A contribuição principal aqui se dá em definir agentes minimamente cognitivos que participam ativamente na dinâmica do fluxo de informações, sofrendo influência das mensagens que recebem e também interferindo no que irá passar adiante. O modelo contempla tanto características relacionadas ao ambiente e sociedade, definidos usando ontologias, quanto à "mente", arquitetura e funcionamento dos agentes. Cada personagem possui três módulos de decisão, podendo acessar meios de comunicação em massa, assimilar informações recebidas e também falar com seus amigos. Para o módulo de assimilação, estão apresentadas quatro formas que os agentes podem usar para avaliar as informações que recebem. Primeiramente foi elaborada uma função, depois foram definidas três máquinas de estados finitos, aumentando gradativamente a complexidade e a interdependência entre os parâmetros envolvidos em cada uma. Foi também elaborada uma função adaptativa, a qual a partir de uma regra definida pelo usuário para a troca entre as máquinas de estado que os agentes dispõem, propiciou resultados satisfatórios mesmo nos casos onde alguma das máquinas de estado apresentou deficiências. Visando reproduzir uma situação inspirada na vida real, estão apresentados resultados de uma versão combinada (definida pelo autor) onde foram considerados três grupos e a possibilidade de acesso a meios de comunicação em massa e/ou troca de mensagens entre amigos. Usando o modelo como base, um simulador foi desenvolvido onde é possível ter não só uma visão global da dinâmica que está acontecendo na sociedade, mas também o que alguns agentes ficam sabendo e que podem falar sobre. Os estudos de caso visaram comparar as diferentes formas de assimilação de informações que os agentes podem usar (elaboradas pelo autor), avaliar a influência da variação de alguns parâmetros e reproduzir a dinâmica do fluxo de informações em redes sociais, a comparando com o que acontece quando se tem a divulgação broadcast.

Palavras-chave: Sistemas Multiagentes, Simulação de Humanos Virtuais, Aspectos Cognitivos, Fluxo de Informação, Ontologia. 


\begin{abstract}
This work was developed considering concepts of four research areas: computer science, cognitive science, information science and social communication. The main contribution here is to define minimally cognitive agents who actively participate in dynamic of information flow interfering on the messages received and are being affected by them. The model consider characteristics related to the environment and the society, defined by using ontologies, and the "mind", architecture and functioning of the agents. Each character has three decision modules. They can access means of mass communication, assimilate information received and talk to their friends. To the assimilation module were presented four forms that agents can evaluate received information, a function, and three finite state machines (FSM). They were elaborated increasing the complexity. After, it was developed an adaptive function, in which using a rule the user define how to exchange between the finite state machines that agents have. This function provided satisfactory results even in cases where some of the FSMs presented problems. Aiming to reproduce a situation inspired in real life a combined version was defined by the author, in where were considered three groups that can access means of mass communication and / or talk to their friends. Based on the model, a simulator was developed in which there are not only an overview of the society dynamics, but also what agents learn and what they can talk about. The case studies were performed aiming to compare the different assimilation forms (developed by the author), to evaluate the influence of some parameters variation and to reproduce the dynamics of information flow, comparing the influence of a social network communication and the mass communication activity
\end{abstract}

Keywords: Multiagent Systems, Virtual Humans Simulation, Cognitive Aspects, Information Flow, Ontology. 


\section{LISTA DE FIGURAS}

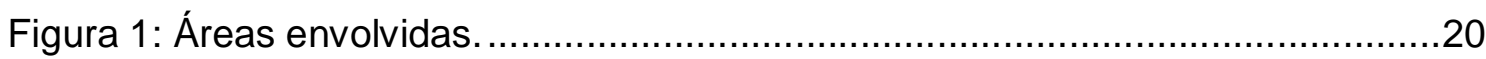

Figura 2 Estrutura de um agente - adaptada de Russell e Norvig (2004).................29

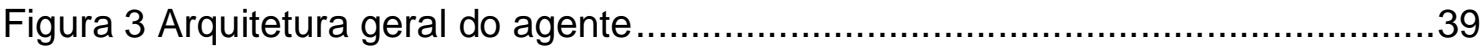

Figura 4:Exemplo de comunicação direta entre agentes.......................................44

Figura 5:Exemplo de comunicação indireta entre agentes.......................................4

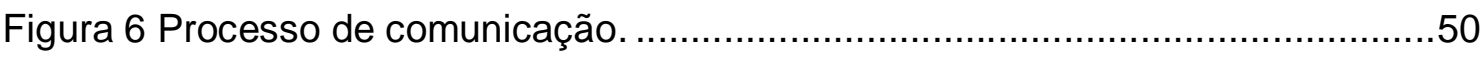

Figura 7: Modelo Modal de Memória adaptada de (Atkinson, Shiffrin, 1968)...........52

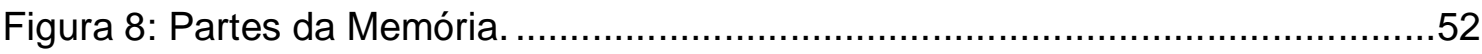

Figura 9: Áreas com relação mais próxima com a Ciência da Informação, segundo

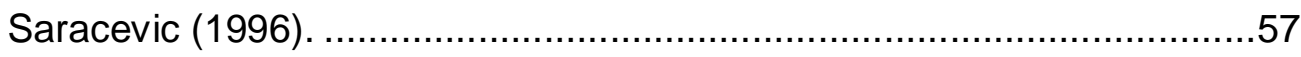

Figura 10: Níveis de abstração que compõem este projeto: a sociedade com agentes (círculos) e meios de comunicação em massa (retângulos) e o funcionamento interno de cada um dos agentes...................................68

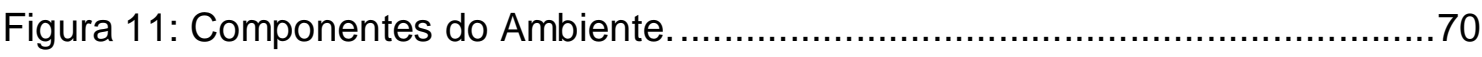

Figura 12: Relacionamento direto entre agentes (círculos) e através dos meios de comunicação em massa (retângulos).................................................. 71

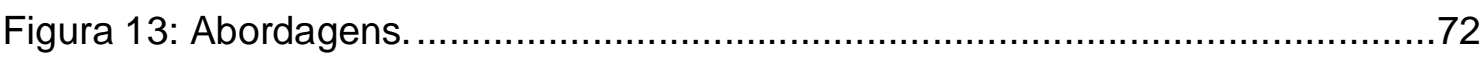

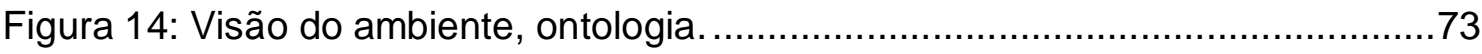

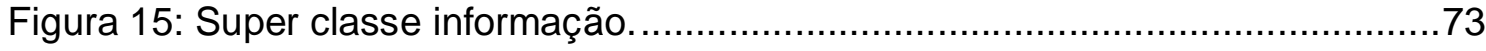

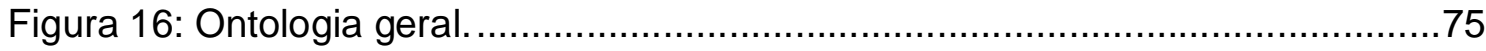

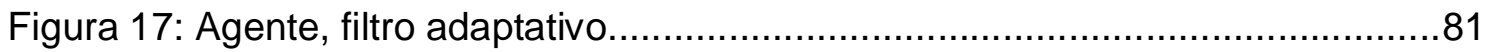

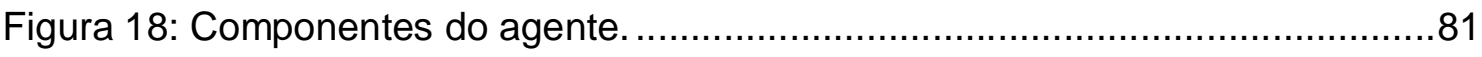

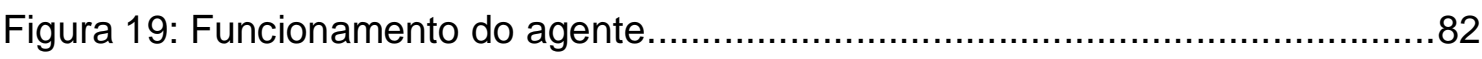

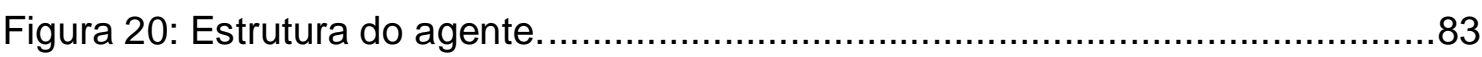

Figura 21: Dinâmica tendo como base os possíveis estados internos do agente.....84

Figura 22: Processo usado para decisão de acessar algum meio de comunicação em

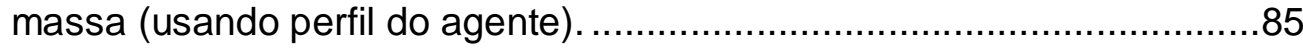

Figura 23: Processo usado para receber e tratar informações advindas de algum

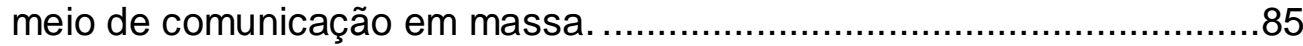

Figura 24: Processo usado para receber e avaliar o que "ouviu" de algum amigo....86 
Figura 25: Processos usados para a decisão de falar............................................86

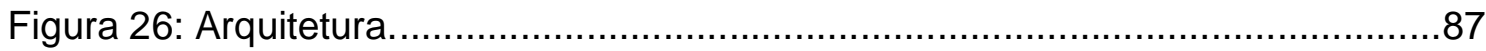

Figura 27: Versão agrupada das informações no agente......................................90

Figura 28: Máquina de estados que o agente usará para assimilar informações às

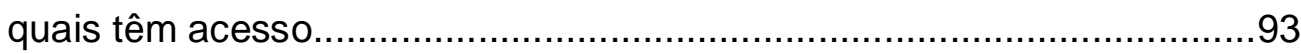

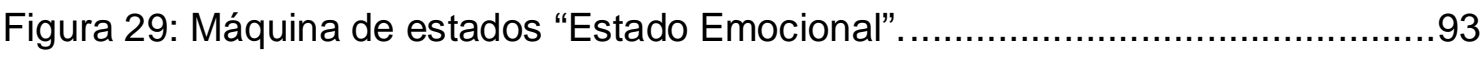

Figura 30: Máquina Dois: modificações decorrentes dos "estados emocionais" ansioso e deprimido na avaliação que os agentes consideram para

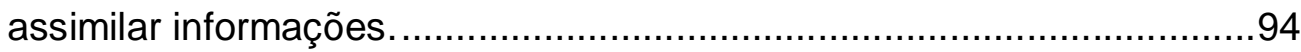

Figura 31: Máquina Três: efeito do interesse e estado emocional na avaliação que os agentes consideram para assimilar informações....................................95

Figura 32: Visualização do andamento da simulação (100 agentes) a) Interface: últimos 10 frames (linhas) dos primeiros 10 agentes. b) Gráfico: quantidade de agentes que sabe de cada um dos assuntos nos últimos

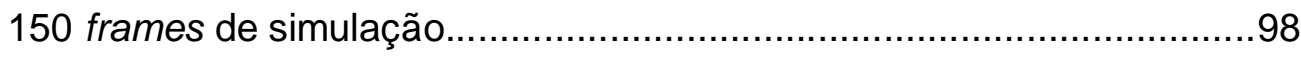

Figura 33: Visualização do andamento da simulação (100 agentes) - interface: frame atual de todos os agentes. .........................................................99

Figura 34: Divisão dos Estudos de Caso - Nível da Sociedade. ............................100

Figura 35: Divisão dos Estudos de Caso - Nível do Agente..................................100

Figura 36: Acoplamento entre dois agentes.................................................107 


\section{LISTA DE GRÁFICOS}

Gráfico 1: Exemplo de alteração na reação dos agentes (saída) para informações recebidas (entrada).

Gráfico 2: Resultados com o uso pelos agentes da função de assimilação (INT * IMP) > Limiar.

102

Gráfico 3: Resultados com o uso pelos agentes da máquina de estados que leva em consideração ((INT * IMP) > Limiar) para a progressão de estado.

Gráfico 4: Resultados com o uso pelos agentes da máquina de estados dois (interesse afeta estado emocional e este afeta a assimilação).

Gráfico 5: Resultados com o uso pelos agentes da máquina de estados três (interesse afeta estado emocional e ambos afetam assimilação). 105

Gráfico 6: Resultados da divulgação de informações nos meios de comunicação em massa com a dinâmica na rede social quando os agentes utilizam a função de assimilação (INT * IMP) > Limiar. 109

Gráfico 7: Resultados da divulgação de informações nos meios de comunicação em massa com a dinâmica na rede social quando os agentes utilizam a máquina de estados que leva em consideração ((INT * IMP) > Limiar) para a progressão de estado.

Gráfico 8: Resultados da divulgação de informações nos meios de comunicação em massa com a dinâmica na rede social quando os agentes utilizam a máquina de estados dois (interesse afeta estado emocional, EE afeta a assimilação).

Gráfico 9: Resultados da divulgação de informações nos meios de comunicação em massa com a dinâmica na rede social quando os agentes utilizam a máquina de estados três (interesse afeta estado emocional e ambos afetam assimilação).

Gráfico 10: Comparativo entre as máquinas de estado com quando os agentes usam função adaptativa. Nível de Interesse: baixo / Estado Emocional: deprimido. 
Gráfico 11: Comparativo entre as máquinas de estado com quando os agentes usam função adaptativa. Nível de Interesse: médio / Estado Emocional: deprimido.

Gráfico 12: Comparativo entre as máquinas de estado com quando os agentes usam função adaptativa. Nível de Interesse: médio / Estado Emocional: normal.

Gráfico 13: Comparativo entre as máquinas de estado com quando os agentes usam função adaptativa. Nível de Interesse: médio / Estado Emocional: ansioso.

Gráfico 14: Comparativo entre as máquinas de estado com quando os agentes usam função adaptativa. Nível de Interesse: alto / Estado Emocional: ansioso. Situação onde a maior quantidade de agentes sabe de algo por um maior período de tempo.

Gráfico 15: Versão combinada, apenas meios de comunicação em massa. 118

Gráfico 16: Versão combinada comunicação através dos meios de comunicação em massa e na rede social. Agentes com personalidade falante tentam falar a todo minuto. 119

Gráfico 17: Versão combinada comunicação através dos meios de comunicação em massa e na rede social. Agentes com personalidade normal tentam falar a cada 10 minutos. 


\section{LISTA DE QUADROS}

Quadro 1: Exemplo de mapa de mídia......................................................66

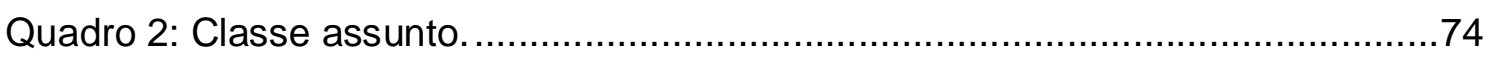

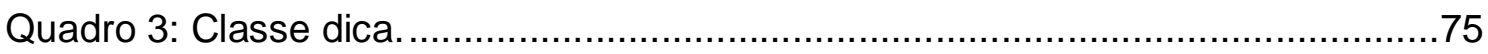

Quadro 4: Classe grupo de relacionamento................................................ 76

Quadro 5: Classe meios de comunicação entre agentes. .................................76

Quadro 6: Classe meios de comunicação em massa.........................................77

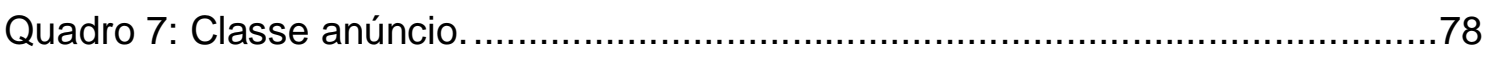

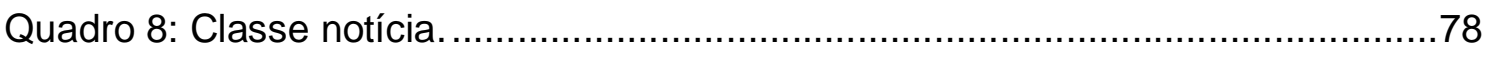

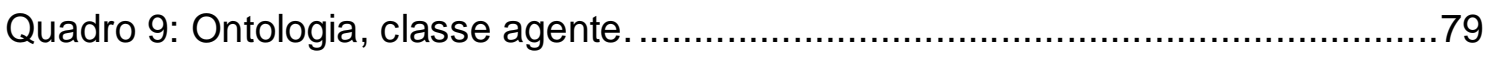

Quadro 10: Classe personalidade. .................................................... 79

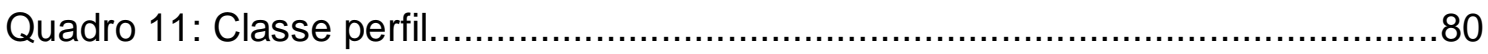

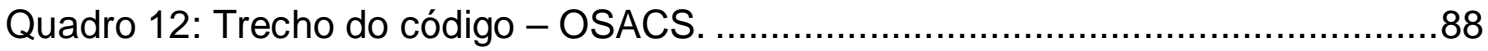

Quadro 13: Trecho do código: rotina principal dos agentes - OSACS....................89

Quadro 14: Relação entre interesse e impacto. Valores que interferem no estado emocional. ............................................................................... 94

Quadro 15: Influência do interesse e do estado emocional na velocidade de assimilação de informações. ............................................................95

Quadro 16: *Legendas que identificam no próximo gráfico os resultados referentes a cada uma das possíveis combinações de estado emocional e nível de interesse com as máquinas dois e três. 


\section{LISTA DE TABELAS}

Tabela 1: Arquivo de Configurações. 


\section{LISTA DE ABREVIATURAS E SIGLAS}

\begin{tabular}{|c|c|}
\hline$A C L$ & Agent Communication Language \\
\hline $\mathrm{ACP}$ & Armazenamento de Curto Prazo \\
\hline ALP & Armazenamento de Longo Prazo \\
\hline AS & Armazenamento Sensorial \\
\hline $\mathrm{BC}$ & Base de Conhecimento \\
\hline BDI & Beliefs, Desires and Intentions \\
\hline $\mathrm{Cl}$ & Ciência da Informação \\
\hline CS & Comunicação Social \\
\hline DAc & Decisão de Acessar algum meio de comunicação em massa \\
\hline DAs & Decisão de Assimilar \\
\hline DF & Decisão de Falar \\
\hline DI & Decisão \\
\hline ECA & Escola de Comunicação e Artes \\
\hline El & Estado Interno \\
\hline EP & Escola Politécnica \\
\hline FAPESP & Fundação de Amparo à Pesquisa do Estado de São Paulo \\
\hline FIPA & Foundation for Intelligent Physical Agents \\
\hline FPS & Frames por Segundo \\
\hline FSM & Finite State Machine \\
\hline IA & Inteligência Artificial \\
\hline IAD & Inteligência Artificial Distribuída \\
\hline IBBD & Instituto Brasileiro de Bibliografia e Documentação \\
\hline le & Informação de Entrada \\
\hline Is & Informação de Saída \\
\hline KQML & Knowledge Query and Manipulation Language \\
\hline LCA & Linguagem de Comunicação de Agentes \\
\hline MCM & Meio de Comunicação em Massa \\
\hline OSACS & Ontology Simulator for Agents with Cognitive Skills \\
\hline RDP & Resolução Distribuída de Problemas \\
\hline MA & Sistemas Multiagentes \\
\hline & Universidade de São Paulo \\
\hline
\end{tabular}




\section{SUMÁRIO}

CAPÍTULO 1.

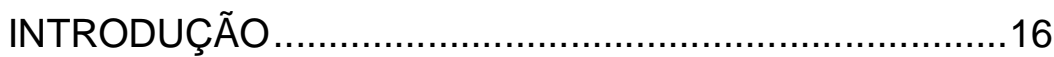

1.1

MOTIVAÇÃO E JUSTIFICATIVA...................................................................................17

1.2 SOLUÇÃO PROPOSTA.................................................................................................18

1.2.1 Áreas Envolvidas...........................................................................................19

1.2.1.1 Ciência da Computação ...................................................................................21

1.2.1.2 Ciência Cognitiva..............................................................................................22

1.2.1.3 Ciência da Informação e Comunicação Social..........................................23

1.3 OBJETIVOS ..............................................................................................................24

1.3.1 Objetivo Geral .................................................................................................

1.3.2 Objetivos Específicos .....................................................................................

1.4 ORGANIZAÇÃO DA TESE ...........................................................................................25

CAPÍTULO 2. CIÊNCIA DA COMPUTAÇÃO ………............................26

2.1 DEFINIÇÃO E USO DO TERMO “AGENTE” ......................................................................... 29

2.2 CARACTERÍSTICAS DOS AGENTES..........................................................................

2.2.1 Continuidade Temporal e Autonomia....................................................31

2.2.2 Reatividade ou Pró-Atividade.........................................................................32

2.2.3 Racionalidade ......................................................................................................

2.2.4 Adaptação e Aprendizagem..........................................................................34

2.2.5 Comunicabilidade.........................................................................................

2.2.6 Cooperação ................................................................................................

$2.3 \quad$ TIPOS DE AGENTES................................................................................................

2.4 ARQUITETURAS DE AGENTES ....................................................................................38

2.4.1 Agentes Cognitivos e a Abordagem Mentalista.........................................40

2.5 AMBIENTE E SUAS CONFIGURAÇÕES ......................................................................41

2.6 TRABALHOS RELACIONADOS ................................................................................43

2.6.1 Pesquisas que envolvem comunicação entre agentes no âmbito da ciência da computação ..................................................................................... 43

2.6.1.1 Linguagens para Comunicação entre Agentes..........................................45

CAPÍTULO 3. CIÊNCIA COGNITIVA ……….....................................

3.1 COMUNICAÇÃO ................................................................................................

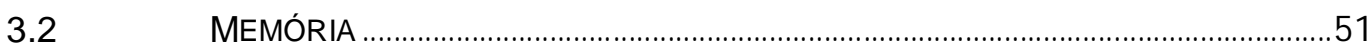

3.3 APRENDIZAGEM ....................................................................................................53 


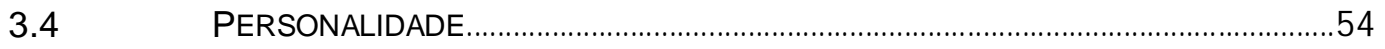

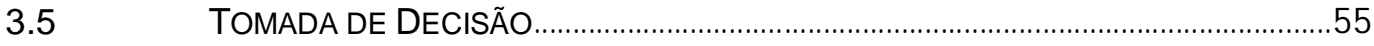

CAPÍTULO 4. CIÊNCIA DA INFORMAÇÃO E COMUNICAÇÃO SOCIAL56

4.1 REDES SOCIAIS ..........................................................................................................58

4.1.1 Redes Sociais na Internet.............................................................................60

4.1.1.1 Blogs e Fotologs ..........................................................................................61

4.2 MEIOS DE COMUNICAÇÃO EM MASSA (MCM) E SUA INFLUÊNCIA NO PÚBLICO.

4.3 FORMAS E OBJETIVOS DA DIVULGAÇÃO DE UMA NOTÍCIA OU ANÚNCIO...........64

4.3.1 Plano de Mídia.........................................................................................................65

CAPÍTULO 5. MODELAGEM COMPUTACIONAL …................................

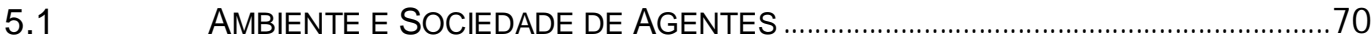

5.1.1 Abordagens de Comunicação..........................................................................

5.1.2 Desenvolvimento usando Ontologia.............................................................. 73

5.1.2.1 A Classe Agente .............................................................................................78

5.2 FUNCIONAMENTO DOS AGENTES COM ASPECTOS COGNITIVOS.........................81

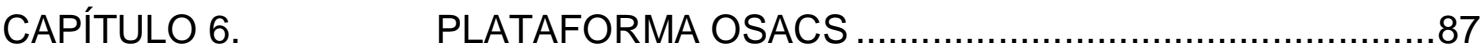

6.1 FORMAS DE ASSIMILAÇÃO DE INFORMAÇÕES........................................................91

6.1.1 Função Limiar - onde o Interesse Interfere na Assimilação................92

6.1.2 Máquina de Estados Um - onde o Interesse Interfere na Assimilação

6.1.3 Máquina de Estados Dois - onde o Interesse e o Impacto Interferem no Estado Emocional e este Último Interfere na Assimilação

6.1.4 Máquina de Estados Três - onde o Interesse e o Impacto Interferem no Estado Emocional e todos estes Interferem na Assimilação.........95

6.2 FORMA DE ESCOLHA SOBRE O QUE E PARA QUEM FALAR...................................96

CAPÍTULO 7. ESTUDOS DE CASO E RESULTADOS ….......................98

7.1 A INFLUÊNCIA DOS MEIOS DE COMUNICAÇÃO EM MASSA NAS INFORMAÇÕES CONHECIDAS PELOS AGENTES ............................................................................... 101

7.1.1 Estudo de Caso MCM - 1: Função Limiar .................................................102

7.1.2 Estudo de Caso MCM - 2: Máquina de Estados Um............................103

7.1.3 Estudo de Caso MCM - 3: Máquina de Estados Dois.........................103

7.1.4 Estudo de Caso MCM - 4: Máquina de Estados Três..........................105

7.1.5 Considerações Finais ......................................................................................106 
7.2 INFLUÊNCIA DO FLUXO DE INFORMAÇÕES NAS REDES SOCIAIS EM COMPARAÇÃO COM A COMUNICAÇÃO BROADCAST ............................................ 106

7.2.1 Estudo de Caso RS - 1: Função Limiar....................................................108

7.2.2 Estudo de Caso RS - 2: Máquina de Estados Um................................109

7.2.3 Estudo de Caso RS - 3: Máquina de Estados Dois..............................110

7.2.4 Estudo de Caso RS - 4: Máquina de Estados Três...............................111

7.2.5 Considerações Finais ....................................................................................112

7.3 Os AgEntes DeVEM AgIR Assim! - FunÇÃo AdAPTATIVA..............................113

7.4 VERSÃO COMBINADA...................................................................................118

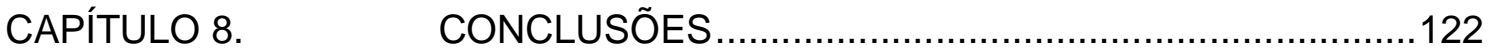

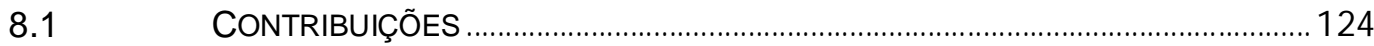

8.2 POSSÍVEIS APLICAÇÕES .................................................................................124

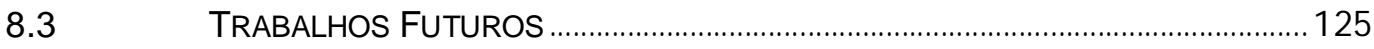

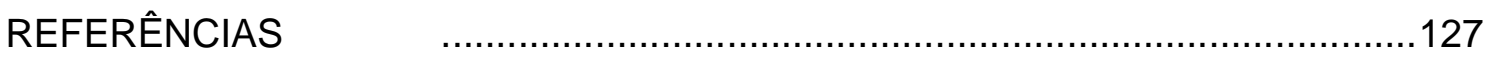

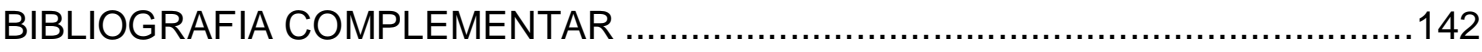

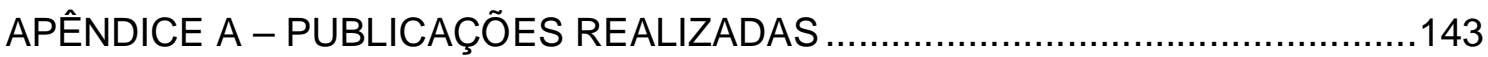

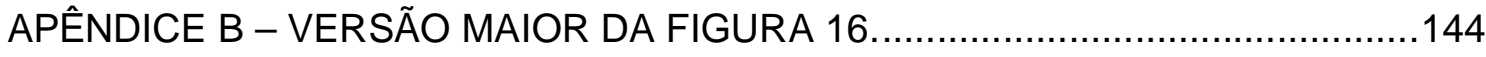




\section{Capítulo 1. INTRODUÇÃO}

Compreender as características dos seres humanos é uma tarefa complexa principalmente quando se considera o aspecto social. Desta forma, a modelagem e simulação do comportamento de humanos virtuais tornaram-se alvo de estudo em diferentes ramos da Ciência. Mesmo sendo simplificações dos seres humanos reais, a descrição das propriedades dos humanos virtuais (ou agentes com aspectos cognitivos, no âmbito deste projeto) tem se revelado um desafio em função de sua complexidade e diversidade. Isso ocorre, pois as características individuais e coletivas das pessoas produzem grande variedade de comportamentos, tornando sua modelagem complexa e requerendo que uma grande quantidade de atributos seja considerada para que bons resultados sejam obtidos (ALT; LIEBERMAN, 2010; CASTELFRANCHI, 1998; THALMANN; MUSSE, 2007).

Juntamente com o desafio de elaborar agentes que reproduzam comportamentos identificados em situações reais, está a abordagem de formas de comunicação. Isto se dá, pois os tipos de informação que circulam em diferentes ambientes variam em função dos grupos, dos aspectos sociais e da cultura. A frequência com que uma informação é disseminada é altamente variável, podendo ocorrer continuamente durante o dia, uma vez por dia ou por semana, ou ainda sem uma periodicidade definida. Os meios pelos quais a comunicação ocorre também são flexíveis, podendo ser, por exemplo, face a face, por e-mail ou telefone.

Aqui, dada a atualidade do tema (BOUYER, 2008; PEREIRA; FREITAS; SAMPAIO, 2007, SIMPKINS et. al., 2010, SUGAHARA, 2008), se busca estudar a dinâmica do fluxo de informações em ambientes sociais virtuais, pois se verifica a grande importância da comunicação, que pode ocorrer tanto diretamente, ou seja, entre agentes de um mesmo grupo ou rede social, quanto através de meios de comunicação em massa (tipicamente eletrônicos) que propiciam uma vasta disseminação das informações (broadcasting). 


\subsection{Motivação e Justificativa}

Especificamente, o problema a ser tratado neste trabalho refere-se ao estudo, modelagem e simulação computacional do comportamento de humanos virtuais como interlocutores em processos de disseminação de informações. Neste sentido há especial interesse em compreender as formas de aquisição e troca de informações (mediadas por processos cognitivos), além do relacionamento entre os agentes do sistema, configurando a dinâmica das redes sociais.

Dos trabalhos que podem ser identificados na literatura, grande grupo de pesquisadores, principalmente no âmbito da Psicologia (ALMADA, OLIVEIRA, 1997; FITZGERALD, 1986; KIHLSTROM; PARK, 2002) e das pesquisas de opinião (GOMES, 2007; IBOPE, 2010, TOM MICRO, 2010), estuda o indivíduo e suas decisões, analisando dados coletados usando questionários ou entrevistas. Objetivase nestes casos compreender alguns comportamentos pessoais e sociais, muitas vezes para identificar melhores formas de ajuste dos mecanismos de divulgação de uma notícia ou da propaganda de um produto. No entanto, tais pesquisas são restritas a um pequeno universo e às condições e enfoque que dela fazem parte, com o que se torna difícil (em alguns casos, impossível) realizar avaliações mais genéricas, como o impacto de alguma variante não observada.

Uma possibilidade é complementar estas pesquisas com o uso de simulações computacionais as quais permitem, em um primeiro momento, reproduzir situações conhecidas e avaliar cenários diversos. A seguir, num segundo momento pode-se ter uma visão da dinâmica através da qual é possível identificar e estudar a emergência de fenômenos complexos e as implicações dos mesmos, fato dificilmente observado ou possível de ser controlado se não num laboratório virtual.

Acredita-se que isto seja possível a partir da utilização da modelagem baseada em agentes, em especial considerando formas de aquisição e troca de informações e buscando reproduzir a dinâmica do relacionamento entre indivíduos. Além disto, um aspecto importante neste projeto é entender porque um agente decide se comunicar, quais as conseqüências desta ação e analisar o seu impacto na propagação das informações. 
Outra motivação aqui é prover simulações que reproduzam características identificadas no mundo real, onde agentes que possuam aspectos cognitivos povoem o mundo de maneira coerente com suas funcionalidades. Para isto propõese um modelo simples, de fácil configuração e uso, que permita a simulação de diferentes cenários em ambientes virtuais e que contemple populações com características variadas. Neste sentido o uso de ontologia como descrito em (GRUBER, 1993) se mostra adequado.

A tese neste doutorado repousa no fato de que a incorporação de aspectos cognitivos em agentes proporciona resultados coerentes no âmbito de fluxo de informações. Desta forma, considera-se que é possível realizar a modelagem e desenvolvimento de sociedades de agentes considerando tanto seus impactos sobre as informações a serem propagadas quanto no sentido inverso entender a influência exercida pelas mensagens sobre o sistema "cognitivo" do receptor-transmissor das mesmas.

\subsection{Solução Proposta}

Seguindo a linha de modelagem comportamental, e dado o problema descrito, a solução proposta é considerar aspectos cognitivos, em especial comunicação e aprendizado, de forma que os agentes alterem a si próprios e modifiquem as informações a que têm acesso durante a simulação. Além disto, eles devem possuir representação das informações e dos outros agentes da sociedade, planejar ações futuras conforme a capacidade de memória que possuam, na qual armazenam seus conhecimentos e o histórico das comunicações passadas. Pretende-se também que eles possam receber informações publicadas em meios de comunicação em massa, conversar com outros agentes e tomar decisões considerando não apenas funções probabilísticas fixas, mas também a influência do ambiente e da sociedade na qual estão inseridos (região cinza no Gráfico 1). Afinal não é de interesse que o agente reaja sempre da mesma forma (linha tracejada no mesmo gráfico), mas que possa dar mais valor para uma informação sobre política em determinado momento e 
menos em outro, como representado em amarelo, devido a, por exemplo, proximidade das eleições.

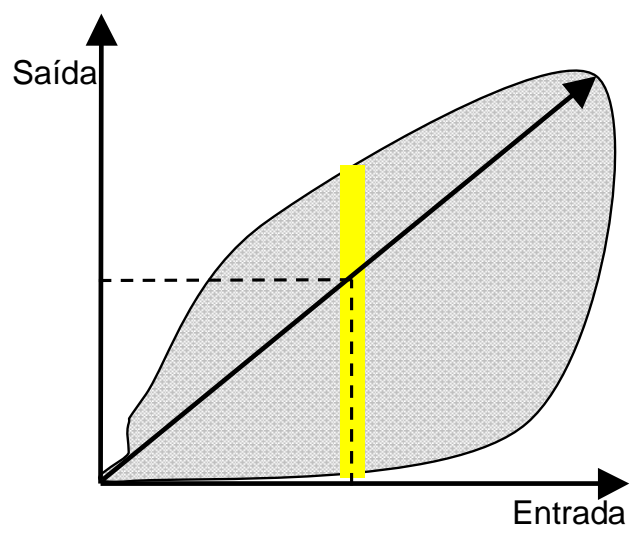

Gráfico 1: Exemplo de alteração na reação dos agentes (saída) para informações recebidas (entrada).

Neste sentido se propõe um modelo que permita representar aspectos realistas e importantes do comportamento humano em situações da vida cotidiana, e assim usar o simulador para testar diferentes padrões de divulgação e avaliar os resultados.

\subsection{1 Áreas Envolvidas}

Nesta seção estão apontadas as quatro áreas envolvidas no presente trabalho e, nas subseções, destacados os pontos de cada uma delas que se relacionam com este projeto de doutorado. Também é preciso esclarecer que os conceitos relevantes e trabalhos de cada uma destas áreas estão abordados nos três próximos capítulos desta tese de doutorado. 


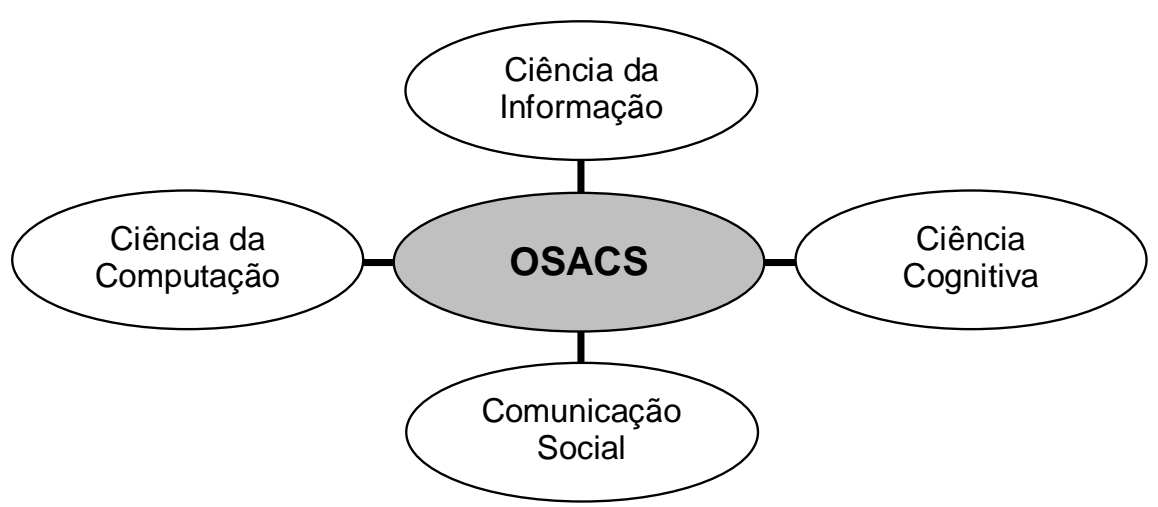

Figura 1: Áreas envolvidas.

Podem ser vistas na Figura 1, as quatro áreas importantes para a elaboração do OSACS (acrônimo definido pelo autor para Ontology Simulator for Agents with Cognitive Skills). Na parte horizontal, estão àquelas relacionadas com o desenvolvimento do simulador e a definição dos personagens. A primeira é a Ciência da Computação, na qual a Inteligência Artificial (RUSSEL; NORVIG, 2004) e Sistemas Multiagentes (WOOLDRIDGE, 2009) são considerados e mais especificamente os agentes, suas características, além da estrutura e organização da sociedade onde estão inseridos. Já a segunda, a Ciência Cognitiva (GAZZANIGA, 1999; WILSON; KEIL, 1999), fornece características mais realistas para a definição do funcionamento interno e os aspectos cognitivos dos agentes, através das quais eles podem receber, assimilar $^{1}$ e trocar informações sobre alguns assuntos.

$\mathrm{Na}$ parte vertical, estão as áreas relacionadas com a dinâmica da simulação, importantes para a aplicação e estudos de caso pretendidos. Considerase que a informação pode ser recebida por um agente advinda de duas fontes: na primeira, ela pode ser publicada por meios de comunicação de massa (BELTRAO; QUIRINO, 1986), cuja área de estudo é a Comunicação Social, e a segunda possibilidade é a troca de informações entre membros de grupos de relacionamento ou Redes Sociais (MARTELETO, 2001; MIKA, 2007; TOMAÉL, 2008), parte muito estudada pela Ciência da Informação e que também é importante aqui.

De forma sucinta o OSACS é, portanto, uma plataforma onde agentes elaborados considerando aspectos cognitivos participam na dinâmica do fluxo de

\footnotetext{
${ }^{1}$ Em todo este trabalho o termo assimilar está relacionado com a atualização (incremento) do tempo que $o$ agente se lembra do assunto recebido.
} 
informações trocando mensagens com seus amigos e também acessando aos meios de comunicação em massa. Cabe ressaltar, portanto que este trabalho não trata das redes sociais reais (comunicação direta ou intermediada por interfaces eletrônicas), mas sim da implementação de uma sociedade virtual inspirada nelas para a definição dos grupos de agentes. Da mesma forma, os aspectos cognitivos são inspirados no conhecimento que se tem dos seus correspondentes reais, não se

pretendendo dizer que os modelos que serão propostos representem fielmente o que ocorre em seres ditos cognitivos.

\subsubsection{Ciência da Computação}

Este projeto enquadra-se na linha de pesquisa de Ciência da Computação e em especial de simulação de comportamento de humanos virtuais. Nesta área de estudo, diversas frentes de trabalho são encontradas (PELECHANO, ALLBECK, BADLER, 2008; THALMANN; MUSSE, 2007). No entanto, é possível fazer a divisão em algumas partes, sendo que em uma delas grande grupo de profissionais e pesquisadores se preocupa com aspectos realistas do ponto de vista visual (SILVA, 2005; TORRES, MAC IEL, NEDEL, 2002), com aplicação para filmes e jogos. Outro grupo se preocupa com entretenimento e desenvolve tanto técnicas de raciocínio e tomada de decisão voltada para jogos, quanto se preocupa com a qualidade visual. Um terceiro grupo foca na utilidade, ou seja, na construção, principalmente, de robôs na busca por facilitar e automatizar a execução de tarefas.

Além destas três frentes, a simulação de comportamento social é um tema diretamente relacionado ao propósito deste projeto. Neste sentido, duas áreas são identificadas, sendo que a primeira e mais freqüente, trata de simulação de situações de emergência, útil para a definição arquitetônica de ambientes e cujo objetivo é maximizar o número de pessoas salvas caso ocorra alguma situação de perigo (BARROS, SILVA, MUSSE, 2004; BRAUN, 2004; CONY, 2007; COURTY, MUSSE, 2004; 2005; HELBING, FARKAS, VICSEK, 2000; HELBING, MOLNAR, 1995; PAN, 2006; PELECHANO, BADLER, 2006; THALMANN, MUSSE, 2007). A segunda frente é relativa à simulação de situações da vida cotidiana, caracterizada quando os personagens realizam atividades comuns ao dia a dia de uma sociedade 
(CONY ET. AL., 2007; HELBING, MOLNAR, 1998; MUSSE, 2001; MUSSE, THALMANN, 2001; PLETSCH, 2006; THALMANN, MUSSE, 2007). É preciso ressaltar que neste projeto de doutorado estão sendo consideradas características relativas a segunda frente, com a qual o autor inclusive já trabalhou (PAIVA, 2006; PAIVA, VIEIRA, MUSSE, 2005). Deve-se esclarecer também que em (ibidem) se encontra uma vasta pesquisa sobre simulação de humanos virtuais e que neste projeto optou-se por abordar áreas não contempladas na pesquisa então apresentada.

Além dos temas acima apresentados este trabalho tem forte relação com o desenvolvimento de simulações utilizando multiagentes inteligentes e com o uso de ontologias como técnica para modelagem formal do sistema, a qual está abordada no Capítulo 5.

\subsubsection{Ciência Cognitiva}

A segunda área de grande importância neste trabalho é a Ciência Cognitiva, a qual é definida como o estudo interdisciplinar da mente (pensamento, entendimento) e da inteligência ou também como estudo científico dos processos mentais (NETTO, 2007). Entender a mente humana requer numerosos métodos e teorias, e neste sentido, a Ciência Cognitiva tem estreitos laços com a Psicologia, a Filosofia, a Inteligência Artificial, a Neurociência e a Lingüística (GARDNER, 1996).

A Ciência Cognitiva estuda fenômenos, "a princípio manifestados em um substrato cerebral, mas passíveis de serem simulados computacionalmente. As Neurociências colaboram na parte referente ao cérebro, a Psicologia com as teorias de funcionamento da mente, a Filosofia, através da Lógica e da Epistemologia, a Lingüística com o exame da linguagem e a Inteligência Artificial, com os modelos de máquinas reais ou teóricas que podem simular o funcionamento do cérebro ou de suas partes" (CESCON, 2009).

Na prática, trabalhos relativos à Ciência Cognitiva descrevem, explicam, e, eventualmente, simulam algumas das disposições e capacidades da cognição humana, buscando copiar e reproduzir os modos de pensar, falar, compreender, 
visando elaborar uma réplica da inteligência humana, reproduzindo algumas das manifestações da mente.

Apesar de se tratar de uma área cujas principais dificuldades são a grande complexidade do cérebro e a grande flexibilidade do pensamento humano, no âmbito deste projeto têm-se particular interesse na proposição de um modelo computacional simples que possa simular algumas das capacidades cognitivas dos seres humanos. A respeito destas capacidades, estão sendo consideradas questões relativas às informações, sua aquisição e processamento, raciocínio, memória; perfil; personalidade; aprendizagem e adaptação; tomada de decisão e, principalmente comunicação. No entanto não se tem a pretensão aqui de reproduzir o funcionamento da mente humana, mas sim aspectos do comportamento de seres humanos.

Conceitualmente, o processamento da informação está centrado no conhecimento baseado no modelo de mundo do indivíduo, e associado ao contexto e à maneira com que cada um vê o mundo.

A contribuição da Ciência Cognitiva é aqui referente ao detalhamento e melhor definição do funcionamento interno de agentes virtuais na busca por entender processos mentais e tentar reproduzir partes deles.

\subsubsection{Ciência da Informação e Comunicação Social}

As duas áreas que completam o presente trabalho são a Ciência da Informação (Cl) e a Comunicação Social (CS).

$\mathrm{Na} \mathrm{Cl}$ o estudo das Redes Sociais (principalmente abordando redes de pesquisadores (LUIZ, 2006; NORONHA et. al., 2007; PINHEIRO; SAVI, 2005; SILVA, SILVA, 2007)) e suas características estão em nível avançado e bem estabelecido (GUTIÉRREZ, 1999; LE COADIC, 2004; MUELLER, 2007; NORONHA et. al., 2007; PINHEIRO, 2007; TOMAÉL, 2008), sendo importante neste trabalho para o tratamento do relacionamento direto entre os agentes.

Já com relação à Comunicação Social, a identificação das subáreas relevantes aqui é mais simples, uma vez que o estudo dos diversos meios de comunicação em massa e formas de divulgação (publicidade, jornalismo) de 
informações são os principais alicerces desta área (BELTRÃO; QUIRINO, 1986; MALANGA, 1979; VIAPIANA, 2010).

\subsection{Objetivos}

Neste projeto de doutorado tem-se como objetivo principal a modelagem e simulação de agentes com aspectos cognitivos, contemplando em parte, características relacionadas à sua "mente" (funcionamento interno) e dando especial ênfase ao tratamento de formas de comunicação e ao fluxo de informações. Considera-se que as simulações precisam conter estórias coerentes tanto coletivas quanto individuais.

\subsubsection{Objetivo Geral}

A investigação de características de personagens com aspectos cognitivos é o objetivo geral, principalmente os considerando como interlocutores em processos de fluxo de informação. Busca-se então a modelagem e simulação de agentes que sejam membros de comunidades e possuam capacidade de receber informações, avaliá-las, tratá-las de algum modo e passá-las a diante.

\subsubsection{Objetivos Específicos}

Os objetivos específicos são, portanto voltados para:

1) Elaborar um modelo de sociedade de agentes que possibilite a troca de informações;

2) Conceber modelos de aspectos cognitivos para a definição de agentes; 
3) Investigar técnicas para simulação de tais agentes e desenvolver um simulador;

4) Avaliar a influência que os parâmetros definidos exercem sobre os resultados passíveis de serem obtidos;

5) Agregar ao sistema aspectos que se assemelhem àqueles que ocorrem na vida cotidiana;

6) Discutir perspectivas futuras com relação ao campo das simulações de sociedades de humanos virtuais e fluxos de informação.

\subsection{Organização da Tese}

Esta tese está organizada de forma que, nos três próximos capítulos estão abordados conceitos importantes e trabalhos relacionados de cada uma das áreas envolvidas no presente projeto de doutorado, no intuito de facilitar o entendimento e também de situar este trabalho na literatura conhecida. O Capítulo 2 se refere à Ciência da Computação, o Capítulo 3 à Ciência Cognitiva, e o Capítulo 4 à Ciência da Informação e Comunicação Social, que por serem áreas auxiliares ao presente trabalho foram agrupadas.

Após a parte teórica e de contextualização, no Capítulo 5 está apresentado o modelo, precedido pelas informações necessárias ao entendimento da ontologia (técnica utilizada para a modelagem) desenvolvida. Ainda neste capítulo estão explicados detalhes do relacionamento entre os agentes e deles com os meios de comunicação em massa, além dos aspectos cognitivos que são abordados e como é seu tratamento.

A arquitetura elaborada, assim como dados da construção, configuração e funcionamento do protótipo estão no Capítulo 6. A seguir, no Capítulo 7 estão as especificidades de cada um dos estudos de caso e os resultados.

Por fim, têm-se no Capítulo 8 as considerações finais e indicações de próximos passos nesta pesquisa. 


\section{Capítulo 2. CIÊNCIA DA COMPUTAÇÃO}

A principal área da Ciência da Computação relacionada com este projeto é a Inteligência Artificial (IA). Esta corresponde a um ramo recente da ciência cujo objetivo geral é "compreender e construir entidades inteligentes (conforme consenso entre diversos livros modernos)" (BURDELIS; ANDRADE, 2009).

São várias as conceituações de IA. Por exemplo, para Minsky (1980) ou para Rich e Knight (1993), a Inteligência Artificial permite entender, construir e validar sistemas que realizam tarefas que necessitariam de aspectos do que se chama de inteligência quando efetuadas por seres humanos. Com a IA se busca, portanto, reproduzir o modo como os seres humanos pensam, com o objetivo de modelar entidades computacionais, tentando construir explicações algorítmicas dos processos mentais humanos.

Nas abordagens clássicas de Inteligência Artificial a ênfase é no comportamento humano individual e o foco na representação de conhecimento e métodos de inferência. Já na Inteligência Artificial Distribuída, ou IAD, os sistemas computacionais são vistos como sociedades de agentes inteligentes (BOND; GASSER, 1988). Esta metáfora coloca os sistemas mais próximos da realidade, onde a solução de problemas, em muitos casos, é resultado da cooperação de vários indivíduos.

Na IAD o foco está na interação entre os agentes, quer na perspectiva de suas capacidades internas, quer da sua participação em uma sociedade, cooperando a fim de atingir algum objetivo. Assim, um dos principais motivos para o interesse em IAD é a capacidade de avaliar uma grande gama de possibilidades e analisar o comportamento e a evolução de sociedades, tanto de seres humanos como de outros seres. Nestas sociedades é importante que os agentes se comuniquem a fim de que haja uma melhor organização. Além disto, a análise e a busca por reproduzir fatores envolvidos em sistemas complexos possibilitam melhor entendimento do comportamento de indivíduos (KABBAJ, 2009, OLIVEIRA, 1996; SICHMAN; DEMAZEU; BOISSIER, 1992). 
Duas áreas constituem a chamada IAD: a Resolução Distribuída de Problemas (RDP) e os Sistemas Multiagentes (SMA) (WOOLDRIDGE; JENNINGS, 1994; BOND; GASSER, 1988).

Na RDP se pressupõe a existência de um problema global (ou classe deles) e os agentes são projetados para resolvê-lo(s) através da cooperação e integração de competências individuais (LORENZI; SANTOS; BAZZAN, 2005), sendo, portanto, adotada uma visão top-down (OLIVEIRA, 1996).

A segunda área, Sistemas Multiagentes, se propõe ao estudo do comportamento e da organização de agentes autônomos que têm existência própria e independente dos outros e que podem ser heterogêneos ou homogêneos, colaborativos ou competitivos, etc. Na visão de Bond e Gasser (1988), um SMA pressupõe coordenação de comportamentos, pois, apesar de ser possível que cada agente tenha características distintas (próprias), estas, juntamente com as capacidades comuns de cada um, vão influenciar suas decisões e os resultados visando atingir o objetivo do sistema.

Os SMAs, portanto, são compostos por uma rede de entidades (DURFEE; LESSER, 1989) que individualmente não precisam ter alto nível de complexidade, mas que podem possuir: (1) agentes idênticos ou que diferem apenas pelos recursos disponíveis a eles; (2) agentes que diferem também pelos métodos de resolução de problemas ou (3) agentes que somente compartilham uma mesma linguagem de interação, sendo que suas outras características podem ser completamente diferentes. Esta variação decorre do fato de que o objetivo é a solução de um problema que está além das capacidades individuais, mas que pode ser alcançado levando se em consideração o comportamento global inteligente (WOOLDRIDGE; JENNINGS, 1994). Este resultado é obtido através do compartilhamento, cooperação e adaptação por parte dos agentes às variações no ambiente e / ou ao problema a ser resolvido em determinado momento (OLIVEIRA, 1996).

Um ponto importante certamente é a habilidade social dos agentes. Estes, segundo Álvares e Sichman (1997), para serem partes de um SMA devem ser desenvolvidos de forma que possam receber dados do ambiente, se adaptar ao problema proposto e realizar suas tarefas. Além disto, para Weiss (1999) os agentes devem atuar de forma conjunta ou concorrente, sendo que, para ele, conjunta é quando eles agem em grupo, compartilhando conhecimento e habilidades a fim de atingir um objetivo comum e concorrente, quando eles agem em prol de seus 
objetivos e contra os dos demais, fato este que ocorre quando os objetivos dos diferentes agentes são conflitantes.

Existem também algumas preocupações comuns aos SMAs (WOOLDRIDGE, 2009), como por exemplo, as formas de coordenação do processo, ou seja, como os agentes podem chegar a acordos sem a existência de conflitos e como deve ser a coordenação das atividades a fim de que sejam atingidas as metas. Além disto, existem desafios ligados especificamente à comunicação abordando aspectos relativos ao tipo de linguagem que os agentes devem utilizar, como devem ocorrer as interações, dentre outros.

Deve-se esclarecer que, no âmbito deste projeto, não está sendo considerada a possibilidade de coordenação, negociação ou cooperação entre os agentes para resolução de nenhum problema. Já com relação à comunicação, a fim de simplificar o escopo, a linguagem está sendo considerada apenas como um instrumento para troca de símbolos que permite aos agentes "falar"" ou "ficar sabendo" de algo ${ }^{3}$. Deve-se ressaltar também que o conhecimento do agente está sendo tratado apenas como "sabe" ou "não sabe" de determinado assunto e que cada um só pode falar sobre aquilo que conhece.

Após esta visão geral, dada a importância para o presente trabalho neste capítulo estão abordados tópicos mais específicos no que se refere aos agentes. $\mathrm{Na}$ seção 2.1 estão apresentadas algumas das definições para o termo encontradas na literatura. A seguir, na seção 2.2, estão abordadas as características que um agente deve possuir para que seja considerado, em algum nível, cognitivo. Na seção 2.3 estão apresentados alguns tipos de agentes conhecidos e algumas das possíveis arquiteturas estão na seção 2.4. Outro fato importante a se ressaltar são as características do ambiente no qual os agentes devem estar inseridos, o que é tratado na seção 2.5. Para finalizar este capítulo, na seção 2.6, tem-se uma breve lista de aplicações e trabalhos onde são utilizados agentes e/ou sistemas multiagentes.

\footnotetext{
${ }^{2}$ Neste trabalho o termo falar se refere à possibilidade de enviar uma mensagem a algum amigo.

${ }^{3}$ Não havendo, portanto, grandes preocupações com os aspectos apresentados em (AHEARN, 2001; HRUSCHKA et. al., 2009; HURFORD, STUDDERT-KENNEDY, KNIGHT, 1998; JACKENDOFF, 2002; JURAFSKY, MARTIN, 2000; LAPPIN, 1997; ROCHA, 1996).
} 


\subsection{Definição e uso do termo "agente"}

Alan Kay (1984) diz que "a idéia de um agente teve origem com John McCarthy na metade da década de 50, e o termo foi criado por Oliver G. Selfridge poucos anos antes, quando ambos estavam no Massachusetts Institute of Technology". Diz ainda que estes autores "tinham em mente um sistema que, quando definido um objetivo, pudesse resolver os detalhes das operações computacionais apropriadas e pudesse pedir e receber conselhos, oferecidos em termos humanos, quando estivessem em dificuldade". Além disto, "um agente poderia ser um 'soft robot' vivendo e realizando suas tarefas dentro do mundo dos computadores".

Em uma pesquisa a respeito da origem da palavra "agente" é identificada a expressão "agens" do Latim, que significa: "a causa de um efeito, uma substância ativa, uma pessoa ou uma coisa que age, ou um representante" (TOKORO, 1994).

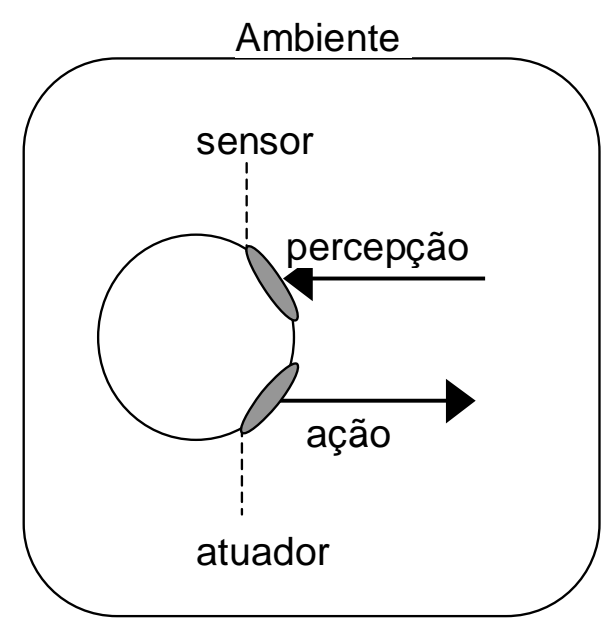

Figura 2 Estrutura de um agente - adaptada de Russell e Norvig (2004).

Após identificar a origem do termo, é preciso ressaltar o que indicam autores reconhecidos na Inteligência Artificial, dentre os quais Russell e Norvig (2004). Para eles, "um agente é tudo o que pode ser considerado capaz de perceber seu ambiente por meio de sensores e de agir sobre esse por intermédio de atuadores", como pode ser visto na Figura 2. Para Ferber (1999) agentes podem ser entidades físicas (algo concreto e que atua no mundo real, um robô, por exemplo) ou 
virtuais (i.e. componentes de software). De forma complementar, a Foundation for Intelligent Physical Agents (FIPA) ${ }^{4}$ define agente como "uma entidade que reside em um ambiente onde interpreta dados através de sensores que refletem eventos (sentidos) e executam ações que produzem efeitos no ambiente".

Outro autor de grande relevância, Wooldridge (2009) afirma que "um agente é um sistema de computação capaz de agir independentemente de um usuário, ou seja, de modo autônomo".

O termo "agente" tem sido usado em diversas áreas e os pesquisadores têm proposto grande variedade de definições, cada qual tentando explicar o uso deste termo no contexto do seu trabalho, usando diversos nomes, por exemplo, knowbots, softbots, userbots, personal agents.

No entanto, durante a pesquisa, percebeu-se que vários autores versam a respeito das mesmas características, por exemplo, explicitando a execução de tarefas, Maes (1995), Wooldridge (1999) concordam que agentes têm identidade única e cumprem uma determinada tarefa empregando informações extraídas do ambiente, com base nos mecanismos internos que possuem e no conhecimento que têm, no sentido de completá-las de modo bem sucedido.

Já para Álvares e Sichman (1997), Bordini e Vieira (2003), Ferber (1999), Nwana (1996) um agente é uma entidade que pode agir, deliberar e que possui comportamento resultante das observações, interações com outros e conhecimento de mundo. São atores que se comunicam com outros através da passagem de mensagens e realizam ações concorrentes.

Apesar da quantidade de definições que foram encontradas a maioria dos pesquisadores concorda que "agente" é uma entidade artificial complexa que está inserida em um contexto (ambiente) (RUSSELL; NORVIG, 2004), que pode percebêlo, agir sobre ele e cumprir uma agenda própria ou metas definidas por algum usuário ou outro agente.

É notável que as definições sofram ainda muitas alterações até que se chegue a um consenso, mas, no geral, agentes são entidades autônomas que atuam em determinado ambiente de forma a interagir com este e com outros agentes, além de produzir ações e ter percepções sem requerer intervenções humanas constantes (JENNINGS, 2001; HEILMANN; LIGHT; MUSEMBWA, 1995).

\footnotetext{
${ }^{4}$ http://www.fipa.org/specifications/index.html acessado em 01/10/2010.
} 
Para Wooldridge (1999) e Yepes, Barone (2003), um agente pode ter diversas características com diferentes níveis de importância que dependem especificamente do trabalho em questão, podendo ser desde imprescindíveis até indesejáveis, tema este abordado na próxima seção.

\subsection{Características dos Agentes}

É consenso que os agentes não precisam apresentar grande diversidade de características. Com base nesta informação e seguindo o que recomenda (MOYA; TOLK, 2007, WOOLDRIDGE, 1999; 2009), optou-se por abordar nesta seção apenas aquelas características fundamentais para os agentes definidos neste projeto de doutorado.

Aqui, um agente ideal deve ser capaz de funcionar continuamente, "aprender" e se adaptar a algumas situações. Ele deve raciocinar e tomar decisões de maneira realista e coerente com o enfoque proposto e se comunicar para que possa trocar experiências e conhecimentos na sociedade na qual está inserido.

\subsubsection{Continuidade Temporal e Autonomia}

Dentro de um SMA, cada agente possui sua própria linha de execução e uma característica importante é a continuidade temporal, ou seja, que cada um esteja continuamente ativo. Assim sendo, mais que uma estrutura composta por métodos e estado interno, cada agente de uma sociedade pode ser visto como um processo computacional que deve tomar decisões e ações importantes sem a necessidade da interferência do ser humano ou de qualquer outra entidade (WOOLDRIDGE, 2009).

Outra característica primordial é a autonomia, pela qual se entende que o agente tem sua própria existência, que não é justificada pela de outros. Além disto, ele pode perceber o ambiente, representá-lo (DEMAZEAU, 1995), agir conforme 
seus conhecimentos e capacidades e ter controle sobre suas próprias ações (FRANKLIN, 1997).

Para Maes (1995) um agente pode ser considerado autônomo em relação ao ambiente (quanto aos seus objetivos) e / ou em relação a outros agentes (quanto aos meios de execução) (CASTELFRANCHI, 1998). Trata-se de uma capacidade que "requer aspectos de ação periódica, execução espontânea e iniciativa", de forma que cada "agente precisa ser capaz de tomar ações preemptivas (optativas) e independentes que eventualmente beneficiarão o usuário" (FLEISCHHAUER, 1996).

Há essencialmente um consenso de que autonomia é a principal característica do agente (REZENDE, 2003; WOOLDRIDGE, 2009) e que ela está diretamente ligada à existência de certo grau de inteligência, pois apenas desta forma eles são capazes de sobreviver em um ambiente dinâmico. Além disto, um agente se diferencia de um objeto por ter a flexibilidade para decidir de forma dinâmica se irá atender a uma solicitação ao invés de obedecê-la cegamente (BRAGA, PEREIRA, 2001; WOOLDRIDGE, 2009). Afinal ele pode definir quais ações irá tomar e qual o momento mais apropriado para executá-las de modo que seus objetivos sejam atingidos com sucesso, independente de controles externos (BREITMAN, 2005).

Russell e Norvig (2004) complementam esta explicação dizendo que um agente só é realmente autônomo se, tendo tempo de adaptação suficiente, for capaz de se comportar de forma coerente em vários tipos de ambientes.

\subsubsection{Reatividade ou Pró-Atividade}

O agente tem "percepção" do ambiente no qual está inserido (que pode ser o mundo físico, um ambiente com uma coleção de agentes, a Internet, ou uma combinação destes) e, reage a alterações que ocorram nele (RUSSEL; NORVIG, 2004), ou seja, percebe o meio e responde.

É exatamente o modo de funcionamento interno que define se um agente é reativo (ou reflexivo, como em Yepes (2003)). Neste caso ele apenas responde aos estímulos recebidos, o que também é conhecido por situação-ação ou estímuloresposta. Isto ocorre, segundo Ferber (1999), pelo fato de que agentes deste tipo 
não possuem representação explícita do ambiente nem dos outros agentes, nem memória das ações. Desta forma uma ação não é influenciada diretamente por aquelas executadas anteriormente (WOOLDRIDGE, 2009), o que os torna também incapazes de prever ou antecipar ações (OLIVEIRA, 1996). É reconhecida, no entanto, a grande utilidade deste tipo de agentes, principalmente quando o objetivo é reproduzir colônias de animais, insetos, por exemplo, (OLIVEIRA, 1996). Nestes casos o comportamento inteligente emerge de toda a sociedade, que usualmente têm grande número de membros (agentes simples).

Por outro lado, os agentes pró-ativos não respondem simplesmente aos estímulos do ambiente, mas são capazes de tomar iniciativas e exibir um comportamento direcionado aos seus objetivos (WOOLDRIDGE, 2009). Conforme (FERNANDES, 2005) o agente que implementa este atributo possui maior flexibilidade, pois é capaz de resolver problemas inesperados. Este comportamento é obtido considerando alguma arquitetura ou modelo mais complexo, sendo alguns apresentados na seção 2.3 .

\subsubsection{Racionalidade}

O raciocínio é talvez o aspecto mais importante que distingue um agente inteligente dos outros agentes. Assim, um agente que raciocina é capaz de realizar inferências baseando-se no seu conhecimento atual e nas suas experiências. Diversas podem ser as formas de raciocínio (BARBOSA, 2008), por exemplo: (1) com base em regras, ou seja, quando um conjunto de condições é satisfeito, o agente escolhe uma ação a realizar; (2) com base em conhecimento, ou seja, os agentes possuem grandes conjuntos de dados sobre situações anteriores e as respectivas ações resultantes e, assim, deduzem as ações que devem realizar.

Especificamente com relação ao conceito de racionalidade, pode-se dizer que está intimamente ligado ao conceito de inteligência e à suposição de que um agente atuará para atingir seus objetivos. Assim, segundo Russell e Norvig (2004) este conceito depende de alguns atributos, como: capacidade para atingir um objetivo; percepção do agente em relação ao ambiente que o envolve; compreensão 
pelo agente da situação atual; natureza das ações que o agente poderá executar, dentre outros.

O ideal de agente racional para Russell e Norvig (2004) é aquele que, para cada percepção do ambiente e, com base no seu conhecimento, busca maximizar a sua utilidade e seu desempenho. Além disto, para Oliveira (1996), ele deve escolher sempre a ação mais coerente com seus objetivos.

\subsubsection{Adaptação e Aprendizagem}

Além de serem racionais, é necessário que os agentes sejam robustos o suficiente para tomar decisões baseando-se em informações incompletas ou escassas, e sejam capazes de lidar com erros e principalmente de representar da maneira mais próxima possível aspectos da realidade em que estão inseridos e para a qual foram propostos. Muitas vezes o pesquisador não tem conhecimento total do que é preciso desenvolver. É exatamente para estes casos que os agentes devem ser criados de forma que possam aprender e se adaptar às situações com as quais se depararem.

É dito que um agente tem a capacidade de aprender quando pode acumular conhecimento (FRANKLIN, 1997), e combiná-lo com as informações que já possui em sua estrutura interna. A aprendizagem ocorre não apenas através da exposição ao conteúdo, mas também através da interação, imitação, reflexão, treino, estudo, etc (HEILMANN; LIGHT; MUSEMBWA, 1995; HEINEN, 2002; MERLOFLORES, 1999). Para Maes (1994) deve ser um processo incremental e cumulativo,

e os agentes devem aprender de forma autônoma. É sabido também que, apesar dos diversos métodos de aprendizagem, o mais comum é por reforço (reinforcement learning) (BARBOSA, 2008).

$\mathrm{Na}$ busca por melhorar seu desempenho um agente pode ser capaz de se adaptar a alterações no ambiente ou até mesmo novas situações, modificando seu comportamento. A adaptatividade diz respeito exatamente ao fato deles serem capazes de "modificar dinamicamente, de forma autônoma, seu próprio comportamento, em resposta à sua configuração corrente e ao estímulo de entrada recebido" (NETTO, 2007). Além disto, formas avançadas de adaptação estão ligadas ao homem enquanto ser social (BREITMAN, 2005). 
Aprendizagem e adaptatividade são, portanto processos dinâmicos, pessoais ou globais, contínuos, interativos e evolutivos de aquisição de conhecimentos e a mudança daqueles já existentes (NETO, 2009b; 2009c), onde experiências passadas condicionam a aquisição no presente e possibilitam reestruturações cognitivas (MOURA, 2002).

\subsubsection{Comunicabilidade}

Um agente é parte integrante de uma sociedade na qual, através da interação ocorre à evolução dos relacionamentos existentes e a criação de novos (JENNINGS; WOOLDRIDGE, 1996). Além disto, a capacidade de transmitir (e receber informações) e realizar decisões possibilitam que um agente mude ou reforce o entendimento de mundo que possui.

A comunicação serve, portanto de base para coordenar as ações dos agentes e facilitar a troca de experiências. Desta forma, eles não precisam necessariamente ter sido desenvolvidos utilizando as mesmas ferramentas e modelos, mas devem concordar no uso de uma linguagem comum, tendo, portanto capacidade de comunicação (comunicabilidade). Esta última é a capacidade de trocar informações com outras entidades, sejam elas agentes, humanos, objetos ou o próprio ambiente (RUSSEL; NORVIG, 2004).

É importante então definir que tipo de declaração eles serão capazes de gerar e compreender, pois a comunicação pode ser na forma de um pedido com um simples e conciso conjunto de respostas, ou com um grau de complexidade que possibilite respostas variáveis (HEILMANN; LIGHT; MUSEMBWA, 1995). Além disto, é necessário que sejam definidas as possíveis interpretações dos termos, pois a mesma sequência de caracteres pode ter diferentes significados, o que pode gerar conflitos (BRAZDIL et al., 1996).

Muitas são as ferramentas, modelos, arquiteturas, interfaces e linguagens encontradas na literatura que incorporam essa capacidade e, dado o interesse e importância para este trabalho, na seção 2.6 .1 estão apontadas maiores informações e trabalhos conhecidos que abordam formas de comunicação e a troca de informações entre agentes. No entanto é preciso ressaltar que se optou aqui pela 
definição de uma linguagem simples e a restrição das possíveis interpretações que podem ocorrer.

\subsubsection{Cooperação}

A cooperação surge naturalmente em decorrência do avanço na discussão sobre as formas de relacionamento entre os agentes, particularmente quando se tem por objetivo avaliar sua capacidade de trabalhar em conjunto e combinar seus objetivos.

Um possível tipo é coordenação, no qual os agentes são organizados para alcançar um objetivo comum no sistema (FERREIRA; GIRARDI, 2002). Além deste, outros são colaboração, competição (BREITMAN, 2005, PROENÇA, 2003). Nestes casos os agentes podem trabalhar juntos para benefício mútuo na realização de uma tarefa, bem como pode ser definido algum tipo de disputa, visando desenvolver / encontrar o melhor agente para dado problema.

Geralmente para cooperações serem bem sucedidas, cada agente deve manter um "modelo" dos outros, usar linguagens e um protocolo padrão para que seja possível o convívio em sociedade e se alcancem metas definidas (BREITMAN, 2005).

\subsection{Tipos de Agentes}

No intuito de situar o presente trabalho na literatura e também de facilitar o entendimento do mesmo, nesta seção estão apresentados alguns dos tipos de agentes existentes.

É sabido que existem diversas classificações e taxonomias para agentes (BRANDSHAW, 1997). Cada autor ou grupo de autores adota uma linha para realizar a sua classificação, levando em conta uma ou mais propriedades, as tarefas que o agente é capaz de executar, sua arquitetura de controle, ambientes que podem atuar (FRANKLIN, 1997), dentre outros. No entanto, cada uma das 
classificações foi definida a fim de ser uma alternativa (facilitada) à identificação e descrição de todas as possíveis combinações de características que um agente pode ter.

De forma geral, alguns pesquisadores (RUSSELL; NORVIG, 2004) classificam agentes como fortes ou fracos na sua essência, de acordo com as propriedades que apresentam (principalmente quanto ao conhecimento e raciocínio) (BRANDSHAW, 1997). Na chamada noção fraca de agentes, eles são conceituados como sistemas computacionais, sendo hardware ou software, com propriedades tais como autonomia, reatividade e pró-atividade. Já na noção forte, o agente possui, além das propriedades acima citadas, características mais relacionadas ao comportamento humano tais como conhecimento e intenção (WOOLDRIDGE, 2009).

Além disto, Nwana (1996) e Brandshaw (1997) identificam algumas dimensões de classificação: (1) Mobilidade - estáticos ou móveis; (2) Presença de um modelo de raciocínio simbólico - deliberativos ou reativos; (3) Exibição de atributos ideais e principais, como cooperação, autonomia e aprendizado colaborativos, de aprendizado colaborativo, interfaces e espertos; (4) Papéis - de informação ou Internet; (5) Filosofias híbridas, que combinam duas ou mais abordagens em um único Agente; (6) Atributos secundários, como versatilidade, benevolência, veracidade, continuidade temporal, qualidades mentais e emocionais, etc.

De forma mais geral, para Yepes (2003) os agentes são divididos em alguns tipos, citados a seguir. (1) Agentes de interface, também chamados assistentes pessoais ou agentes de usuário. (2) Agentes colaborativos, que enfatizam a autonomia e a cooperação com outros agentes, devendo ser capazes de negociar entre si a fim de encontrar soluções adequadas e (3) Agentes móveis, os quais podem se deslocar entre diversas máquinas. Existem ainda os (4) agentes de informação ou agentes de Internet e (5) os agentes híbridos que são uma alternativa no momento em que um agente puramente deliberativo deve tomar uma decisão rápida e espontânea ao enfrentar uma situação imprevista. Em contrapartida, servem também para proporcionar a um agente puramente reativo, uma capacidade de raciocínio e planejamento. Rickel e Johnson (1997) falam sobre Agentes pedagógicos, que atuam em ambientes educacionais.

Wooldridge e Jennings (1994) propõem uma classificação segundo o nível de sofisticação dos Agentes: (1) Gopher - executam tarefas baseadas em 
regras pré-especificadas; (2) Service performing - executam tarefas a partir de requisições de usuários; (3) Predictive - disponibilizam informações ou executam ações para o usuário de forma voluntária, até certo ponto.

Moulin e Chaib-draa classificam agentes segundo a sua capacidade para resolver problemas (BRANDSHAW, 1997). Na mesma linha, Russell e Norvig (2004) apresentam: agentes reflexivos simples, agentes que guardam caminho do mundo, agentes baseados em objetivos e agentes baseados em utilidades. Esta classificação apresenta um maior detalhamento em relação à dicotomia reativo / deliberativo no que tange à maneira como o agente atua no ambiente no qual está inserido (OLIVEIRA, 1996).

Bezek e Gams (2003) definem três tipos de agentes, segundo o tipo de interação que realizam: (1) reativo a agentes - somente respondem à demanda de outros agentes; (2) reativo ao sistema - utiliza informações obtidas de outros agentes, mas não fornece informação, sua tarefa principal é monitorar o sistema de agentes e reagir de acordo com seus objetivos; (3) colaborativo - sincroniza suas ações de acordo com requisições e respostas do sistema de agentes. Suas ações podem ser iniciadas ou canceladas de acordo com as ações de outros agentes. Os agentes coordenados ou colaborativos com a finalidade de alcançar um objetivo maior realizam tarefas especificas, porém coordenando-as entre si de forma que suas atividades se completem.

Maglio e Barret (2000) discutem Agentes intermediários, que transformam significativamente a informação à medida que ela trafega de uma máquina para outra. Para eles "agentes intermediários, se colocados em meio ao fluxo de informações trocadas entre produtor e consumidor, podem personalizar essas informações de acordo com pessoas, dispositivos e situações".

\subsection{Arquiteturas de Agentes}

Por arquitetura se entende a parte que fornece e gerencia os recursos primitivos de um agente (WOOLDRIDGE, 2009), um modelo estruturado hierárquico que serve 
para explicar a construção, de forma a ajudar a entender o seu funcionamento e que aborda as partes que compõem o sistema e suas relações.

Todas as propriedades que um agente apresenta devem estar em sua arquitetura, pois com o conjunto dos módulos e suas interações deve ser possível identificar a resposta que será dada à entrada de algum estímulo nos sensores e seu estado interno, ou seja, quais serão suas ações e futuros estados (WOOLDRIDGE, 1999).

A arquitetura mais genérica de um agente inteligente (Figura 3) deve então permitir a captação e interpretação das percepções de modo mais ou menos inteligente, e originar uma tomada de decisão condizente a uma ação.

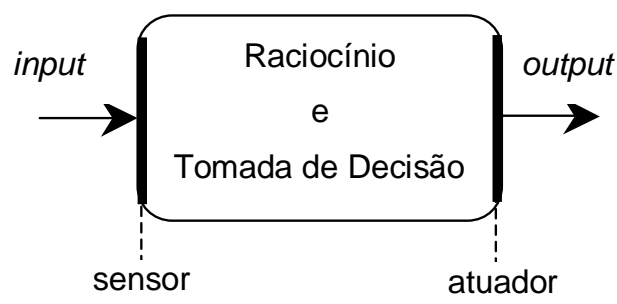

Figura 3 Arquitetura geral do agente

As arquiteturas podem ser reativas, deliberativas ou híbridas. $\mathrm{Na}$ arquitetura reativa é utilizado um modelo simples, onde a tomada de decisão está previamente compilada e há um mapeamento direto entre a interpretação das percepções e a seleção das ações. $\mathrm{Na}$ arquitetura deliberativa, os agentes possuem um modelo simbólico do ambiente, explicitamente representado, tendo capacidade de tomar decisões lógicas baseadas em inferências e suas ações são decididas por raciocínio lógico. Já a chamada arquitetura híbrida é um misto das duas citadas anteriormente. Neste caso é possível identificar um subsistema deliberativo (que planeja e toma decisões de maneira simbólica) e um reativo (que reage a eventos ocorridos no ambiente sem ocupar-se de raciocínios complexos).

Várias aplicações destas arquiteturas podem ser contempladas em (WOOLDRIDGE, 1999). Deve-se ressaltar também que, de importância para este trabalho é a chamada arquitetura deliberativa, em especial considerando a abordagem mentalista e os agentes cognitivos, os quais estão detalhados na próxima seção. 


\subsubsection{Agentes Cognitivos e a Abordagem Mentalista}

Abordagem mentalista é o nome dado à modelagem de agentes inspirada nos estados mentais humanos (ZAMBERLAM; GIRAFFA, 2001, 2001a). Considerando esta visão e o fato de que o que caracteriza um agente são as interações que ele realiza com o ambiente e os processos internos que possibilitam estas interações, dependendo do seu nível de inteligência e autonomia, este agente pode ser classificado como cognitivo.

Os agentes cognitivos baseiam-se no conhecimento do estado do mundo que possuem para decidirem que ações vão realizar. Eles têm controle sobre o seu próprio comportamento e não se limitam a reagir a estímulos recebidos, como os reativos.

Ferber (1999) afirma que cada agente deve ter uma base de conhecimento disponível, que compreende os dados e a capacidade de realizar suas tarefas e interagir com outros agentes e com o ambiente. Sua representação interna e seus mecanismos de inferência permitem que ele atue independentemente dos outros e the dão grande flexibilidade. Além disso, devido a sua capacidade de raciocínio baseado nas representações do mundo, são capazes de memorizar situações, analisá-las e prever possíveis reações para suas ações.

As abordagens utilizadas para a modelagem de agentes cognitivos, segundo Álvares e Sichman (1997), são as mais diversas. Afinal, um agente pode incluir diferentes estruturas de conhecimento como fatos, crenças, objetivos ou intenções, preferências, desejos, etc.

Apesar disto, o modelo mais conhecido inclui crenças, desejos e intenções ("Beliefs, Desires and Intentions"), o BDI de Rao e Georgeff (1991). Este modelo considera que o raciocínio humano é regido por estes três estados mentais. O BDI se apóia nos pilares do raciocínio prático, ou seja, o processo de decisão, momento a momento, de qual ação adotar visando atingir um objetivo, e envolve dois processos fundamentais: a decisão de quais objetivos se quer alcançar e como estes serão alcançados. Este processo é conhecido como deliberação.

Em uma arquitetura BDI existem alguns componentes principais, estando abaixo àqueles apresentados em (WEISS, 1999), que são: 
(1) Um conjunto de crenças atuais que são as informações que o agente possui sobre o ambiente, as quais podem apresentar incorreções ou inconsistência (BAPTISTA, 2007).

(2) Uma função que revê as crenças, sendo ativada quando o agente recebe uma nova informação que entra em contradição com alguma que já tinha, situação onde é necessário abandonar algumas das suas crenças, e desta forma atualizar o conjunto delas;

(3) Uma função que gera opções, determinando aquelas disponibilizadas para o agente (seus desejos).

(4) Um conjunto de desejos atuais, os quais estão relacionados a situações futuras. O que falta ao agente para que seu desejo venha a se tornar algo concreto é conhecimento para fundamentar as crenças relacionadas a ele, além da situação propícia para sua realização (BAPTISTA, 2007). Estes podem ser inconsistentes ou até inatingíveis.

(5) Uma função filtro, que representa o processo de deliberação do agente e que determina suas intenções, baseando-se nas suas crenças, desejos e intenções atuais;

(6) Um conjunto de intenções atuais, os desejos que o agente está disposto a atingir (BAPTISTA, 2007), que deve ter prioridades associadas, se assemelhando a um plano hierárquico.

(7) Uma função de seleção de ação, que determina o que executar tendo como base as intenções atuais.

\subsection{Ambiente e suas configurações}

Os agentes precisam estar em um ambiente cujas características podem influenciar a decisão pela execução de uma ou outra ação (ALVARES; SICHMAN, 1997). Este ambiente pode ser classificado de acordo com os seguintes critérios:

- Acessível ou Inacessível: essa característica está relacionada ao nível de acesso que o agente tem em relação ao estado do ambiente. Um ambiente é considerado efetivamente acessível se os sensores do 
agente podem detectar todos ou os principais aspectos nele presentes. Caso haja alguma restrição, o ambiente pode ter níveis de acessibilidade ou ser inacessível.

- Determinístico ou Não-Determinístico: um ambiente determinístico é aquele onde não há nenhuma incerteza sobre o estado resultante de uma ação. Por outro lado, os ambientes não determinísticos são mais complexos, pois o agente não tem certeza sobre o resultado da ação que irá executar.

- Episódico ou Não Episódico: em cada momento o agente toma a decisão que avaliar mais correta de acordo com a sua percepção do sistema. Ele é, portanto mais eficiente em um ambiente com episódios discretos, pois sua ação não precisa levar em consideração conseqüências futuras. Ao contrário, para agirem nos ambientes não episódicos os agentes precisam avaliar os impactos que podem decorrer de suas ações.

- Estático ou Dinâmico: os estáticos não sofrem modificações durante o processo de decisão de um agente. Por outro lado, ambientes dinâmicos podem sofrer alterações de estado enquanto o agente seleciona a ação mais apropriada a executar. Ambientes também podem ser semidinâmicos ou semi-estáticos.

- Discreto ou Contínuo: um ambiente discreto é aquele onde pode ser identificado um número finito de estados, de possíveis percepções e ações para os agentes. Por outro lado, um ambiente onde novas situações e ações podem ser adicionadas com o decorrer do tempo é definido como contínuo.

Além disto, o ambiente pode ser formado por: um único agente; um grupo de agentes que realizam as mesmas tarefas ou diferentes tipos de agentes (FERREIRA; GIRARDI, 2002). 


\subsection{Trabalhos relacionados}

Alguns trabalhos que se relacionam a este projeto abordam fluxos de informação em grupos de agentes (ALT; LIEBERMAN, 2010; CARNEIRO, 2008; CHUNG; HOSSAIN, 2010; FREITAS; PEREIRA, 2005; ITO, 1997; SANTOS, SICHMAN, 1997; SUGIYAMA et. al., 2004) ou o uso de ontologias (BILLE et. al., 2004; 2004a; CASARE, 2005; GAO et. al., 2005; GUTIERREZ, 2005; HUHNS; SINGH, 1997; NARDIN, 2009; PINTO, 2008; TSAMPOULATIDIS et. al., 2004; WILKENS; MORAES, 2007).

Além destes, na seção a seguir é abordada a frente de pesquisa onde se tem interesse na complexidade da linguagem e comunicação utilizada pelos agentes de forma que eles podem negociar, competir, dentre outros.

\subsubsection{Pesquisas que envolvem comunicação entre agentes no âmbito da ciência da computação}

A possibilidade de troca de informações é fundamental para permitir interação, colaboração, cooperação, dentre outros. Em sistemas multiagentes existem várias maneiras que os personagens podem se comunicar (CHAUHAN, BAKER, 1997), podendo ser de forma direta (entre agentes) ou indireta (quando o "falante" emite um sinal ou age no ambiente, e a mudança que ele provoca no ambiente afeta outro(s) agente(s)) (ALVARES; SICHMAN, 1997).

$\mathrm{Na}$ comunicação direta todos os agentes precisam se conhecer e saber

como fazer para trocarem mensagens. Este fato certamente acarreta grande complexidade e robustez, no entanto, trata-se de um processo mais rápido, pois ocorre linearmente de um agente a outro (FERREIRA; GIRARDI, 2002). No exemplo da Figura 4 o agente A conhece B, C e D, mas o agente D só conhece A e B. 


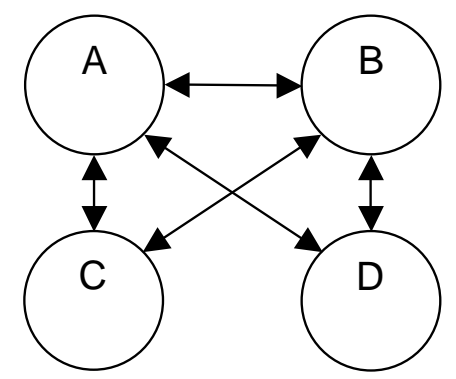

Figura 4:Exemplo de comunicação direta entre agentes.

Outra forma de comunicação é conhecida como broadcast útil quando o emissor não conhece os destinatários, mas tem interesse em divulgar algo massivamente. Neste caso a mensagem fica disponível a todos os agentes e cabe a cada um avaliar seu interesse nela (AZAMBUJA, 2007).

No entanto, à medida que se faz necessário simular uma sociedade maior, é preciso criar um facilitador ou mediador das "conversas" (01 na Figura 5). Este tem o papel de receber as mensagens e repassá-las aos destinatários, numa busca por diminuir a quantidade de mensagens trocadas no ambiente, pois não é necessário que cada agente estabeleça uma conexão com outro, sempre que queiram se comunicar (CHAUHAN, BAKER, 1997; FERREIRA; GIRARDI, 2002).

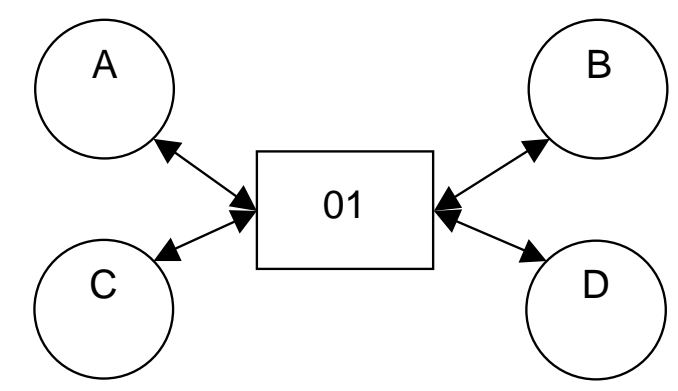

Figura 5:Exemplo de comunicação indireta entre agentes.

Em uma alternativa conhecida como comunicação por quadro-negro ou blackboard é definida uma espécie de memória compartilhada, onde os agentes inserem e consultam se existe alguma mensagem disponível para eles (CHAUHAN, BAKER 1997).

Independente da estrutura de comunicação ou interação escolhida é preciso definir uma linguagem que os agentes vão utilizar para se comunicarem. 
Especificamente na área de computação, existem padrões definidos para estas linguagens, alguns dos quais estão apresentados na próxima seção. No entanto cabe esclarecer que durante este trabalho optou-se por simplificar a linguagem utilizada pelos agentes, deixando a possibilidade de incorporar o uso de algum destes padrões.

\subsubsection{Linguagens para Comunicação entre Agentes}

Os padrões existentes para a definição de linguagens que os agentes podem usar têm o papel de fornecer mecanismos para troca de informação de modo robusto, sem inconsistências, pretendendo ser universais e tendo um número limitado de primitivas (BRAGA, PEREIRA, 2001; COMUNICAÇÃO, 2008).

Segundo Álvares e Sichman (1997) e Labrou, Finin e Peng (1999) praticamente a totalidade dos trabalhos em interações entre agentes cognitivos se baseia na teoria de atos de fala ("speech act theory") (Searle, 19695). Tal teoria propõe uma categorização de primitivas de comunicação associadas às suas conseqüências. Os atos de fala podem ser classificados segundo três aspectos: (1) ato locucionário: emissão de palavras e sentenças com algum significado; (2) ato ilocucionário: intenção da emissão: requisição (request), ordem (order), desculpa (apologize), afirmação (assert); (3) ato perlocucionário: resultado (desejado) da emissão: convencimento (convince), insulto (insult), ameaça (frighten).

Esta teoria usa o conceito de performativas para permitir conduzir ações. Ricardo Gudwin (2010) afirma que "os atos comunicativos são interpretados a partir da mensagem do contexto..." e "...nem sempre essa interpretação é obvia...". Em outras palavras, significa que esses atos estão sujeitos a interpretações dúbias que podem ter significados diferentes de acordo com "o ponto de vista de" cada agente.

Dentre os padrões existentes, dois se destacam: KQML e FIPA ACL. KQML (Knowledge Query and Manipulation Language) é uma especificação de linguagem e protocolo de comunicação entre agentes independente de conteúdo e da ontologia aplicável. Ela surgiu da necessidade de uma linguagem aceita

\footnotetext{
${ }^{5}$ Esta é a referência original, a qual não se conseguiu acesso.
} 
universalmente, onde fosse possível expressar perguntas e informações de forma não ambígua.

É amplamente adotada principalmente por ter algumas características importantes, como: (1) a linguagem dos conteúdos das mensagens transmitidas é deixada a critério do utilizador, podendo ser LISP, Prolog, Português, por exemplo; (2) as informações necessárias para compreender o conteúdo das mensagens estão incluídas na própria comunicação; (3) o mecanismo de transporte é transparente; (4) o formato das mensagens é simples.

Em KQML, as mensagens são expressas por meio de performativas e a lista completa delas e seus significados pode ser encontrada em (COMUNICAÇÃO, 2008).

Geralmente, arquiteturas que utilizam KQML adicionam um agente facilitador à sociedade. Além disto, seu uso é particularmente interessante para aplicações voltadas para Internet e agentes web (RHEINHEIMER, 2004).

A FIPA - ACL foi criada pela Foundation for Intelligent Physical Agents, fundação sem fins lucrativos que se dedica à produção de padrões para a interoperabilidade de agentes heterogêneos e interativos e sistemas baseados em agentes. Esta entidade se apóia em dois pontos principais: o tempo para alcançar o consenso não deve ser longo para não impedir avanços na área, e apenas comportamentos externos devem ser especificados, ficando os detalhes de implementação e arquiteturas internas a serem definidos pelos desenvolvedores de agentes ${ }^{6}$.

Para a definição da sigla, a FIPA adicionou a seu nome o acrônimo de Agents Communication Language (ACL), o que significa Linguagem de Comunicação de Agentes (LCA), termo usado nas pesquisas nacionais. Especificamente, a FIPA-ACL está baseada nos mesmos princípios da KQML, a teoria dos atos de fala, e tem a mesma sintaxe para as mensagens. No entanto, o conjunto de performativas é diferente e a semântica das mensagens não é a mesma.

Sobre a FIPA-ACL, Ricardo Gudwin (2010), prevê que: "deve vir a substituir o KQML, pois resolve a maioria dos problemas criticados por diferentes autores na concepção do KQML”. De acordo com Meneses (2001), KQML tem sido criticada por usar o termo performativo para se referir às primitivas de comunicação.

\footnotetext{
${ }^{6}$ http://www.fipa.org/
} 
Ao contrário, em FIPA-ACL, essas primitivas são chamadas de ações ou atos comunicativos (communicative acts).

Apesar dos padrões existentes, aqui se optou por simplificar a forma de comunicação que os agentes podem utilizar. Além disto, ao invés de "agentes cognitivos" que comumente são elaborados usando a arquitetura BDI (por exemplo, MENEGUZZI, 2004), aqui se usa o termo "agente com aspectos cognitivos" devido ao fato de que será apresentado um modelo próprio, elaborado pelo autor tanto estrutural quanto com relação ao modo de funcionamento dos agentes.

As informações abordadas neste capítulo são, no entanto, importantes para situar, delimitar e facilitar o entendimento do presente trabalho. 


\section{Capítulo 3. CIÊNCIA COGNITIVA}

A Ciência Cognitiva se presta a auxiliar o entendimento dos processos de aquisição de conhecimentos e dos processos mentais, e para tal busca criar modelos que permitam realizar simulações computacionais (NETTO, 2007).

Cognição, segundo o dicionário Houaiss (2001 apud Comunicação, 2010) é a "capacidade de adquirir conhecimento", sendo, no meio acadêmico, o emprego deste termo geralmente associado à "investigação dos processos mentais superiores" (MELLO, 2003) e que envolvem processos ditos cognitivos, tais como ler, pensar, julgar, tentar lembrar de algo, etc.

A Ciência Cognitiva lida com o estudo sobre como o conhecimento pode ser representado e manipulado nas suas formas mais diversas (POSNER, 1998). Para Johnson-Laird (1988), a ciência cognitiva explica como funciona a mente, e, de forma complementar, Gardner (1996), a considera como a "nova ciência da mente", a descrevendo como "um esforço contemporâneo (...) para responder a questões principalmente relativas à natureza do conhecimento, seus componentes, suas origens, seu desenvolvimento e seu emprego".

É consenso na comunidade científica que a Ciência Cognitiva foi reconhecida oficialmente em 1956 (RUSSELL; NORVIG, 2004, p. 15), a partir do Simpósio sobre Tecnologia da Informação, realizado no Massachusetts Institute of Technology, onde foram apresentados trabalhos de estudiosos das ciências humanas e da comunicação. Neste evento, o psicólogo George Miller destacou-se com a apresentação de um artigo (MILLER, 1956) em que afirmava que a capacidade da memória humana de curto prazo limitava-se a sete itens.

Durante os anos 60, começaram a surgir livros e outras publicações sobre a Ciência Cognitiva, disponibilizados principalmente a partir de estudos realizados em Harvard (WILSON; KEIL, 1999). O crescimento desta área se deu em três pontos distintos: (1) o desenvolvimento da psicologia do processamento da informação, na qual a meta era especificar o processamento interno envolvido na percepção, linguagem, memória e pensamento; (2) a invenção dos computadores e (3) o desenvolvimento da teoria da gramática generativa e outras derivações da lingüística (DRIGO, 2007). 
$\mathrm{Na}$ última década a Ciência Cognitiva apresentou grande desenvolvimento situando-se entre os mais novos campos interdisciplinares do conhecimento, buscando alternativas para o estudo da mente, onde se inserem as diversas propostas de agentes inteligentes que buscam reproduzir processos realizados por humanos. Alguns destes processos e aspectos cognitivos, de particular relevância para este projeto de doutorado estão abordados nas seções a seguir.

\subsection{Comunicação}

O primeiro processo é a comunicação e, numa busca pela origem do termo, identificou-se que este deriva do latim communicare, com o sentido de tornar comum, partilhar, repartir, trocar opiniões, associar ou conferenciar (BARBOSA; RABAÇA, 1987). Ou seja, "exprime a totalidade do processo que coloca em relação duas (ou mais) pessoas" (MARTINO, 2001) e inclui procedimentos por meio dos quais uma mente pode afetar outra.

Não se têm dados precisos sobre quando e como ocorreu o primeiro ato de comunicação. Sabe-se, no entanto, que o homem, desde os tempos primitivos precisa se comunicar para sobreviver e satisfazer suas necessidades, e que para isso, dispõe de vários recursos (BORDENAVE, 2007). Ele pode utilizar sinais de natureza verbal ou não verbal, relatar atos no presente, referir-se ao passado e fazer especulações sobre o futuro.

Para gerar processos de comunicação, é preciso que exista uma estrutura com inteligência suficiente para conhecer o conjunto de símbolos necessários para elaborar e decodificar mensagens e capacidade de perceber e analisar o que ocorre no ambiente.

A comunicação não é, portanto, apenas o intercâmbio de mensagens, mas uma construção de sentido. Afinal, as pessoas interpretam as mensagens de acordo com seu conhecimento, que pode coincidir, ou não, com o do autor ou "falante". Esta relação entre interlocutores pode acontecer em quatro níveis: 
individual, interpessoal, grupal ou massivo, dependendo de quantos indivíduos estão envolvidos no processo.

Em um ato de comunicação estão envolvidos principalmente o emissor, a mensagem e um receptor. Neste processo (Figura 6): o emissor precisa selecionar uma mensagem, a qual é codificada e enviada através de um canal ao receptor que deve poder assimilá-la. Diz-se então que a transmissão foi bem sucedida se a mensagem foi entendida e é passível de assimilação (decodificação, interpretação e entendimento) pelo destinatário.

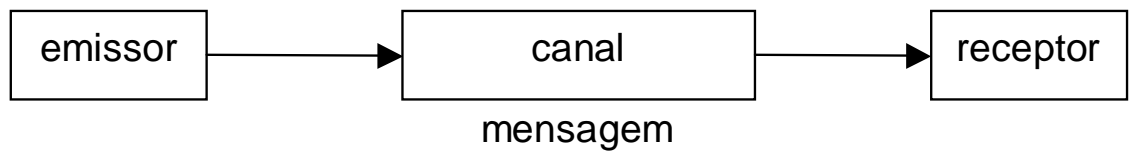

Figura 6 Processo de comunicação.

Nesta estrutura, o emissor, que pode ser um indivíduo ou um grupo (órgão de difusão, por exemplo), é o elemento que organiza, formula e envia a mensagem. Ao transmiti-la ele sempre terá um objetivo, tratado por alguns como fator de intencionalidade (INGEDORE, 2002 apud DEUS, 2006).

A mensagem, objeto da comunicação, é elaborada usando-se alguns códigos, por exemplo, palavras, gestos, sinais de trânsito, desenhos. Sendo assim, é possível se comunicar de diversas maneiras, mas é necessário usar signos (MEUNIER, PERAYA, 2008). Estes tornam visíveis (audíveis) e públicos o que era privado a um determinado indivíduo (DEUS, 2006).

Os signos são representações de alguma coisa. Eles surgem da necessidade do ser humano de representar algo para melhor compreensão, entendimento ou análise, facilitando a comunicação. Eles são então organizados segundo "regras de combinação ou sintaxe" (BORDENAVE, 2002: 53 apud DEUS, 2006). "Os elementos da linguagem escrita, por exemplo, são as letras do alfabeto que, agrupadas segundo certas regras, formam as sílabas e estas as palavras, que, por sua vez, organizam-se em frases, parágrafos, capítulos".

Uma vez que a mensagem é enviada através de um canal cabe ao receptor decodificá-la se seu repertório for comum ao do emissor. Afinal, quando uma frase é pronunciada, ela tem valor diferente dependendo da situação ou 
contexto. Do mesmo modo, a linguagem se caracteriza a partir de um acordo entre os falantes (CHAUI, 2003).

É claro, portanto que a comunicação é muito mais que a transmissão da mensagem do emissor para o receptor, é um processo de organização no qual pessoas interagem, fazendo-se compreender e organizando-se em sociedade, bem como convivem umas com as outras e se influenciam reciprocamente (BORDENAVE, 2002 apud DEUS, 2006).

Como pode ser visto é alto o grau de complexidade da comunicação (DOMINGOS, 2006; KRISTENSEN; ALMEIDA; GOMES, 2001). Além disto, diversos são os trabalhos que buscam torná-la mais eficaz, por exemplo, (DEUS, 2006). No entanto, neste projeto de doutorado a opção é pela simplificação da comunicação, dos códigos e da linguagem utilizada, fato que pode ser incrementalmente complexificado futuramente. O canal aqui não interfere na mensagem, portanto não se considera a existência de ruídos.

\subsection{Memória}

A memória tem importância aqui uma vez que é usada para reter e recordar informações que permitem agir adequadamente. É versátil, possibilita reconhecer rostos, lembrar nomes, pessoas, saber o que foi conversado, como o diálogo transcorreu, dentre outros. Trata-se, portanto de um aparato sem o qual seria impossível a complexidade que se tem nos seres cognitivos, pois informações memorizadas podem ser resgatadas, processadas e transformadas (BAARS, GAGE, 2007; GREEN, 1996; IZQUIERDO, 2007; MARCHELLI, 2009).

Embora não exista uma concordância sobre o número de sistemas de memória existentes, Atkinson e Shiffrin (1968) propuseram um modelo onde ela é concebida contendo três tipos de armazenamento de dados que são diferenciados por capacidade e duração: Armazenamento Sensorial (AS), Armazenamento de Curto Prazo (ACP), Armazenamento de Longo Prazo (ALP) (Figura 7). 


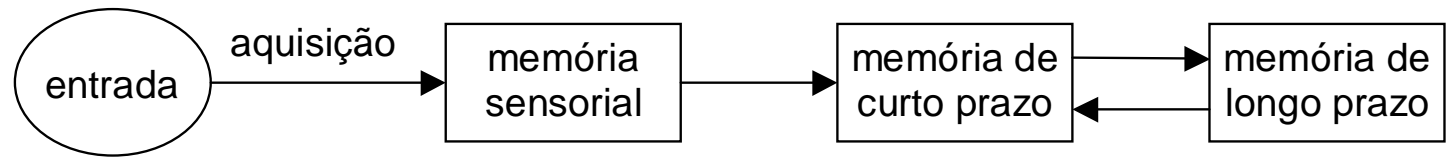

Figura 7: Modelo Modal de Memória adaptada de (Atkinson, Shiffrin, 1968).

Apesar de abrangente, este modelo é considerado por alguns pesquisadores como inexato, mas mesmo assim continua sendo muito utilizado em pesquisas sobre memória (GAZZANIGA, 1999). Atualmente acredita-se que a memória possua mais de três sistemas, como pode ser visto na Figura 8.

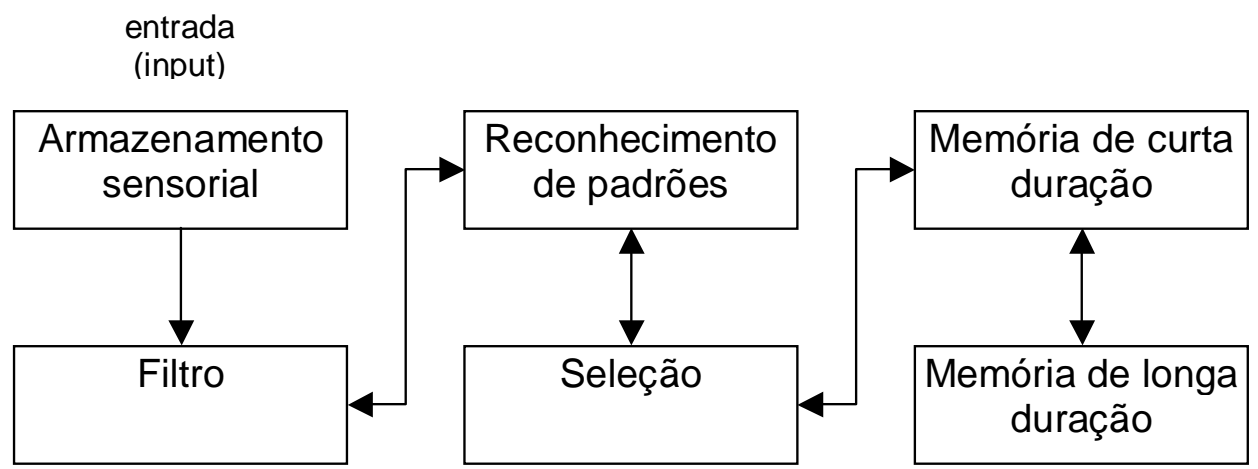

Figura 8: Partes da Memória.

O primeiro processo, envolvido com o acesso e retenção de memória, é a aquisição que consiste na entrada de um evento: um objeto, um som, um acontecimento, um pensamento, uma seqüência de movimentos.

Tecnicamente, existe um depósito sensorial diferente para cada sensação, onde a informação decai rapidamente. Esta primeira fase, segundo George Sperling, consiste em memória de muito curto prazo onde os dados ficam no cérebro por alguns segundos e depois desaparecem. É preciso, então, que uma decisão aconteça para que a informação seja transferida para o próximo depósito.

Para passar para o segundo nível de armazenamento de memória a informação deve ser importante para o indivíduo naquele momento (ter o foco da atenção). É então ativado um processo de Reconhecimento de Padrão para transferi-la para a memória de curto prazo que envolve associação do padrão sensorial como algo significante e armazenamento por categoria, mas esta parte ainda não é completamente compreendida (IZQUIERDO, 2007). 
O depósito de memória de curto prazo, também definido como depósito de memória primária, por William James, consiste em um buffer de capacidade limitada (no máximo sete itens) onde a informação desaparece a não ser que seja tratada ou repetida. A duração de uma informação na memória de curto prazo é pequena e o decaimento acontece dentro de aproximadamente 20 segundos (IZQUIERDO, 2007; MARCHELLI, 2009).

Desta forma, alguns eventos ficam disponíveis para serem lembrados, mas outros são descartados rapidamente, isto é consequência de um processo de filtragem que é utilizado para definir que informação será processada e memorizada. As motivações do individuo explicam grande parte dos esquecimentos, aquilo que ele não tem tanto interesse é assimilado com dificuldade e esquecido rapidamente. Este fenômeno atinge todas as pessoas e desempenha um papel importante para prevenção de sobrecarga, podendo ser também patológico para menos ou para mais (amnésia ou hipermnésia). Pesquisadores, entre os quais se destaca Ebbinghaus, estudam o processo de esquecimento e ressaltam que a repetição periódica do contato melhora a memorização, diminuindo a velocidade do esquecimento.

Uma vez na memória de curto prazo, as informações podem ser copiadas ou transferidas para o depósito de memória de longo prazo, ou depósito secundário, onde ficam disponíveis por um grande período ou até permanentemente. A capacidade deste depósito é ilimitada e sua importância está relacionada com o fato de que recordar é extremamente importante para a vida, principalmente dos seres humanos.

Apesar de existirem diversos tipos de memória (de representação perceptual, de procedimentos, associativa, não associativa, dentre outros) dado o escopo deste projeto optou-se por não explorá-los.

\subsection{Aprendizagem}

A aprendizagem está diretamente relacionada com a forma como o indivíduo percebe, seleciona, organiza e atribui significados aos objetos e acontecimentos. Ela 
ocorre através de ciclos iterativos e o permite adquirir modos de agir, reagir, adaptando-se a novas circunstâncias (SIEMENS, 2005).

Aprendizagem é aquisição ou mudança relativamente estável e duradoura do comportamento e / ou do conhecimento, devido à experiência, ao treino ou ao estudo, fundamentada nas vivências anteriores do indivíduo. Deve ser mais que apenas o acúmulo de volume de informação através da exposição ao conteúdo, mas também através da interação e / ou reflexão.

Trata-se de um processo dinâmico, pessoal ou global, contínuo, interativo, cumulativo e evolutivo de aquisição de conhecimentos, seja entre atores e meio ou entre ator-ator. Está desde sempre ligada ao homem enquanto ser social que estabelece relações em uma rede onde cada um impacta outros, modificando a organização. Visto desta maneira, a aprendizagem afeta diretamente a estrutura e a organização da rede.

Existem diversas frentes que abordam a aprendizagem, desde aquela realizada com animais em laboratório (LABNEC, 2009; MEDNICK, 1973) até a que afeta o rendimento dos alunos (CARVALHO, 2000; RIBEIRO, 2003; THOMPSON, 1973). Aqui se optou por não aprofundar este estudo, mas sim identificar aspectos relevantes para o desenvolvimento de aprendizagem em simulações de animais ou humanos virtuais, onde, segundo (MAES, 1994), ela precisa ser incremental, deverá ser não supervisionada, sendo mais usada a aprendizagem por reforço ("reinforcement learning") (SUTTON, 1990). Apesar disto, seja qual for o método utilizado o aprendiz deve combinar os dados recebidos com a informação que possui na sua estrutura interna, numa tentativa de aperfeiçoar e aumentar o seu conhecimento e com isso melhorar o seu desempenho no futuro.

\subsection{Personalidade}

A personalidade é um conjunto de padrões distintos de comportamento que caracteriza os seres humanos e que é importante, sendo, portanto possível dizer, segundo Del Nero (1998) que as pessoas buscam "se conduzir bem e de acordo com uma série de valores e preceitos". 
O primeiro autor a publicar um livro sobre personalidade foi Gordon Allport em 1937, intitulado "Personality: A Psychological Interpretation" (MATTHEWS; DEARY; WHITEMAN, 2003 apud NETO, 2009a). Apesar de historicamente importante, a definição de Allport não é mais utilizada (PERVIN; JOHN, 2003 apud NETO, 2009a). Atualmente, a personalidade é compreendida como um sistema o qual, a partir de um conjunto de padrões inatos da pessoa, interage com o ambiente social nas dimensões afetivas, cognitivas e comportamentais para produzir as ações e as experiências de uma vida individual (GARCIA, 2006 apud NETO, 2009a). Entretanto os psicólogos exploram diferentes aspectos dessa definição e, dependendo da abordagem utilizada, enfatizam: características biológicas, genéticas, experiências de infância, maneira de pensar, cultura, etc.

\subsection{Tomada de Decisão}

A tomada de decisão envolve um processo cognitivo que avalia as informações recebidas e escolhe uma ou mais alternativas a ser realizada. Esta decisão é baseada naquilo que foi recebido, nas propriedades internas e na experiência do indivíduo (HAN; LERNER, 2009). Ela busca atingir algum objetivo e é tomada a partir de possibilidades ou considerando probabilidades. Trata-se de um processo fortemente dependente do contexto, pois uma opção boa agora pode ser ruim em algum outro momento devido a alterações nas condições que envolvem a decisão (CORRÊA, 2009).

Finalizando este capítulo deve-se ressaltar que aqui foram apresentados aparatos e processos importantes para a elaboração de agentes minimamente cognitivos que podem se comunicar, ser modificados pelas informações às quais venham a ter acesso, bem como modificá-las. Optou-se por abordar formas de comunicação, memória e personalidade, dando especial ênfase em aspectos relativos à aprendizagem (assimilação) e à tomada de decisão. 


\section{Capítulo 4. CIÊNCIA DA INFORMAÇÃO E COMUNICAÇÃO SOCIAL}

Neste capítulo estão abordadas duas áreas que se relacionam com o presente trabalho considerando o tratamento de comunicação, divulgação e fluxos de informação, redes sociais e meios de comunicação em massa.

A Ciência da Informação (Cl) é uma área nova, de 1948 (BRAGA, 1995, ROZADOS, 2003), mas nascida formalmente apenas em 1962 (SARACEVIC, 1996, p.46) que surgiu abordando questões relativas à recuperação de informações e ampliou seus horizontes a partir do momento em que buscou identificar a natureza, a estrutura e aspectos do comportamento humano diante da quantidade cada vez maior de informações.

Dentre seus componentes estão diversos processos como a coleta, organização, disseminação, recuperação e uso de informações (GUTTIÉRREZ, 1999, LIMA, 2003). No Brasil, a área teve seu surgimento marcado pela criação em 1970 do mestrado em ciência da informação no Instituto Brasileiro de Bibliografia e Documentação (IBBD). A partir de então, os contornos da $\mathrm{Cl}$ foram se adaptando e mostrando uma área cada vez mais multi, trans e interdisciplinar tanto na intenção e como na prática.

Um dos mais importantes teóricos da área, Saracevic (1996, p.47), aponta que a ciência da informação tem especial atenção aos "problemas de efetiva comunicação do conhecimento e de seus registros entre os seres humanos, no contexto social, institucional ou individual do uso e das necessidades de informação".

Este mesmo autor aponta quatro áreas que mantêm relação estreita com a Cl: a biblioteconomia, a ciência da computação, a ciência cognitiva e a comunicação (Figura 9) (SARACEVIC, 1996, p.48). 


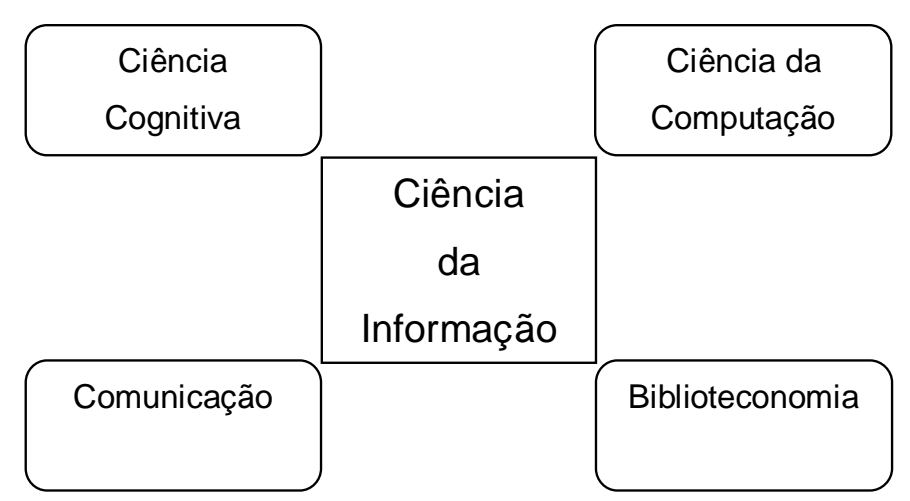

Figura 9: Áreas com relação mais próxima com a Ciência da Informação, segundo Saracevic (1996).

Para ele com a Biblioteconomia o relacionamento se dá no sentido de organização e reutilização de informações. Já a Ciência da Computação, também conhecida na $\mathrm{Cl}$ como tecnologia, é útil para desenvolvimento de ferramentas que facilitem a representação, organização e aperfeiçoem o tratamento e recuperação de informações. As contribuições da Comunicação Social e da Ciência Cognitiva estão muito relacionadas, pois a primeira trata de trocas de informação e características relativas a estes fluxos e a segunda a aspectos do indivíduo, usuário, que interage com os sistemas, modelos e métodos, seu conhecimento prévio, quais procedimentos ele utiliza mais freqüentemente na interação com os sistemas, como o cérebro armazena e processa as informações, dentre outros.

A inclusão do estudo de $\mathrm{Cl}$ neste trabalho busca, a partir da experiência adquirida no contato com professores da Escola de Comunicação e Artes da USP, o embasamento a respeito das redes sociais (Seção 4.1), sua estrutura e organização.

A segunda área abordada neste capítulo é a Comunicação Social (CS), a qual lida com notícias e divulgação de informações na busca por informar e entreter, influenciando a rotina diária, as relações pessoais e de trabalho.

A CS foca principalmente na relação entre a população e os meios de comunicação em massa, abordando formas de jornalismo, publicidade e propaganda em meios como rádio, televisão e internet.

Um primeiro ponto da CS útil aqui é a divulgação de notícias, sendo portanto importante o estudo dos meios de comunicação em massa, o que está feito na Seção 4.2. 
Outro ponto útil proveniente da Comunicação Social é a finalidade da divulgação, assim, na Seção 4.3 estão apontados aspectos relativos à publicidade, propaganda e jornalismo. Além disto, é apresentado o conceito de Plano de Mídia, o qual é produzido pelas agências de publicidade e apresenta como deve ser feita uma campanha, levando em consideração os resultados pretendidos, o custobenefício e o público alvo.

\subsection{Redes Sociais ${ }^{7}$}

As redes sociais são utilizadas tanto no nível individual, como organizacional (CRUZ; SEGATTO, 2009). No primeiro caso as pessoas participam de grupos e se relacionam com aquelas pelas quais têm alguma afinidade. Já as empresas e organizações buscam identificar e implantar a melhor forma e estrutura para relacionamento entre seus funcionários. Neste sentido, Oinas-Kukkonen (2010) diz que nos dias atuais está ocorrendo "uma mudança conceitual e tecnológica, e rápida evolução das plataformas para gerenciar as redes sociais" (tradução do autor).

Observando as pessoas e sabendo que há uma interligação entre elas, o sociólogo Stanley Milgram conduziu um experimento onde enviou uma determinada quantidade de cartas a vários indivíduos. Eles eram escolhidos de forma aleatória e deviam tentar enviar aquilo que receberam a um alvo específico. Caso não conhecessem o alvo, as pessoas eram solicitadas a enviar as cartas para alguém que acreditassem estar mais perto do destino. Milgram descobriu que, daquelas que chegaram a seu destinatário final, a maioria das cartas havia passado apenas por um pequeno número de indivíduos. Isso indicaria que as pessoas estariam efetivamente, a poucos graus de separação umas das outras.

Depois do experimento realizado por Milgran, grande passo nas redes sociais foi dado com a definição dos grafos por Ëuler estabelecendo os conceitos de nó e aresta, os quais são importantes para a compreensão das relações existentes entre as pessoas.

\footnotetext{
${ }^{7}$ Esta seção foi feita a partir do estudo inicial do trabalho (RECUERO, 2009) e da posterior busca por aprofundamento.
} 
Pode-se dizer que uma rede social, estruturada por vínculos, é um conjunto de indivíduos (nós) que compartilham interesses, idéias, ou objetivos em comum, conectados por elos (arestas) ou comunidades com algum tipo de relação (CARRINGTON; SCOTT; WASSERMAN, 2005).

Considerando estes conceitos, vários pesquisadores dedicaram-se ao estudo das propriedades dos vários tipos de redes sociais e como se dava o processo de sua construção, ou seja, como seus nós se agrupavam (AGUIAR, 2006; ROSVALL, 2003; STEHLÉ, BARRAT, BIANCONI, 2010).

O trabalho de Erdös e Rényi é considerado fundamentalmente importante porque foi o primeiro a relacionar grafos com redes sociais e tentar aplicar suas propriedades e características para grupos humanos. Eles acreditavam que o processo de formação dos grafos era randômico, no sentido de que os nós se agregavam aleatoriamente. Desta premissa, Erdös e Rényi concluíram que todos os nós, em uma determinada rede, deveriam ter mais ou menos a mesma quantidade de conexões, ou igualdade nas chances de receber novos links, constituindo redes igualitárias.

Outra importante contribuição foi dada pelo sociólogo Mark Granovetter (1973), que considera o que chamou de laços fracos (weak ties) e laços fortes (strong ties). Granovetter mostrou que pessoas que compartilhavam laços fortes (de amigos próximos, por exemplo) em geral participavam de um mesmo círculo social (um mesmo grupo). Enquanto àquelas com quem se tinha um laço mais fraco, ou seja, conhecidos ou amigos distantes, eram importantes porque conectariam vários grupos sociais. O trabalho de Granovetter trouxe à tona a importância das tríades nas redes sociais, afinal dois desconhecidos que têm em comum um amigo possuem mais chances de virem a se conhecer do que pessoas sem interesses ou conhecidos em comum.

A partir do experimento de Milgram e do estudo de Granovetter, Ducan Watts e Steven Strogatz, criaram um modelo semelhante ao de Erdös e Rényi. Nele os laços eram estabelecidos entre as pessoas mais próximas, além de alguns que eram criados de modo aleatório, criando o que chamaram de mundo pequeno. Desta forma eles mostraram que bastavam poucos links entre um número pequeno de pessoas para formar um mundo pequeno em uma grande rede, transformando a própria rede em um grande cluster. 
O primeiro problema da teoria dos mundos pequenos de Watts foi explicado por Barabási. Ele demonstrou que as redes não eram formadas de modo aleatório, mas que existia uma ordem na dinâmica de estruturação das redes, algumas leis bem específicas. Esta foi chamada de "rich get richer" - ricos ficam mais ricos - assim, quanto mais conexões um nó possui, maiores as chances que ele tem de ter outras, em uma espécie de "conexão preferencial". Isto implica que as redes possuam "nós" que seriam altamente conectados (hubs), mas que a grande maioria dos nós teriam poucas conexões, o que, ele chamou de "sem escalas" (scale free).

Ainda na tentativa por relacionar os modelos existentes, Scharnhorst explica que eles foram criados sob olhar teórico, mas que, no mundo real, as redes costumam exibir um grau de distribuição (conectividade) variado, que não necessariamente funciona segundo um modelo ou outro.

\subsubsection{Redes Sociais na Internet}

Apesar de não ser o foco neste trabalho considerar as redes sociais na internet ou mídias sociais conectadas (como definido em LIMA JUNIOR, 2009), a maioria dos trabalhos encontrados sobre o tema se refere a levantamentos e avaliações relativas à influência do uso destas redes no comportamento das pessoas. Por este motivo, optou-se por citar a seguir características de algumas das redes sociais on line, dando preferência por comentar aquelas mais comuns nos países da América.

Especialmente on-line as redes sociais servem para conectar pessoas com interesses semelhantes, estabelecer contatos profissionais e troca de arquivos, funcionando como uma ferramenta para comunicação. Atualmente as empresas buscam tais redes para divulgar produtos, conhecer seu público alvo e criar uma identificação com sua marca (QUINTANILHA, ALMEIDA, 2008).

Criado por Orkut Buyukokkten, ex-aluno da Universidade de Stantford e lançado pelo Google em janeiro de 2004, o software Orkut ${ }^{8}$ é uma espécie de conjunto de perfis de pessoas e suas comunidades. Nele é possível colocar fotos e preferências pessoais, listar amigos e formar comunidades. O Orkut mostra os

\footnotetext{
${ }^{8}$ http://www.orkut.com
} 
indivíduos enquanto perfis e nele é possível perceber as conexões diretas (amigos) e indiretas (amigos dos amigos) das pessoas. Além disso, ele possibilita interação de formas variadas, seja através de fóruns, envio de mensagens para amigos, para comunidades ou para amigos dos amigos.

Entre as redes sociais on-line mais conhecidas está o MySpace ${ }^{9}$, uma rede interativa de compartilhamento de fotos, vídeos e músicas, perfis de usuário, fóruns e comunidades, a mais popular dos Estados Unidos.

O Facebook ${ }^{10}$ que também é uma rede de relacionamento social, era inicialmente restrita aos estudantes do Harward College, onde foi criada. Hoje é aberta a qualquer usuário. O Flickr ${ }^{11}$, com milhões de usuários e centenas de milhões de fotos e vídeos, é uma comunidade fotográfica. Fundado em 2004, é um site de hospedagem e compartilhamento de arquivos de imagens e vídeos, onde é permitido criar álbuns e o acesso livre, também por usuários não registrados.

Há também redes sociais com focos profissionais como o Linkedln que é especifico para carreira e negócios, com uma abordagem corporativa, onde usuários criam seus perfis profissionais. Este tipo de rede é útil para o mercado de trabalho, e é onde, a cada dia mais empresas buscam candidatos, pois facilita o contato.

\subsubsection{Blogs e Fotologs}

Blogs e Fotologs também apresentam um campo interessante de estudo das redes sociais, na medida em que representam um indivíduo (ou um grupo) refletindo suas características. Neles as pessoas personalizam a página como desejam (cores, figuras, fontes, etc.) e colocam posts (blocos de texto ou imagens) com uma certa periodicidade. No caso dos fotologs, embora seja possível colocar imagens e texto, a preferência é dada para as imagens, já no blogs tem-se maior predominância de textos.

Nestes sistemas é possível definir uma lista de "amigos" ou favoritos, bem como utilizar mecanismos de interação. O uso dos comentários é uma forma simples

\footnotetext{
${ }^{9} \mathrm{http}: / /$ www.myspace.com/

${ }^{10} \mathrm{http}: / /$ www.facebook.com/

11 http://www.flickr.com/
} 
de observar a interação, seja criando, fortalecendo uma conexão (pessoas que concordam sobre determinado assunto) ou enfraquecendo, apagando alguma que exista (RECUERO, 2009).

\subsection{Meios de Comunicação em Massa (MCM) e sua Influência no Público}

As características fundamentais dos Meios de Comunicação em Massa são a instantaneidade, a atualidade e a simplicidade. Eles atingem simultaneamente uma vasta audiência. Este público é heterogêneo, está disperso geograficamente e é, normalmente, anônimo para a fonte, mesmo que a mensagem, em função dos objetivos do emissor, ou da estratégia mercadológica do veículo, seja dirigida a uma determinada parcela do público, isto é, um sexo, uma faixa etária (FRANCISCATO, 2003; SÁ, 2008).

São exemplos de meios de comunicação em massa à televisão e o rádio (PERLES, 2010). Nestes veículos a pessoa precisa apenas ligar o aparelho, ouvir e / ou assistir, mas com pouca ou nenhuma forma de interação. Estes são exemplos da comunicação unidirecional, onde, segundo Negroponte (1995:24 apud DEUS, 2006), "a inteligência encontra-se no ponto de origem", "o transmissor determina tudo", cabendo ao espectador simplesmente receber o que lhe é imposto.

O rádio é um veículo que busca um tom confidencial a fim de criar uma relação pessoal com o público. Nele as mensagens precisam ser claras e simples, pois enquanto a pessoa está ouvindo ela pode dirigir, correr em um parque, ler um livro, escrever, dentre outras coisas, estando atenta ou não ao que está sendo transmitido.

Já a comunicação pela televisão trabalha com imagem, áudio e texto. Sua programação busca manter a fidelidade do público e o atrativo para os anunciantes (BRITTOS; MIGUEL, 2005). Neste sentido Alexandre (2001) ressalta que deve haver uma boa relação entre as finalidades comerciais e as necessidades da população.

É sabido que diariamente informações tentam criar, mudar ou cristalizar atitudes ou opiniões nos indivíduos. É o efeito dos meios de comunicação de massa 
nas relações sociais. Os comunicadores buscam produzir aprendizagem ou fortalecer hábitos nos espectadores através de estratégias mostrando que ele pode obter algum "status" (BATISTA; CAVALHEIRO; LEITE, 2008) agindo de uma forma ou comprando algo, por exemplo.

Cada uma destas atividades pode exercer funções e também disfunções, pois influenciam opiniões, provocam reações e afetam decisões, que podem ser de compra, satisfação ou repudia (BATISTA; CAVALHEIRO; LEITE, 2008).

Segundo Aranda (2005) a maior influência da televisão no comportamento humano é "indireta, sutil e cumulativa - não imediata e direta". De forma complementar, para McLuhan (apud DEUS, 2006) "os meios são mais do que transportadores mecânicos, eletrônicos ou digitais de mensagens, eles expressam idéias e servem para comunicação interpessoal, formando assim comunidades ou grupos". Ele diz ainda que "qualquer compreensão de mudanças sociais e culturais é impossível sem um conhecimento do modo como os meios de comunicação funcionam como ambientes" (McLuhan 1967, p. 26 apud DEUS, 2006), ou seja, onde as pessoas ficam "imersas" e sofrem interferência direta em seus comportamentos.

As preocupações de ordem social com o fenômeno da comunicação de massa acompanharam, segundo (Alexandre, 2001), sua disseminação, pois "a partir dos anos 60, a Sociologia e a Psicologia passaram a estudar o poder exercido pela mídia, apontando para o espaço social que constitui o mercado consumidor de informação, classificando-o, nomeando e reconhecendo sua influência na formação da sociedade".

Ainda seguindo esta linha, diversos trabalhos são encontrados na literatura identificando pontos positivos e negativos, principalmente da televisão e buscando avaliar os impactos provocados pela "manipulação" ou "escolha tendenciosa" da programação pelos veículos (PEREIRA; VIAPIANA, 2004; ARANDA, 2005; BATISTA et. al., 2008; GOMIDE, 2000; LEÃO; MELLO, 2009; HÜSKES; SILVEIRA; TONTINI, 2003; SÓLIO, 2006).

Em (BARBOSA; RABAÇA, 1987) e (ALEXANDRE, 2001) é possível identificar como aspectos positivos o fato de que os meios de comunicação em massa proporcionam diversão, divulgam informações culturais e desvios de conduta, ensinam, dentre outros. Já como aspectos negativos, eles enfatizam que a população fica cada vez mais conformada, passiva e acritica; valorizando a 
informação atual e se esquecendo da história. Além disto, apontam que os MCMs difundem, em sua maioria, uma cultura homogênea e nivelam superficialmente as mensagens para que elas sejam entendidas pelo maior número possível de pessoas.

De forma geral, para (MERLO-FLORES, 1999) "as opiniões sobre os efeitos especialmente da televisão poderiam ser resumidas em três pontos": as pessoas que consideram que os efeitos são devastadores; aqueles que admitem que ela é um "espelho da realidade social" e uma terceira frente onde tudo é relativo, ou seja, "a relação que as crianças e adolescentes estabelecem com a televisão depende de sua família, ambiente social, características pessoais, etc".

\subsection{Formas e Objetivos da Divulgação de uma Notícia ou Anúncio}

A informação é o maior investimento do comunicador. Na transmissão e difusão das mensagens os assuntos a serem tratados e a forma devem estar bem posicionados dentro da programação e considerar especialmente o horário, o público e a região geográfica (LUPETTI, 2006). Afinal, para que haja assimilação e consumo as mensagens precisam ter apenas a idéia principal adaptada ao público-alvo (FUENTE, 1997, SÓLIO, 2006).

Três são as principais formas de divulgação: jornalismo, publicidade e propaganda (TROIANO, 2009). Para contemplar a primeira forma, no título desta seção se colocou a palavra notícia, pois o jornalismo se presta a divulgar informações, as quais são passíveis de assimilação pelo telespectador ou ouvinte. Cabe a ele então avaliar se considera que a notícia está distorcida (para satisfazer interesses da emissora ou de empresas a ela vinculadas) ou não.

A segunda e terceira formas de divulgação são parecidas e se referem a anúncios, mas possuem diferenças importantes. "Enquanto a propaganda é ideológica, grátis e dirigida ao indivíduo, a publicidade é comercial, paga e dirigida à massa" (MUNIZ, 2004).

Em geral as mensagens publicitárias buscam vender a imagem de que 0 indivíduo é o que consome e será valorizado por isso (SANTOS, 2005), buscam 
"promover o lucro de uma atividade comercial, conquistando, aumentando ou mantendo clientes" (MUNIZ, 2004). Ao despertar no público o desejo de compra, intenciona levá-lo à ação, pois se isto não ocorrer, a finalidade principal da publicidade, que é de estimular a venda, não estará sendo atendida (LUPETTI, 2006).

Já "a propaganda pode ser conceituada como atividade que tende a influenciar o homem, com o objetivo religioso, político ou cívico. É, portanto a propagação de idéias sem finalidade comercial" (LAGE, 2000).

De forma geral, o livro (LUPETTI, 2006; MALANGA, 1979) estabelece que a propaganda visa à adesão individual a um conceito, enquanto a publicidade busca criar o desejo (coletivo) de aquisição, que se deverá materializar como compra.

\subsubsection{Plano de Mídia}

A palavra mídia vem do latim médium e representa o conjunto dos meios de comunicação usados para a veiculação de informações (HOUAISS, 2001 apud COMUNICACAO, 2010).

O Plano de Mídia é o documento no qual é determinada a quantidade de pessoas que a campanha deverá atingir, a intensidade adequada, o tempo suficiente para atender aos resultados pretendidos e estabelece a ação a ser desenvolvida para uma determinada situação mercadológica (TAMANAHA, 2006; VERONEZZI, 2010).

Independente do tipo de produto ou campanha, o plano de mídia deve ter pelo menos três grandes partes: informações básicas, objetivos e estratégias, possui ainda um anexo que é o chamado mapa de mídia (Quadro 1). As informações básicas englobam dados relativos à concorrência, o target (público-alvo), os objetivos, a verba e o período. Sendo o público alvo o perfil que caracteriza o consumidor ideal, o qual permite a transmissão de uma mensagem usando uma linguagem mais direcionada. Os objetivos têm grande importância, pois nesta parte são mencionados os aspectos que a campanha pretende ressaltar. As estratégias de mídia são organizadas estabelecendo os veículos, o número de inserções e os 
valores que serão investidos. Ela deve levar em consideração o cronograma a fim de cumprir os objetivos (VIAPIANA, 2010).

\begin{tabular}{|l|l|}
\hline Cliente & Daniel \& DR \\
\hline Produto & Livro \\
\hline Duração & $30 "$ \\
\hline Mês / Ano & $05 / 2011$ \\
\hline
\end{tabular}

\begin{tabular}{|c|c|c|c|c|c|c|c|c|c|}
\hline $\begin{array}{c}\text { Dia } \\
\text { Programa }\end{array}$ & 01 & 02 & 03 & $\ldots$ & 31 & $\begin{array}{c}\text { Total de } \\
\text { Inserções }\end{array}$ & Audiência & $\begin{array}{c}\text { Custo } \\
\text { Unitário }\end{array}$ & Custo Total \\
\hline A & & 1 & 2 & & & 3 & 10 & 100,00 & 300,00 \\
\hline B & 2 & & & & 2 & 4 & 36 & 150,00 & 600,00 \\
\hline C & & & 2 & & & 2 & 20 & 120,00 & 240,00 \\
\hline D & 3 & & & & 2 & 5 & 25 & 130,00 & 650,00 \\
\hline E & & 2 & & & & 2 & 7 & 80,00 & 160,00 \\
\hline
\end{tabular}

Quadro 1: Exemplo de mapa de mídia.

Para finalizar, neste capítulo foram apresentados conceitos e características das redes sociais, meios de comunicação em massa, além de formas e objetivos inerentes ao jornalismo, publicidade e propaganda. Grande atenção foi dispensada a fim de delimitar e situar o presente trabalho considerando as áreas de Ciência da Informação e Comunicação Social, pois aqui se busca utilizar características das formas de divulgação de notícias e também dos meios de comunicação em massa.

Outro ponto relevante é que neste projeto o conceito de redes sociais é usado no sentido da comunicação direta entre pessoas (personagens na simulação) e posterior tratamento e assimilação das informações por parte delas. 


\section{Capítulo 5. MODELAGEM COMPUTACIONAL}

Segundo Freitas Filho (2001) e Campos (2004) a modelagem pressupõe um processo de criação e descrição, envolvendo um determinado grau de abstração, o que certamente acarreta uma série de simplificações sobre a organização e o funcionamento do sistema real.

Especificamente neste projeto se propõe o uso de um modelo probabilístico (que permita avaliar fenômenos sobre os quais não se tem conhecimento suficiente e extrapolar resultados), dinâmico (que descreva o comportamento do sistema através do tempo) e discreto (que mude em pontos isolados de tempo) (LAW; KELTON, 1991) na busca por reproduzir aspectos realistas do comportamento humano em situações de trocas de informações.

Com este propósito dois níveis de abstração foram definidos: a definição da sociedade e o detalhamento do funcionamento de cada um dos agentes (Figura 10). Para a descrição destes níveis serão usados termos como falar, decidir, por exemplo. Portanto, dado o caráter multidisciplinar dizer que o agente fala não busca reproduzir como ocorre este processo nos seres ditos cognitivos, mas implementar computacionalmente agentes que troquem mensagens seguindo padrões conhecidos na área de Inteligência Artificial e Sistemas Multiagentes.

Será considerado então um sistema onde os personagens interagem e se relacionam, podendo estes também receber informações veiculadas em meios de comunicação em massa (sociedade, no lado esquerdo da figura). O foco então é na simulação de agentes que possuem características similares a algumas das encontradas em seres humanos, para assim transmitir uma sensação de ilusão de vida tanto no âmbito da dinâmica na sociedade, quanto no comportamento de cada indivíduo separadamente (lado direito na mesma figura). Estas informações estão detalhadas nas seções a seguir (5.1 e 5.2), mas é preciso salientar que na Figura 10 os círculos representam os agentes, enquanto os retângulos são os meios de comunicação em massa que eles podem acessar. 


\section{Sociedade}

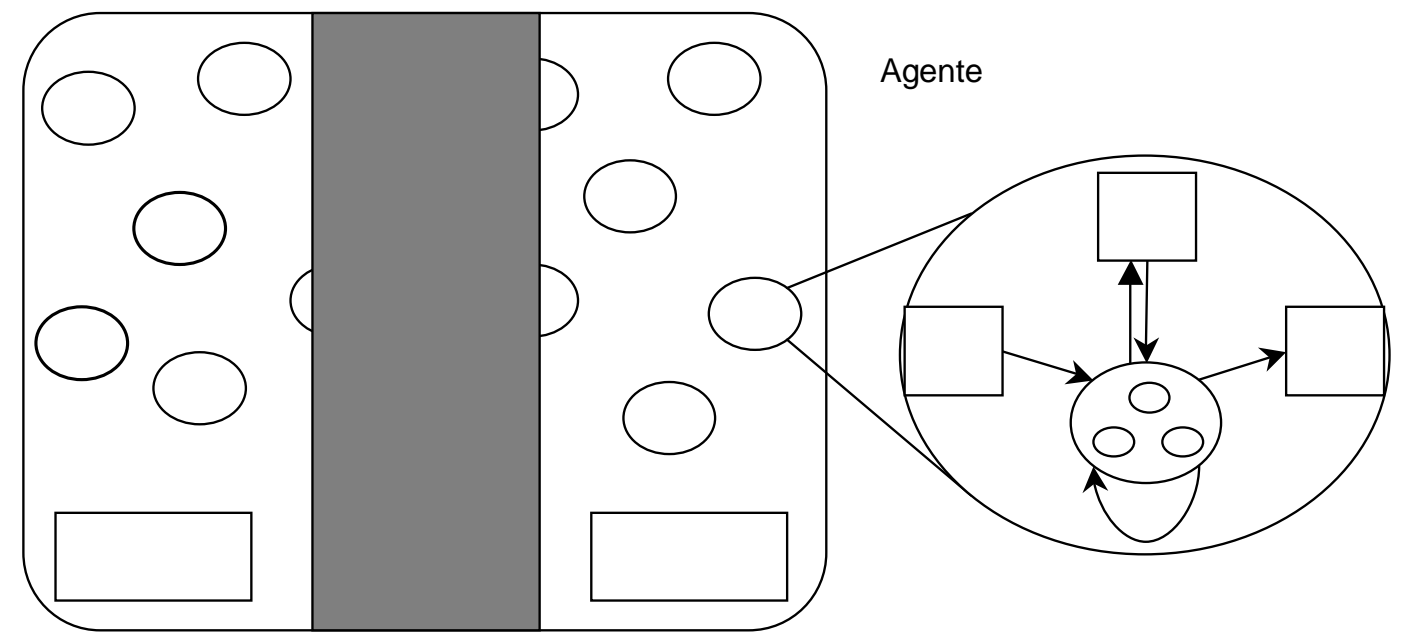

Figura 10: Níveis de abstração que compõem este projeto: a sociedade com agentes (círculos) e meios de comunicação em massa (retângulos) e o funcionamento interno de cada um dos agentes.

Para que os agentes apresentem comportamentos individualmente independentes, está sendo dada atenção especial à reprodução de aspectos envolvidos em processos cognitivos como comunicação, aprendizagem, raciocínio e tomada de decisão, principalmente considerando cenários de jornalismo, publicidade e propaganda. No contexto deste trabalho tanto os termos "agentes cognitivos" quanto "humanos virtuais", conhecidos na literatura, podem ser considerados como sinônimos.

Para a modelagem destes agentes Reynolds (1987) sugere o uso de uma estratégia de acesso parcial à informação, por ser mais realista tanto face à imprecisão nos dados devido à impossibilidade de se ter acesso a todas as informações do ambiente, como pela inerente imperfeição dos sentidos e processos humanos. Desta forma ele advoga ser inadequado o uso de um modelo em que cada agente disponha de toda a informação do mundo virtual. A quantidade e variedade de dados disponíveis certamente influenciam no processo de decisão dos agentes, o qual é ponderado pelo "conhecimento" que eles possuem em função das informações recebidas no decorrer da simulação.

Dada a complexidade envolvida na escolha de quão cognitivos devem ser os agentes e em qual nível de profundidade se deve tratar desta questão, optou-se 
por considerar uma modelagem que agrega fatores $\operatorname{cognitivos}^{12}$ a técnicas tradicionais da Inteligência Artificial. Assim os aspectos cognitivos podem ser desenvolvidos de forma relativamente simples, mas aprimorados e futuramente substituídos por modelos mais completos e robustos, permitindo que as entidades virtuais tomem decisões da forma mais realista possível.

Com o intuito de formalizar a representação do mundo e permitir uma referência comum aos personagens, decidiu-se fazer uso de ontologias, o que propicia uma modelagem formal, que pode ser estendida, adaptada e aprimorada (ALMEIDA, BAX, 2003; GRUBER, 1993). Busca-se então, com o uso de ontologias, uma representação de mundo coerente a todos os agentes que possibilite a simulação de personagens que podem receber e trocar informações.

A opção pelo uso de ontologias, e em particular da ferramenta Protégé®, se deve a uma continuidade do trabalho desenvolvido no mestrado (PAIVA, 2006), quando foi feito amplo levantamento sobre ferramentas, tipos de ontologias, e suas características, principalmente no que tange à modelagem formal. Na próxima seção estão, portanto, apresentadas apenas as informações fundamentais para o entendimento do uso de ontologia aqui e do modelo desenvolvido usando esta técnica.

As características gerais da sociedade de agentes que está sendo desenvolvida estão apresentadas na seção 5.1. As abordagens utilizadas estão citadas em 5.1.1 e a modelagem realizada usando ontologias está na seção 5.1.2.

Outro ponto importante tratado neste capitulo é o modelo proposto para a estrutura "mental" dos agentes. Deste modo a seção 5.2 apresenta a forma proposta para tal modelo, com foco nos aspectos cognitivos (recebimento e assimilação de informações, raciocínio, memória, tomada de decisão,...) e quais relações existem entre estes.

12 Considera-se aqui o uso de fatores cognitivos, ou seja, de características e processos identificados em seres cognitivos, tais como perfil, personalidade, comunicação, aprendizado, memória, por exemplo. Esta opção é adotada devido à complexidade e divergência identificada na literatura para a definição do que é cognição e o que é necessário para que um agente seja minimamente cognitivo. 


\subsection{Ambiente e Sociedade de Agentes}

Sociedades humanas possuem diversos fatores sob os quais muitas interações podem ocorrer. Sendo assim é possível analisá-las de forma macroscópica (o todo) ou microscópica (os indivíduos um por um), já que o comportamento da sociedade emerge justamente das ações de cada um dos indivíduos.

Gilbert (1998) acredita que uma importante característica das sociedades é que elas são resultado de processos dinâmicos. Sendo assim os indivíduos estão em constante mutação, seja falando, escutando ou interagindo. Uma sociedade surge e só se mantém apoiada nesta constante mudança.

Neste sentido o ponto central nesta pesquisa refere-se ao comportamento em sociedade e como é o posicionamento dos personagens. No âmbito da simulação de sociedades artificiais o que se busca também é dotar agentes autônomos de estruturas e mecanismos de inferência e decisão que os capacitem, de forma descentralizada, a exibir um comportamento 'socialmente racional' e coerente com o que pode ser observado em situações cotidianas.

Assim, neste projeto apenas os agentes estão sendo considerados como entidades ativas, pois em um sistema, conforme destaca Demazeau (1995), apenas estas são capazes de controlar suas ações, já que as entidades passivas não têm capacidade de tomada de decisão própria.

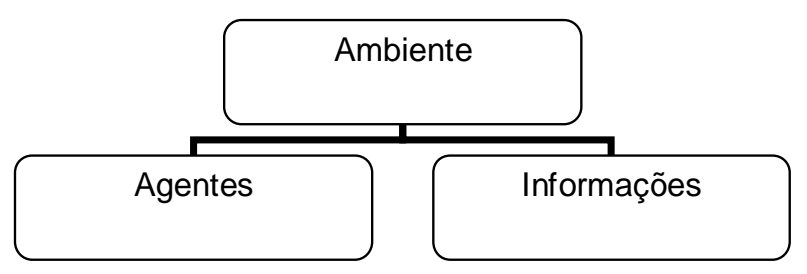

Figura 11: Componentes do Ambiente.

Além dos agentes, outro fator importante quando se pensa no modelo em desenvolvimento neste projeto de doutorado refere-se às informações (Figura 11). Para identificar sua importância, utiliza-se como pano de fundo neste projeto a ideia de que produtores de eventos pretendem descobrir quais as melhores formas para a divulgação de determinado acontecimento e para tal consideram análises sobre, por exemplo, a quantidade de pessoas sensibilizadas, o nível de sensibilização, as 
atitudes tomadas em decorrência da notícia (informação) recebida, inclusive aquelas visando sua propagação.

Pensando em um esquema que facilite o entendimento, na Figura 12 é possível identificar situações como a de um ambiente composto por agentes (círculos) que possuem algum grau de relacionamento com outros e que têm acesso a meios de comunicação em massa (retângulos, na mesma figura).

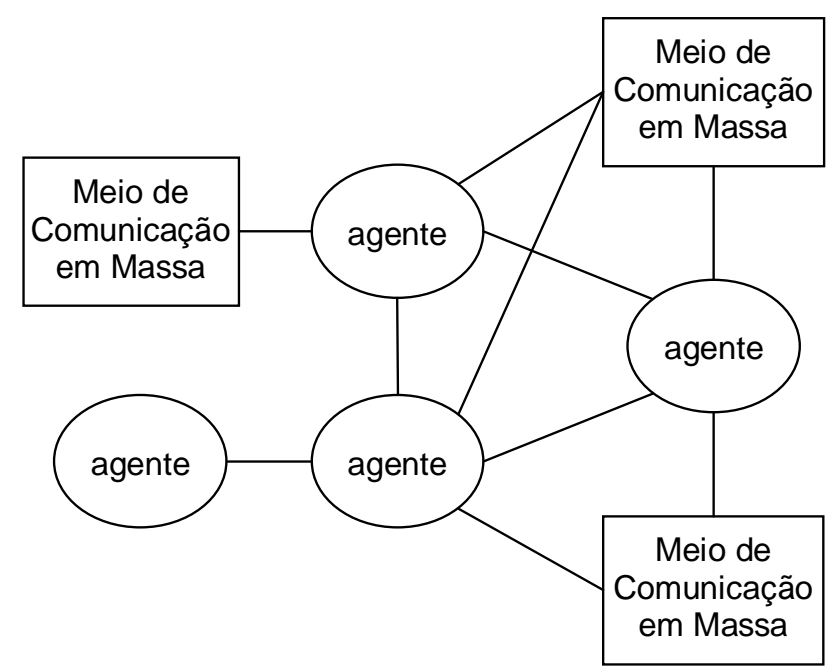

Figura 12: Relacionamento direto entre agentes (círculos) e através dos meios de comunicação em massa (retângulos).

Tendo este esquema, duas possíveis abordagens foram identificadas e estão descritas na próxima seção.

\subsubsection{Abordagens de Comunicação}

Com foco na disseminação de informações, avaliando sua propagação num ambiente com eventos tratados por agentes que possuem aspectos cognitivos, duas abordagens são importantes e estão descritas a seguir. 


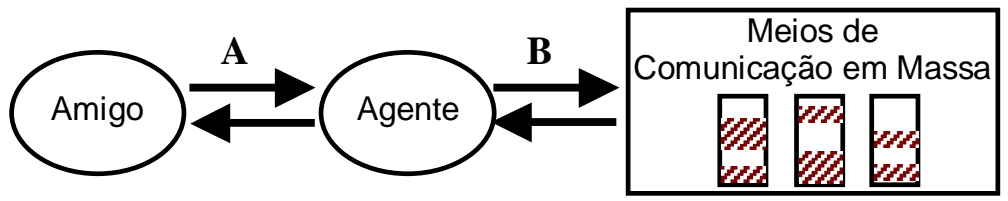

Figura 13: Abordagens.

Em uma primeira abordagem (Parte A da Figura 13), a preocupação maior repousa nas interações entre os diferentes agentes. Desta forma deve-se levar em consideração a existência de redes sociais ou conjuntos de indivíduos diferentes que se relacionam e se comunicam. Tem-se então a possibilidade de troca de informações sobre algum assunto e, desta forma, os agentes podem receber algo novo, decidindo se atualizam o que "sabem". Outro ponto relevante é que estas comunidades são compostas por grupos com certas afinidades, por exemplo: localização geográfica (vizinhos), cultural (gostos), profissional (colegas de trabalho), dentre outros. De forma geral, independente do motivo do relacionamento, os personagens são individualmente diferentes e, ao trocarem informações, devem atualizar o que "sabem" sobre o assunto "conversado" e também características relativas aos amigos que possuem. Estas últimas devem servir de apoio para decisões sobre o que será informado a algum agente futuramente.

Em uma segunda abordagem (Parte B da Figura 13) se considera a comunicação broadcast. Neste caso é possibilitada a divulgação de notícias através de meios de comunicação em massa, como televisão, rádio, Internet, dentre outros, considerando dados relativos à freqüência e ao tempo de divulgação. Nesta abordagem os agentes, acessando alguns destes meios de divulgação, devem ter capacidade de receber notícias, selecionando dentre aquelas com as quais se deparam, quais Ihes interessam, podendo assimilá-las ou não, atualizando suas bases de conhecimento.

Para contemplar estas abordagens, se propõe o modelo que está descrito a seguir. 


\subsubsection{Desenvolvimento usando Ontologia}

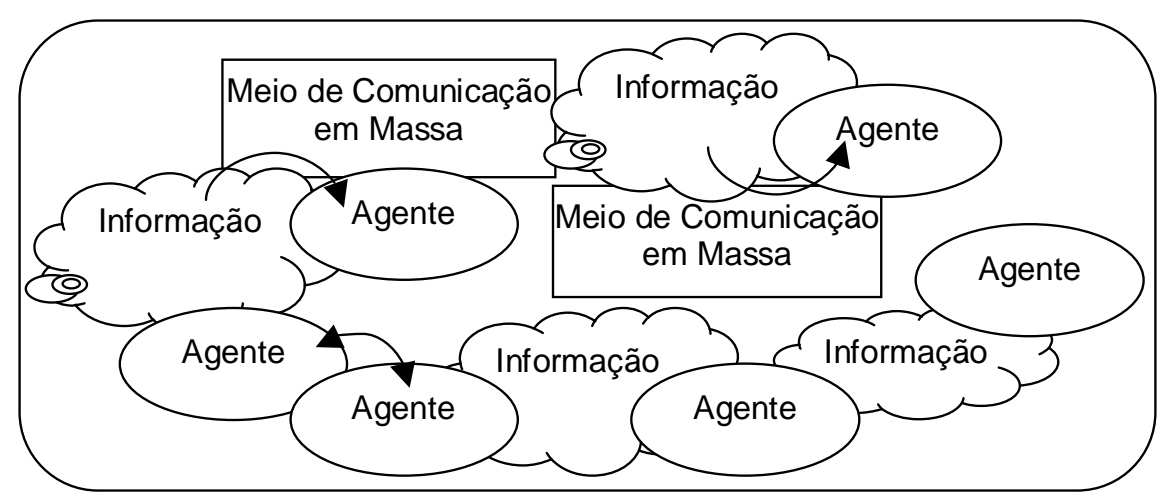

Figura 14: Visão do ambiente, ontologia.

$\mathrm{Na}$ sociedade modelada neste trabalho, os agentes devem compreender as convenções sociais e ter capacidade de tratar informações às quais tenham acesso. Neste sentido, está sendo usado o conceito de ontologia como modelo de mundo (Figura 14), ou seja, um arcabouço que permite aos agentes compreender o que "assistem" em algum meio de comunicação em massa e também manipular os assuntos que vão trocar com seus amigos. Dependendo de quem é o emissor da informação, esta foi classificada em dois tipos, como pode ser visto na Figura 15. Assim, consideram-se dicas (Statement) as informações trocadas entre os agentes e (Advertisement ou News) aquelas disponibilizadas através dos meios de comunicação em massa.

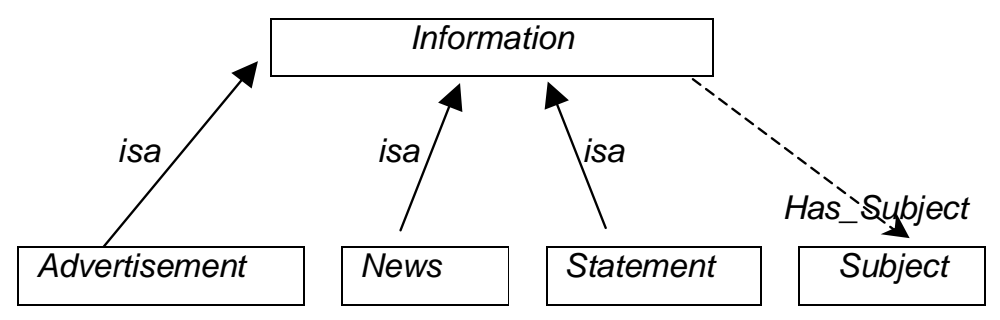

Figura 15: Super classe informação.

Apesar disto, qualquer informação possui pelo menos um assunto (<Has_Subject>, linha pontilhada na Figura 15), cuja definição deve ser feita 
conforme o Quadro 2, ou seja, estabelecendo apenas o título <Subject_Title>, um identificador <Subject_ldentifier>, a descrição do referido assunto $<$ Subject_Description> e o impacto associado a ele <Subject_Impact>. Este último representa uma estimativa que diferencia uma informação sobre uma mudança que afeta diretamente a rotina das pessoas (ataque de 11 de Setembro nos Estados Unidos, por exemplo) e algo relacionado a entretenimento, um show, por exemplo.

Quadro 2: Classe assunto.

\begin{tabular}{|l|}
\hline \multicolumn{1}{|c|}{ Subject } \\
\hline Subject_Title \\
\hline Subject_ldentifier \\
\hline Subject_Description \\
\hline Subject_Impact \\
\hline
\end{tabular}

No modelo desenvolvido (Figura 16, complementar à Figura 15) é possível perceber que estão contempladas as duas abordagens mencionadas na seção anterior. Analisando o lado esquerdo se identifica a possibilidade de divulgação de anúncios (Advertisement) ou notícias (News) em algum meio de comunicação em massa (Means_of_Mass_Communication), as quais podem ser recebidas pelos agentes. Para que isto seja possível, os agentes (agent) possuem perfis (Profile) que definem quais meios de comunicação em massa cada um deve acessar e com qual frequência isto deve ocorrer. Além disto, eles têm interesse $<$ Has_Interest_in> em alguns assuntos (Subject) e com base neles podem avaliar as informações às quais tenham acesso a fim de assimilá-las ou não. 


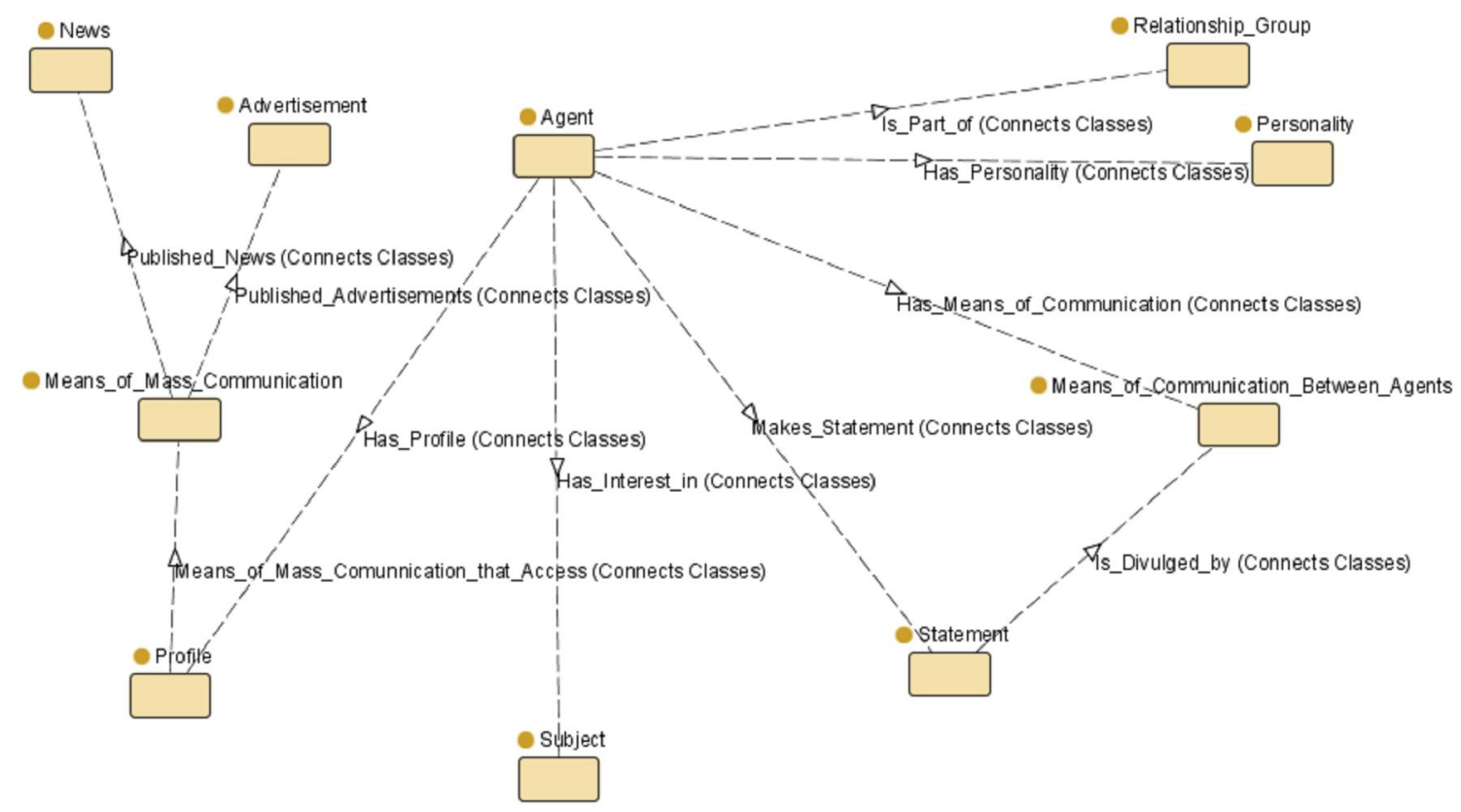

Figura 16: Ontologia geral ${ }^{13}$.

Ainda na Figura 16, no lado direito está modelada a possibilidade de que membros de um mesmo grupo de relacionamento (Relationship_Group) troquem informações. Para isto o agente enquanto parte de um ou mais grupos (Agent $<$ Is_Part_of $>$ ) pode se comunicar com seus amigos, o que é feito dando uma dica (<Agent_Makes $>$ - Statement). Esta, segundo o Quadro 3 deve ter um destinatário <Is_destined_to>, a descrição da informação que está sendo enviada $<$ Statement_Description> e um identificador <Statement_ldentifier> para que cada dica seja única. Deve-se esclarecer também que os assuntos aos quais uma dica se refere devem ser definidos, o que é feito considerando a existência de herança entre classes (Figura 15), pois optou-se por definir que Statement é um tipo de Information.

Quadro 3: Classe dica.

\begin{tabular}{|c|c|c|}
\hline \multicolumn{3}{|c|}{ Statement } \\
\hline \multicolumn{3}{|c|}{ Statement_Identifier } \\
\hline Statement_De & & \\
\hline Is_destined_to & Instance & Agent \\
\hline
\end{tabular}

${ }^{13}$ Esta figura foi gerada usando o Protégé® e o plugin Jambalaya e está repetida no final desta tese por considerar que em tamanho maior facilita a visualização e pode ajudar no acompanhamento da ontologia desenvolvida. 
Ainda com o foco na troca de informações entre membros de uma rede social, cada grupo de relacionamento foi modelado, segundo o Quadro 4, como tendo apenas um nome <Name_of_the_Relationship_Group > e um identificador <ldentifier_of_the_Relationship_Group>, bastando, após esta definição, explicitar quais agentes são parte de quais grupos de relacionamento. Assim, é possível dizer que alguns agentes são Amigos do Agente $\mathbf{X}$ ou que fazem parte do grupo de Funcionários da Empresa Y, por exemplo.

\begin{tabular}{|l|}
\hline \multicolumn{1}{c|}{ Relationship_Group } \\
\cline { 2 - 2 } Quadro 4: Classe grupo de relacionamento.Relationship_Group \\
\cline { 2 - 2 } Identifier_of_the_Relationship_Group \\
\hline
\end{tabular}

Para que a comunicação entre membros de um grupo de relacionamento ocorra, existem algumas possibilidades conhecidas na literatura, como o uso de quadro-negro (RUSSELL, NORVIG, 2004) e a comunicação direta entre os agentes com o estabelecimento de algum mediador. A primeira possibilidade é a mais usada e não requer nenhuma alteração na ontologia aqui definida para que seja tratada. Já para a segunda opção, a qual reflete melhor situações da vida real, foi preciso definir a classe Means_of_Communication_Between_Agents, que pode ser vista no Quadro 5, podendo o meio de comunicação ser celular, o uso de e-mail, dentre outros. $O$ importante aqui é que exista um emissor <Sender da mensagem <Message>, a qual é enviada para um destinatário <Receivers. Estas mensagens são enviadas em determinado horário <Message_time> e ficam disponíveis até que sejam "lidas" e "interpretadas". Deve-se esclarecer, no entanto que apesar de ser possível nos dias atuais que empresas façam publicidade por celular, esta opção não será tratada no desenvolvimento deste projeto.

\begin{tabular}{|c|c|c|}
\hline \multicolumn{3}{|c|}{ Means_of_Communication_Between_Agent } \\
\hline \multicolumn{3}{|c|}{ Identifier_of_Means_of_Communication } \\
\hline \multicolumn{3}{|c|}{ Name_of_Means_of_Communication } \\
\hline \multicolumn{3}{|c|}{ Message_Time } \\
\hline \multicolumn{3}{|l|}{ Message } \\
\hline Sender & Instance & Agent \\
\hline Receiver & Instance & Agent \\
\hline
\end{tabular}

Quadro 5: Classe meios de comunicação entre agentes. 
De acordo com a segunda abordagem, lado esquerdo da Figura 16, os agentes devem poder acessar informações disponíveis em Means_of_Mass_Communication. Neste caso, segundo o Quadro 6, é preciso definir as características relativas ao meio de divulgação em questão que são um identificador <ldentifier_of_the_Means_of_Mass_Communications e um nome $<$ Name_of_the_Means_of_Mass_Communication>, além de estabelecer a grade de programação ali disponibilizada. Esta grade é composta por notícias <Published_News> e anúncios <Published_Advertisements> que devem ser ordenados como ocorre nas emissoras de televisão ou estações de rádio, por exemplo.

\begin{tabular}{|l|c|c|}
\hline \multicolumn{3}{|c|}{ Means_of_Mass_Communication } \\
\hline Published_Advertisements & Instance $^{*}$ & Advertisement \\
\hline Published_News & Instance $^{*}$ & News \\
\hline Name_of_the_Means_of_Mass_Communication \\
\hline Means_of_Mass_Communication_Schedule \\
\hline Identifier_of_the_Means_of_Mass_Communication \\
\hline
\end{tabular}

Quadro 6: Classe meios de comunicação em massa.

A principal diferença entre um anúncio e uma notícia se refere à duração e também ao momento (específico ou variável durante a programação diária da emissora) no qual cada um é veiculado. Um anúncio (Quadro 7) deve ter, portanto, uma duração <Advertisement_Airtime>, o número de vezes que deve ser veiculado ou de inserções <Advertisement_Insertions>, o horário mínimo $<$ Minimum_Time_Limit> e máximo <Maximum_Time_Limit> no qual pode ir "ao ar", além de um identificador <ldentifier_of_the_Advertisements e sua descrição $<$ Description_of_the_Advertisements. Além disto, os assuntos aos quais o anúncio se refere devem ser definidos, o que é feito considerando a existência de herança entre classes (Figura 15), pois optou-se por definir aqui que Information é superclasse de Advertisement. 


\begin{tabular}{|l|}
\hline \multicolumn{1}{|c|}{ Advertisement } \\
\hline Advertisement_Insertions \\
\hline Advertisement_Airtime \\
\hline Identifier_of_the_Advertisement \\
\hline Description_of_the_Advertisement \\
\hline Minimum_Time_Limit \\
\hline Maximum_Time_Limit \\
\hline
\end{tabular}

Quadro 7: Classe anúncio.

Já uma notícia, como pode ser visto no Quadro 8 possui um identificador $<$ News_Identifier >, o horário que começa <News_Start_Time $>$ e que termina $<$ News_End_Time> e sua descrição <News_Description>. Assim como no caso dos anúncios, os assuntos aos quais as notícias se referem devem ser definidos, o que é feito considerando a existência de herança entre classes (Figura 15), pois optou-se por definir que News é um tipo de Information.

Quadro 8: Classe notícia.

\begin{tabular}{|l|}
\hline \multicolumn{1}{|c|}{ News } \\
\hline News_Identifier \\
\hline News_Start_Time \\
\hline News_End_Time \\
\hline News_Description \\
\hline
\end{tabular}

Além das classes apresentadas, considerando um ambiente onde se tem uma sociedade pautada pela divulgação e disseminação de informações, é importante abordar detalhes de cada um dos agentes, o que está feito a seguir.

\subsubsection{A Classe Agente}

No Quadro 9 está apresentada a classe agente e as características que cada um possui. Estas incluem um identificador <ldentifier_of_the_Agent>, um $<$ Emotional_State> que pode assumir valores como deprimido (0), normal (1) ou ansioso (2), e a possibilidade do uso de um meio de comunicação 
(<Has_Means_of_Communication> - Means_of_Communication_Between_Agents) para que seja possível a troca de informações na rede social. Deve-se ressaltar ainda que cada agente possui um <Assimilation_Threshold> que é usado para definir quais informações serão assimiladas.

Quadro 9: Ontologia, classe agente.

\begin{tabular}{|l|c|c|}
\hline \multicolumn{3}{|c|}{ Agent } \\
\hline \multicolumn{2}{|l|}{ Identifier_of_the_Agent } \\
\hline Emotional_State \\
\hline Assimilation_Threshold \\
\hline Is_Part_of & Instance $^{*}$ & Relationship_Group $^{*}$ \\
\hline Has_Interest_in & Instance $^{*}$ & Subject \\
\hline Makes_Statement & Instance* & Statement \\
\hline Has_Personality & Instance & Personality \\
\hline $\begin{array}{l}\text { Has_Means_of_ } \\
\text { Communication }\end{array}$ & Instance* & $\begin{array}{c}\text { Means_of_ } \\
\text { Communication_ } \\
\text { Between_Agents }\end{array}$ \\
\hline Has_Profile & & Profile \\
\hline
\end{tabular}

Para que uma comunicação ocorra, o "falante" precisa ser amigo do "ouvinte", formando assim um grupo relacionamento (<ls_Part_of > Relationship_Group) dele com seus amigos. Cada um dos agentes pode "dar dicas" <Makes_Statements aos seus pares sobre os assuntos pelos quais se interessa $(<$ Has_Interest_in>-Subject).

Quadro 10: Classe personalidade.

\begin{tabular}{|l|}
\hline \multicolumn{1}{|c|}{ Personality } \\
\hline Identifier_of_the_Personality \\
\hline Name_of_the_Personality \\
\hline Talk_Frequency \\
\hline
\end{tabular}

Além disto, cada agente tem uma personalidade <Has_Personality > e um perfil <Has_Profile> que o possibilitam participar da dinâmica de troca de informações entre membros das redes sociais e também acessar às informações disponíveis nos meios de comunicação em massa. Deve-se então esclarecer que estas classes (Personality, Quadro 10 e Profile, Quadro 11) são semelhantes no 
sentido de possuírem apenas um identificador (<ldentifier_of_the_Personality> / <ldentifier_of_the_Profile $>$ ) e um nome (<Name_of_the_Personality> / $<$ Name_of_the_Profile>), mas se diferenciam pois a personalidade define a frequência na qual os agentes devem tentar falar com algum dos seus amigos $<$ Talk_Frequency> e o perfil estabelece os meios de comunicação em massa que determinado agente conhece e que portando tem acesso <Means_of_Mass_ Communication_that_Access>. Além disto, no perfil é definida a periodicidade (Access_time>) e o tempo médio que o agente permanece acessando (calculado com base no <Average_time> e no <Standard_deviation>).

Quadro 11: Classe perfil.

\begin{tabular}{|l|}
\hline \multicolumn{2}{|c|}{ Profile } \\
\hline Identifier_of_the_Profile \\
\hline Name_of_the_Profile \\
\hline Access_time \\
\hline Average_time \\
\hline Standard_deviation \\
\hline $\begin{array}{l}\text { Means_of_ } \\
\text { Mass_Communication_ } \\
\text { that_Access }\end{array}$
\end{tabular}

Como pode ser percebido apesar de membros de um grupo, cada agente é individual. O que propicia esta característica são as informações às quais cada um tem acesso e, consequentemente conhecimento, e a decisão de passar ou não uma informação adiante. Assim, na sociedade virtual os agentes possuem características em comum, embora com diferentes níveis de manifestação.

Além disto, no âmbito deste projeto, para que um agente esteja apto a desempenhar certas funções, faz-se necessário que ele possua representações e mecanismos de inferência, além de um conjunto de processos para tratar das diferentes componentes representantes da sua atividade, o que é descrito a seguir.

Afinal, apesar de considerar que em algumas situações a probabilidade é útil, aqui se tem interesse em saber com maior acuidade o que os agentes estão "pensando" e porque tomaram alguma decisão. Assim, na seção seguinte estão abordadas as características de cada um dos agentes, os aparatos cognitivos utilizados e como ocorre o relacionamento entre eles. 


\subsection{Funcionamento dos Agentes com Aspectos Cognitivos}

Nesta seção se optou por apresentar como cada agente é estruturalmente e como é seu funcionamento interno. Isto é feito de forma complementar, ou seja, aumentando o detalhamento no transcorrer do texto.

De forma geral, o agente pode ser considerado como um filtro adaptativo (Figura 17) que recebe informações e, após algum tipo de avaliação, decide quais temas assimilar e / ou comunicar para outros agentes.

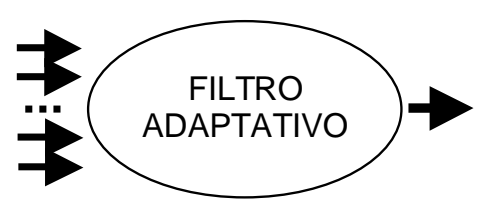

Figura 17: Agente, filtro adaptativo.

Aqui, o agente é considerado como tendo um aparato cognitivo, responsável por todo o processamento das entradas e a decisão do que fazer; e um aparato comunicador, de particular importância, através do qual recebe notícias e troca informações (Figura 18).

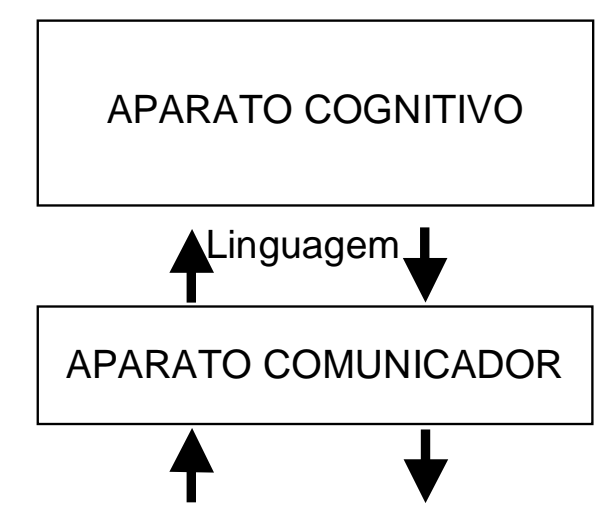

Figura 18: Componentes do agente.

O aparato cognitivo envolve tanto o Estado Interno do agente quanto as Decisões que ele pode tomar (EI e DI na Figura 19). Já para o aparato comunicador são consideradas as informações que o agente pode receber (le) e aquelas que ele é capaz de enviar (Is). 


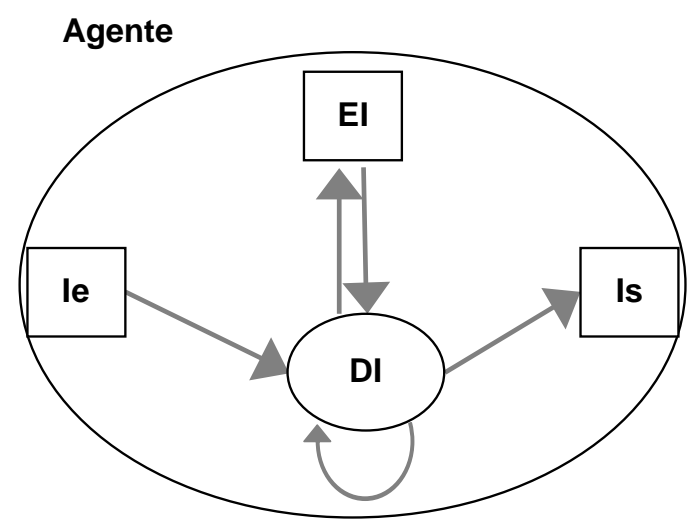

Figura 19: Funcionamento do agente.

A Informação de Entrada (le) possui três dimensões que são os parâmetros de cada mensagem, o emissor, o assunto e o valor de impacto. As les influenciam as Decisões (DI) que o agente pode tomar, desta forma DI atual (t) é função dos valores de DI, le e também do Estado Interno (EI) do agente no instante anterior ( $t$ - 1), como pode ser visto em (1).

$$
D I^{t}=f\left(D I^{t-1}, l e^{t-1}, E I^{t-1}\right)
$$

Os estados internos do agente estão representados por El. Este é composto pelo nível de interesse, estado emocional e atividades que ele é capaz de realizar, como o acesso a algum meio de comunicação em massa e / ou a conversa com algum amigo. O El atual (t) do agente é função do seu Estado Interno no instante anterior e da última decisão tomada, como pode ser visto em (2). Além disto, dependendo da decisão que o agente tomar ele pode enviar uma mensagem, o que está representado por Informação de Saída (Is), a qual é composta pelo assunto, o interesse do agente e o destinatário da mensagem.

$$
E I^{t}=f\left(E I^{t-1}, D I^{t-1}\right)
$$

Estruturalmente cada agente segue o que está apresentado na Figura 20, ou seja, pode receber informações advindas tanto dos Meios de Comunicação em Massa (MCM) como também "ouvir" diretamente algum amigo, por serem parte da 
mesma Rede Social (RS). Todas as informações que o agente receber ficam disponíveis em um repositório para que ele faça a avaliação devida.

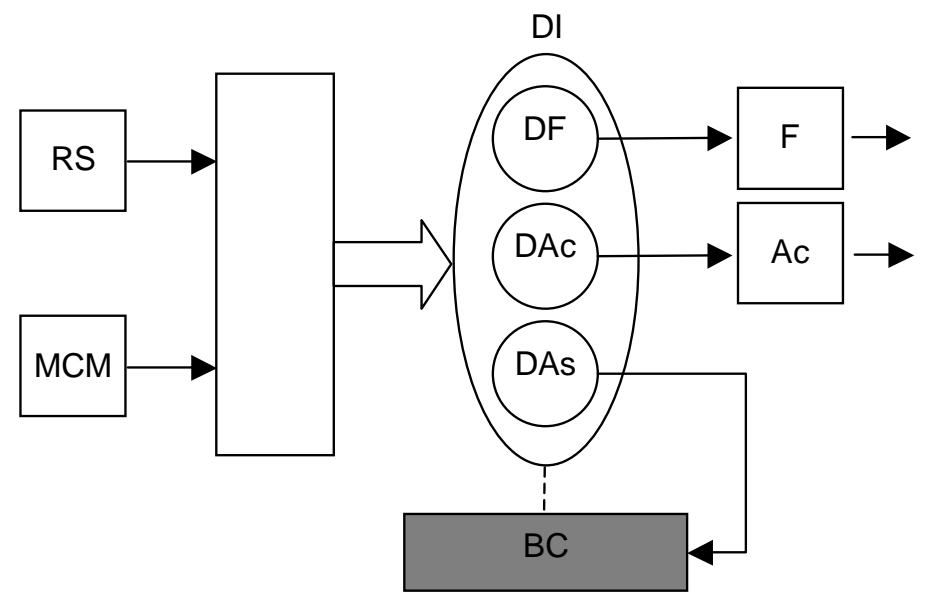

Figura 20: Estrutura do agente.

O módulo DI engloba então as decisões que ele precisa tomar, que podem ser de acessar ou não algum meio de comunicação em massa (DAc), assimilar ou não uma informação recebida (DAs) ou ainda falar sobre algo para alguém (DF).

A DAs leva à atualização da base de conhecimento $(\mathrm{BC})$ do agente, a qual funciona como sua memória (quadrado no canto inferior da Figura 20). Afinal, segundo Conde e Thalmann (2005), para ter maior grau de autonomia, um agente precisa ter capacidade de recordar ou reproduzir o que foi aprendido. $\mathrm{Na}$ BC as informações decaem com o tempo na tentativa de reproduzir o fenômeno do esquecimento, algo natural quando se fala em memória e armazenamento de informações.

A BC engloba além do Estado Interno do agente, dados relativos aos assuntos que "sabe"; amigos que tem; a quais meios de comunicação em massa conhece, além da sua avaliação a respeito das informações às quais tem acesso. Estas são diferentes classes de informações armazenadas separadamente e que dependendo da atividade que o agente vai realizar são usadas e poderão ser atualizadas. Por exemplo, quando recebe alguma informação advinda de algum amigo ou meio de comunicação em massa o agente deve fazer sua avaliação, podendo atualizar os dados relativos aos assuntos que "sabe". 
A BC é uma parte importante, a qual é usada para a escolha de qual meio de comunicação em massa acessar por DAc, mas também sobre o que e para quem falar por DF. Tanto DAc quanto DF resultam em uma ação, seja de acessar determinado meio de comunicação em massa (Ac), seja de falar com algum amigo sobre algo $(\mathrm{F})$.

Pode-se representar então em uma máquina com quatro estados (GIBSON, 2000; RODRÍGUEZ; NÚÑEZ; RUBIO, 2007) o que os agentes podem executar (Figura 21). Nela o estado Em espera (Idle) é onde os agentes são criados e para onde voltam após concluir uma ação. Além disto, a decisão a respeito de quando realizar cada uma das ações é individual, ou seja, cabe a cada agente avaliar e escolher quando vai fazer algo. Para que ocorra a mudança de estado alguns processos devem ser realizados e estão descritos a seguir.

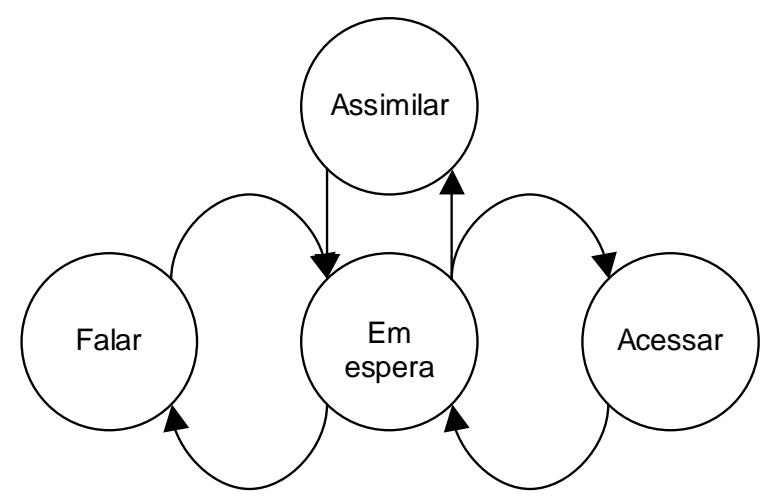

Figura 21: Dinâmica tendo como base os possíveis estados internos do agente.

Levando em consideração o perfil dos agentes, eles possuem hábitos, ou seja, acessam determinado meio de comunicação em massa (MCM) com alguma periodicidade.

Uma vez no estado Acessar, para que o acesso seja efetivamente realizado é preciso que cada agente siga os processos descritos na Figura 22, ou seja, verifique qual MCM costuma acessar no horário atual do sistema, após o que, deve começar a "assistir" e atualizar seu status. Mesmo com status "acessando" o agente volta ao estado Em Espera, pois pode realizar simultaneamente outras ações, no entanto, ele vai parar de assistir o MCM quando identificar que o horário definido em seu Perfil foi atingido e vai alterar seu status. 


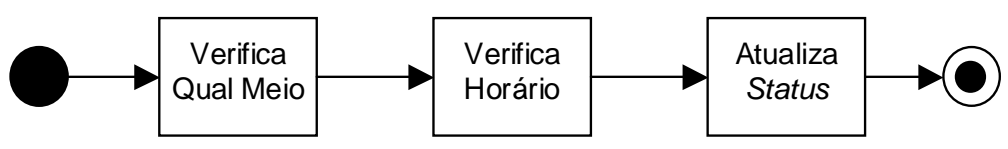

Figura 22: Processo usado para decisão de acessar algum meio de comunicação em massa (usando perfil do agente).

O estado Assimilar envolve duas possibilidades que precisam ser avaliadas pelos agentes: a) de receber alguma informação que esteja sendo veiculada em algum MCM; b) de receber alguma dica que the foi dada por algum amigo. Além disto cada agente precisa em cada um dos casos avaliar se vai assimilar o que foi recebido de uma forma ou de outra (a ou b).

Com relação aos MCM o agente deve seguir os passos descritos na Figura 23 e uma vez que assimile uma informação, deve atualizar sua base de conhecimento, representada em cinza.

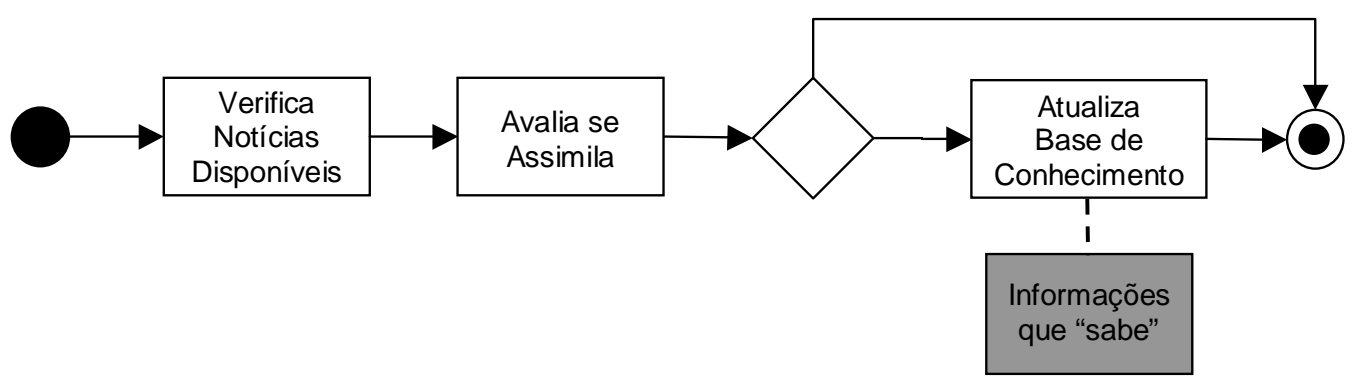

Figura 23: Processo usado para receber e tratar informações advindas de algum meio de comunicação em massa.

Outra forma de receber informações é quando algum amigo "fala" com ele, Figura 24. Para isto foi definido um mediador que armazena as mensagens disponíveis, cabendo então ao agente verificar se recebeu algo, e avaliar se assimila ou não. Neste caso tanto as informações que o agente "sabe", quanto dados relativos aos amigos que tem podem ser atualizados. 


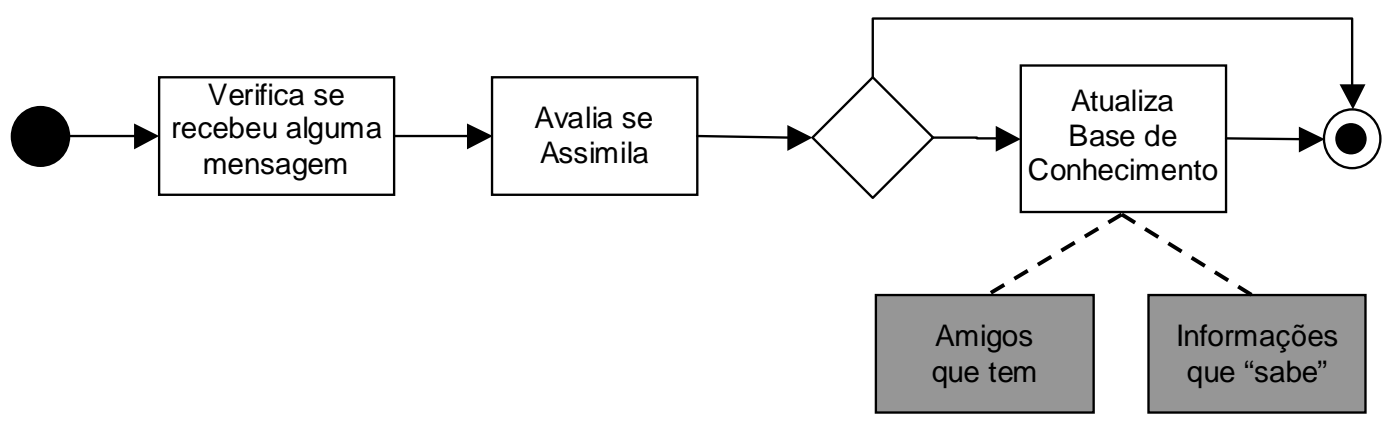

Figura 24: Processo usado para receber e avaliar o que "ouviu" de algum amigo.

Considerando as informações que o agente "sabe", a frequência na qual ele deve avaliar a possibilidade de falar é função da sua personalidade. Para tanto, segundo a Figura 25, ele deve decidir sobre qual assunto e para quem vai falar usando sua base de conhecimento (retângulos cinza).

Uma vez definidas estas partes 0 ato de falar pode ser realizado tanto localmente, diretamente, bem como à distância, usando celular, por exemplo. A mensagem pode então ser enviada ao destinatário. Deve-se ressaltar que a linguagem aqui está sendo considerada apenas como um instrumento para troca de símbolos que permite aos agentes "falar" ou "ficar sabendo" de algo.

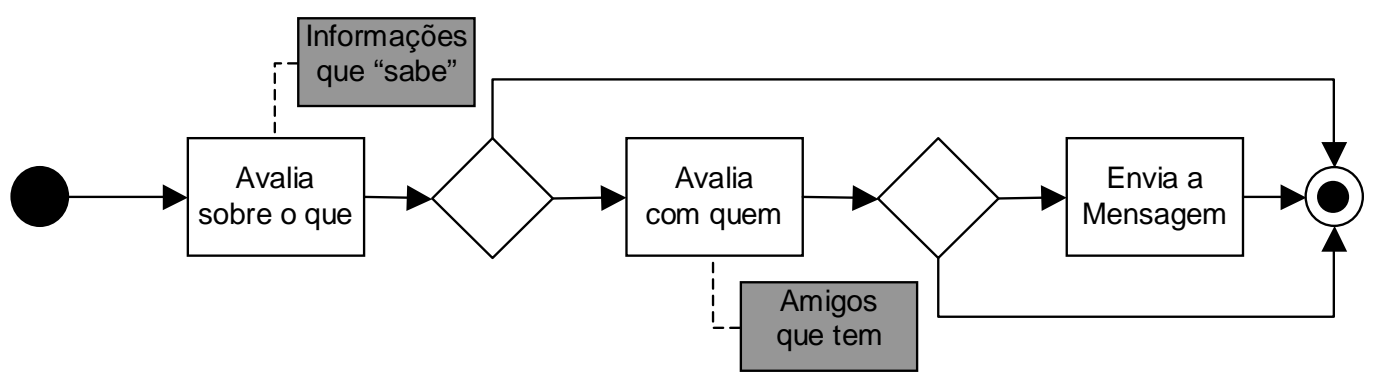

Figura 25: Processos usados para a decisão de falar.

Por fim deve-se esclarecer que a forma de tratamento de cada uma das funções mencionadas (como avalia se assimila ou não e como escolhe qual amigo e sobre o que falar) depende dos resultados pretendidos e elas estão, portanto detalhadas no próximo capítulo. 


\section{Capítulo 6. PLATAFORMA OSACS ${ }^{14}$}

Considerando o modelo apresentado no capítulo anterior, primeiramente é preciso definir informações relativas à ontologia que englobam as configurações dos personagens, seus perfis, suas personalidades e também àquelas relacionadas com os meios de comunicação em massa (Figura 26).

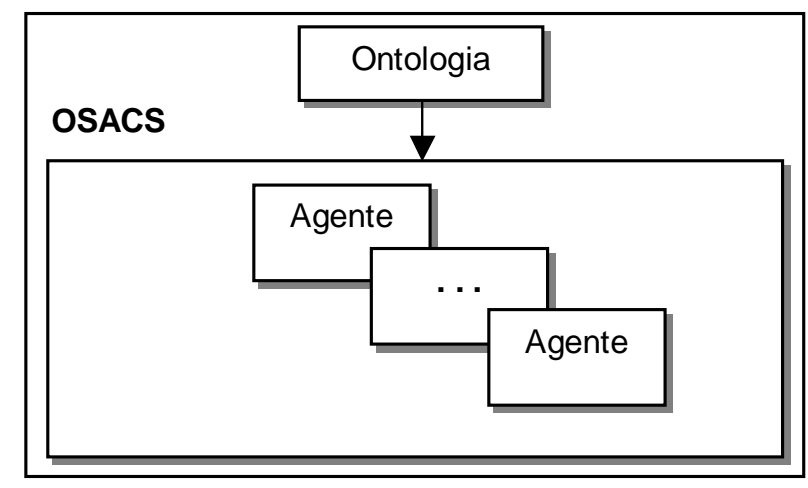

Figura 26: Arquitetura.

Além destas, as configurações específicas da simulação são definidas em um arquivo à parte (Tabela 1). Todas estas informações são processadas em tempo real pelo protótipo desenvolvido e é gerada a visualização em duas dimensões.

Tabela 1: Arquivo de Configurações.

\begin{tabular}{l}
\hline Configurações \\
\hline Intervalo para esquecimento dos assuntos em FPS (DMT) $=1$ \\
Time Step (float) $=0.5$ \\
Utiliza tempo como semente aleatória $=0$ \\
Exibe FPS na tela $=0$ \\
Quantidade de frames para incrementar relógio= 1 \\
Quantidade de dias a serem simulados(sai quando completa) $=1$ \\
Gerar Vídeo $(1$ Sim) $=0$ \\
Frequência de Captura da Imagem $=20$ \\
\hline
\end{tabular}

O protótipo funciona no sistema operacional Windows ${ }^{\circledR}$ e foi desenvolvido usando a linguagem $\mathrm{C}++$, OpenGL ${ }^{15}$ (SANTOS et. al., 2003, SHREINER et. al.,

${ }_{15}^{14}$ Definido pelo autor e acrônimo de Ontology Simulator for Agents with Cognitive Skills.

${ }^{15} \mathrm{http}: / / \mathrm{www}$.opengl.org 
2007) e GLUI (RADEMACHER, 1999) que possui as primitivas básicas para visualização. Foram definidas as classes: <Agente>, <Personalidade>, <MeioDeComunicacaoEntreAgentes>, <Perfil>, <Noticia>, <Anuncio>, $<$ MeioDeComunicacaoEmMassa> e <Principal>. Esta última reúne as funcionalidades das demais de forma a permitir a execução da simulação e cada uma das outras possibilita gerar objetos e apresentá-los.

Como toda a estrutura está orientada a objetos, se torna fácil o armazenamento e manipulação das informações que podem ser acessadas através dos métodos. Atrelado a isto, a modelagem usando ontologia possibilita que o algoritmo seja simples, como pode ser visto no Quadro 12.

Lê_os_dados_de_entrada

Define_meio_de_comunicacao_em_massa

Define_a grade de programação_de_cada um dos meios de_comunicação_em massa Insere noticias divulgadas neste meio de comunicacao em massa

Insere_anuncios_divulgados_neste_ meio_de_comunicacāo_em_massa

Gera_a_população_inicial

Para_cada_agente

Agente_decide_o_que_fazer

Quadro 12: Trecho do código - OSACS.

Inicialmente cada um dos meios de comunicação em massa (emissoras) é instanciado e seus dados seguem os valores pré-definidos de acordo com o modelo. Além disto, um ponto importante que precisa ser realizado é a elaboração da grade de programação, alocando as notícias e os anúncios que foram definidos. Para tal o programa se encarrega de fazer uma combinação que segue o horário de início e fim das notícias e sorteia (considerando o intervalo definido na ontologia, ou seja, horário mínimo e máximo) o momento que vai ser veiculado cada um dos anúncios. Desta forma é possível reproduzir a programação de qualquer emissora, bastando realizar a configuração apropriada e considerando que um programa é composto principalmente por um conjunto de notícias e um intervalo é composto por uma sequência de anúncios.

Usando o conceito de sistemas multiagentes, os personagens são autônomos e individuais. Apesar disto existe um controlador que tem como função gerir a simulação, indicando quem tem vez a cada passo de tempo, não tendo, no entanto, nenhum envolvimento no funcionamento dos agentes. O controlador é, portanto a máquina integrada ao contexto da sociedade multiagentes constituída no 
ambiente que é responsável por coordenar a simulação, dando oportunidade para que os agentes atuem de forma independente (individualidade deles).

Cabe a cada um dos agentes então agir da forma que considerar mais relevante, seja na sua relação com o mundo (através do acesso aos meios de comunicação em massa ou "conversa" com seus amigos) como também nas suas tomadas de decisão (mecanismos ligados à cognição, ou seja, raciocínio, assimilação, decisão, dentre outros).

A decisão do que cada agente deve fazer engloba algumas funções que estão apresentadas no Quadro 13. Inicialmente ele precisa, a cada passo de simulação, verificar se deve acessar algum meio de comunicação em massa, o que é feito levando em consideração seus hábitos, definidos em seu perfil.

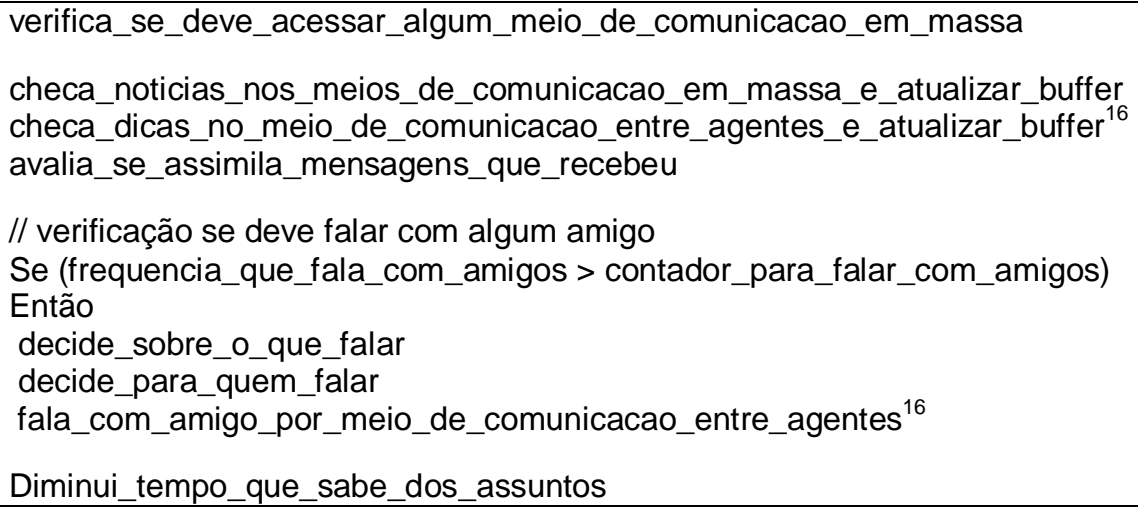

Uma vez que estiver acessando algum MCM, decidido usando DAc (Figura 27), o agente deve avaliar as informações às quais tiver acesso, podendo atualizar seu buffer. Este artefato foi adicionado para que seja um repositório onde todas as mensagens recebidas fiquem armazenadas e funciona como uma pilha de onde o agente vai retirando informações e as avaliando quando puder realizar esta ação. Ali ficam os dados referentes ao assunto, impacto e o emissor de cada uma das mensagens.

16 Neste quadro está apresentada a possibilidade de comunicação usando algum meio de comunicação entre agentes, que funciona como um celular ou email. Esta foi implementada com a classe <MeioDeComunicacaoEntreAgentes> (citada anteriormente), mas também pelo uso de quadro negro, técnica usada na Inteligência Artificial. 
Após verificar as mensagens que tem a receber, o agente deve avaliar se assimila ou não uma delas. Para isto os dados das informações que recebeu (le na Figura 27) e também seu conhecimento atual (quadros cinza que têm conexão com DAs na mesma figura) são utilizados.

Considerando algumas possibilidades de combinação destes parâmetros, foram definidas quatro formas de avaliação para assimilação de informações que os agentes podem usar, as quais estão apresentadas na seção 6.1.

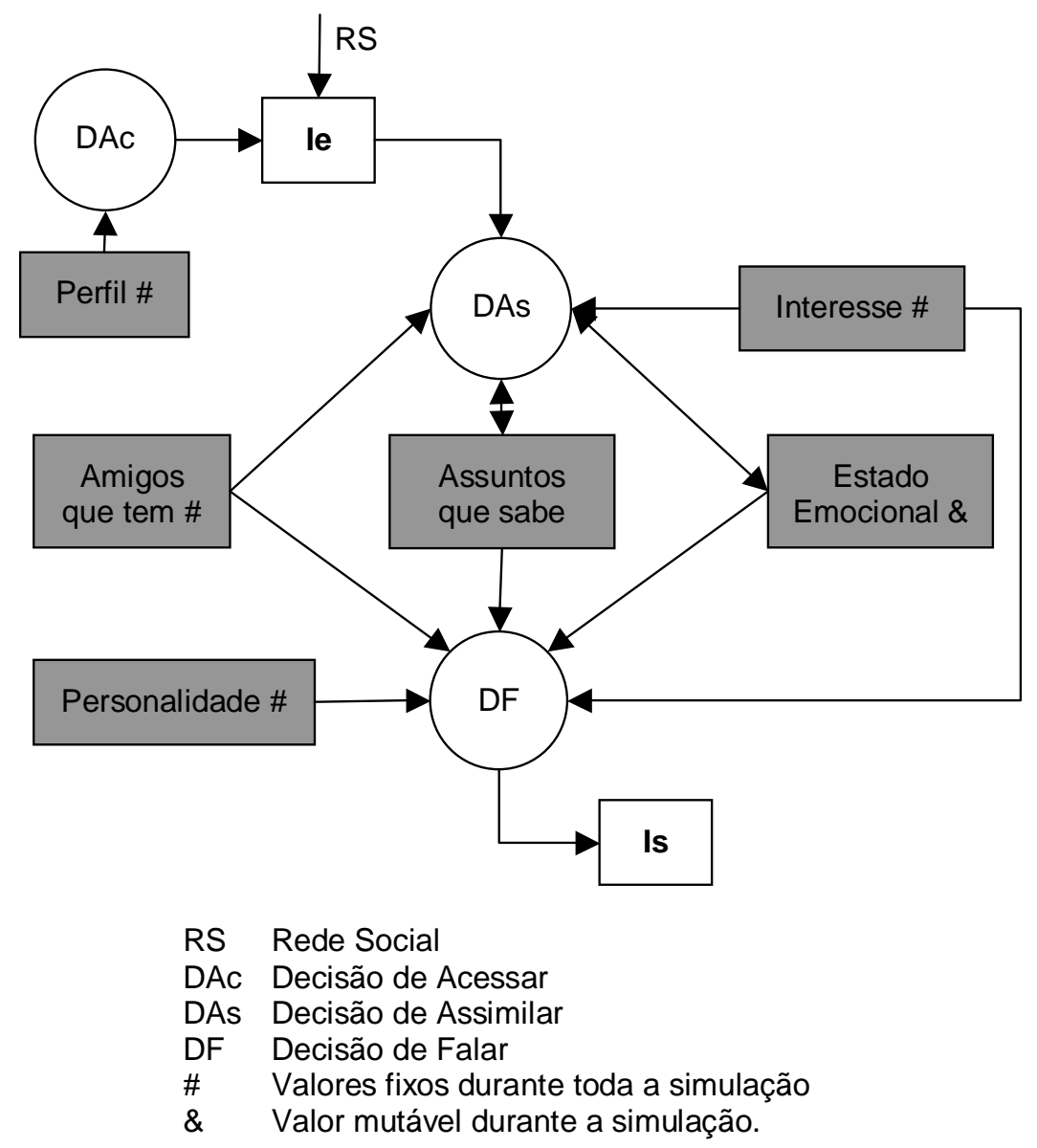

Figura 27: Versão agrupada das informações no agente.

Voltando no Quadro 13, a próxima atividade do agente é avaliar se vai enviar uma mensagem a algum amigo considerando a frequência para falar definida em sua personalidade. Para isto ele precisa realizar a decisão de falar (DF na Figura 27), a qual inclui a escolha sobre o que e para quem (detalhados na seção 6.2).

O envio da mensagem pode ser realizado usando um meio de comunicação entre agentes. Aqui deve-se ressaltar que foi elaborada uma classe 
(Means_of_Communication_Between_Agents, Quadro 5 apresentado no capítulo Modelo), com a qual se busca reproduzir o uso de telefone celular ou e-mail, por exemplo. Trata-se, portanto de um centralizador ou facilitador da comunicação que serve para que cada um dos agentes poste mensagens para qualquer outro, mas só tenha acesso àquelas a ele endereçadas.

Voltando ao laço principal dos agentes, a cada intervalo definido nas configurações é decrementado o tempo que o agente em questão ainda se "lembra" de cada um dos assuntos (Tabela 1 no início deste capítulo), buscando assim reproduzir o fenômeno do esquecimento.

\subsection{Formas de Assimilação de Informações}

Nesta seção estão apresentadas as quatro formas de assimilação de informações que cada um dos agentes pode utilizar, as quais foram definidas pelo autor. Optouse por ordená-las em função da complexidade e da quantidade de variáveis usadas no processo. Para as duas primeiras foi estabelecida uma função de modo que apenas o interesse do agente e o impacto da mensagem interferem na assimilação de cada uma das duas formas, chamadas de Função Limiar (seção 6.1.1) e Máquina Um (seção 6.1.2). A seguir foi incluído o tratamento de estado emocional o qual é afetado pelo nível de interesse do agente (e o impacto da mensagem). Assim, na Máquina Dois (seção 6.1.3), as informações recebidas afetam o estado interno dos agentes e a assimilação de cada um dos assuntos depende diretamente do estado emocional. Já na Máquina Três (seção 6.1.4), as informações interferem no estado interno dos agentes e a assimilação ou não dos assuntos aos quais eles têm acesso depende tanto do estado emocional quanto do nível de interesse de cada agente pelo assunto em questão. 


\subsubsection{Função Limiar - onde o Interesse Interfere na Assimilação}

Inicialmente foi desenvolvida uma versão (Limiar) onde a assimilação depende do nível de interesse que o agente tem pelo assunto (INT) e do nível de impacto da informação recebida (IMP) como pode ser visto em (3).

$$
\text { (INT * IMP) > Limiar para Assimilação }
$$

O valor médio do impacto da notícia a ser divulgada pelo MCM é definido pelo usuário no início da simulação. Já no caso de algum amigo, foi estabelecido que é seu nível de interesse, mas também poderia ser alguma pontuação que ele dá para o referido assunto. Então, seguindo (3), caso o valor calculado (INT * IMP) ultrapasse o limiar o agente irá incrementar o tempo que ainda se "lembra" do assunto em questão usando (4), onde DMT é um valor fixo definido no arquivo de configuração, Tabela 1.

$$
(\text { INT * IMP) + DMT }
$$

\subsubsection{Máquina de Estados Um - onde o Interesse Interfere na Assimilação}

Em um primeiro momento, os agentes avaliavam todas as mensagens que recebiam na tentativa de assimilá-las. No entanto foi elaborada uma máquina de estados ou Finite State Machine (FSM), a qual chama-se de Máquina Um, Figura 28, que leva em consideração a freqüência de informações recebidas. Esta opção tem por objetivo que a assimilação ocorra apenas após o recebimento algumas vezes a respeito de um mesmo assunto, ou seja, ao ouvir XXXXX, por exemplo, é atingido o estado cinza e, portanto o agente atualiza quanto tempo ainda se lembra de $X$. 


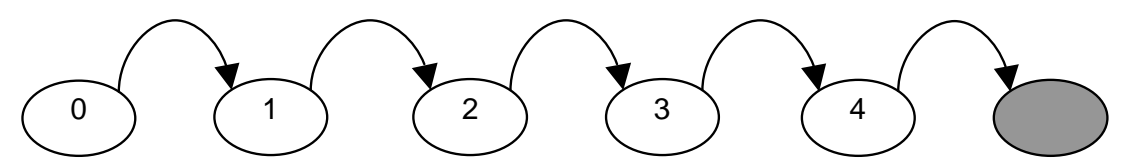

Figura 28: Máquina de estados que o agente usará para assimilar informações às quais têm acesso.

\subsubsection{Máquina de Estados Dois - onde o Interesse e o Impacto Interferem no Estado Emocional e este Último Interfere na Assimilação}

Foi também elaborada uma segunda máquina (Figura 29) na busca por reproduzir aspectos de estado "emocional" ${ }^{\text {, }}$, o qual interfere na avaliação dos assuntos que os agentes podem vir a saber.

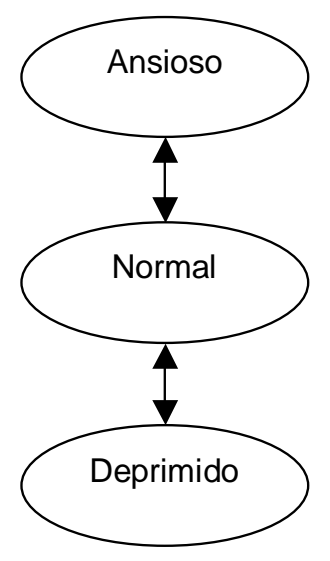

Figura 29: Máquina de estados "Estado Emocional".

Considerando os possíveis valores do nível de interesse (INT) e de impacto (IMP) que as informações podem ter foi feito o Quadro 14.

Nele, os símbolos se referem à comparação do valor de Interesse e Impacto com o Limiar, os quais podem ser: alto $(+)$, médio $(=3$, neste caso) ou baixo (-) e as marcações em cinza representam em que situações haverá a mudança de estado na máquina representada na Figura 29. Desta forma, quando o interesse do agente for alto e o impacto da informação também, o agente mudará para um estado 
de mais "alegria" (Deprimido $\rightarrow$ Normal ou Normal $\rightarrow$ Ansioso). Por outro lado, uma informação com alto nível de impacto, mas que ele tenha baixo nível de interesse deixará o agente mais "triste" (Ansioso $\rightarrow$ Normal ou Normal $\rightarrow$ Deprimido). Deve-se ressaltar ainda que quaisquer das outras combinações de interesse-impacto não afetam o "estado emocional" do agente.

\begin{tabular}{|l|c|c|c|}
\hline \multicolumn{1}{|r|}{ Interesse } & Alto & Médio & Baixo \\
\hline Alto & +1 & 0 & -1 \\
\hline Médio & 0 & 0 & 0 \\
\hline Baixo & 0 & 0 & 0 \\
\hline
\end{tabular}

Quadro 14: Relação entre interesse e impacto. Valores que interferem no estado emocional.

Desta forma considerando que um agente está no estado I (por exemplo, 2 na Figura 30), ao receber novamente dados do assunto em questão irá para I + 1 (3) se estiver em seu estado Normal. No entanto caso esteja Ansioso irá para o estado I + 2 (4), já quando estiver deprimido ele permanecerá sem alteração (linhas tracejadas na mesma figura).

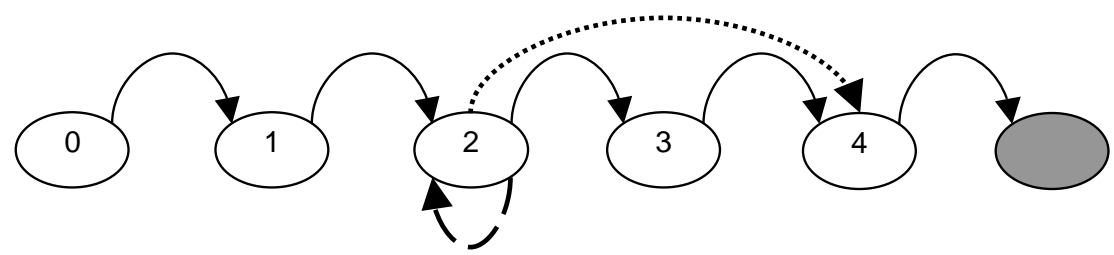

Figura 30: Máquina Dois: modificações decorrentes dos "estados emocionais" ansioso e deprimido na avaliação que os agentes consideram para assimilar informações.

\footnotetext{
${ }^{17}$ Neste trabalho estado "emocional" indica a propensão do agente a realizar uma ação.
} 


\subsubsection{Máquina de Estados Três - onde o Interesse e o Impacto Interferem no Estado Emocional e todos estes Interferem na Assimilação}

$\mathrm{Na}$ terceira e mais complexa forma de assimilação que foi elaborada, considera-se que o nível de interesse do agente e o impacto da mensagem afetam o seu estado emocional como apresentado na seção anterior, mas que além disto, o seu interesse juntamente com seu estado emocional atual interferem na assimilação das informações, da forma como está no Quadro 15.

\begin{tabular}{|l|c|c|c|}
\hline \multicolumn{1}{|r|}{$\begin{array}{c}\text { Interesse } \\
\text { Estado Emocional }\end{array}$} & Alto & Médio & Baixo \\
\hline Ansioso & +3 & +2 & +1 \\
\hline Normal & +1 & +1 & 0 \\
\hline Deprimido & 0 & 0 & -1 \\
\hline
\end{tabular}

Quadro 15: Influência do interesse e do estado emocional na velocidade de assimilação de informações.

Neste quadro estão os possíveis valores para o nível de interesse em sua relação com o limiar para assimilação (colunas) e os estados emocionais (linhas) que o agente pode estar. Ainda no quadro, estão representadas as transições que podem ocorrer na máquina de estados (Figura 31), por exemplo, um agente deprimido irá permanecer no mesmo estado a menos que seu nível de interesse seja menor que o limiar, quando então ele vai voltar um estado (-1 no Quadro 15).

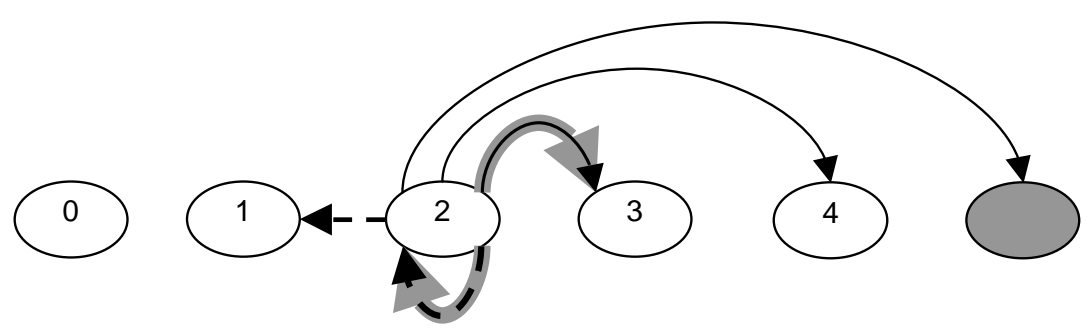

Figura 31: Máquina Três: efeito do interesse e estado emocional na avaliação que os agentes consideram para assimilar informações. 
Na Figura 31 estão apresentadas apenas as possíveis transições, dado que o agente está no estado 2. Quando ele está ansioso, tem-se na parte superior da figura:

- Transição para o próximo estado (3, neste exemplo), se seu interesse pelo assunto é baixo;

- Transição para 4, caso seu interesse seja igual a 3, médio; ou

- Transição para o 5 e assimilação da informação (estado cinza). Já quando o estado emocional do agente é normal, ele pode permanecer em 2 ou ir para 3, como apresentado com as setas em cinza. Neste caso:

- Não haverá transição de estados se seu interesse pelo assunto recebido for baixo (menor que 3); ou

- No caso do interesse ser médio ou alto, a transição será para o próximo estado.

A terceira e última possibilidade de variação do estado emocional dos agentes é quando eles estão deprimidos. Neste caso as linhas pontilhadas na Figura 31 representam que:

- Haverá a transição para o estado anterior (retrocesso) se o agente tiver interesse baixo pelo assunto recebido;

- Haverá estagnação (paralisação) caso o agente tenha interesse médio ou alto pelo assunto em questão.

Descritas as quatro formas que foram elaboradas para que os agentes avaliem se assimilam ou não as informações as quais tiverem acesso, a seguir estão apresentadas as formas de escolha do destinatário e também do assunto que o agente poderá comunicar.

\subsection{Forma de Escolha Sobre o Que e Para Quem Falar}

Para enviar uma mensagem os agentes precisam decidir sobre o que e para quem vão falar. A primeira escolha foi definida levando em consideração os possíveis estados emocionais (Figura 29). Assim, um agente deprimido não fala nada, estando 
em seu estado normal, ele avalia apenas aqueles assuntos que tem interesse médio ou alto (3 ou maior), e quando está ansioso todos os assuntos podem ser falados.

Este funcionamento busca reproduzir aspectos da realidade onde uma pessoa mais ansiosa fala sobre qualquer assunto que sabe, ao passo que quando está no seu estado normal realiza uma avaliação mais criteriosa, simplificada aqui considerando os assuntos que os agentes têm interesse.

Selecionados os assuntos é realizada uma escolha randômica para a definição a respeito do que falar. A decisão de quem será o destinatário da mensagem está feita da mesma forma (probabilística) ${ }^{18}$.

Considerando todos estes pontos é possível perceber que cada personagem é individual, pois, mesmo que possua interesses, perfil e personalidade iguais, ele é moldado pelas diferentes experiências. Além disto, cada uma das decisões depende do histórico pessoal e dos amigos que possui. Apesar de haver naturalmente uma simplificação e os mecanismos cognitivos (escolhidos arbitrariamente pelo autor) terem sido definidos e implantados sem um objetivo a cumprir, os agentes atuam no fluxo de informações e as mensagens às quais ele tem acesso modulam seu estado cognitivo e interferem no seu comportamento.

A seguir, no próximo capítulo estão apresentadas avaliações da influência de alguns parâmetros e alguns resultados obtidos, dentre vários outros que seriam possíveis alterando a configuração das simulações. Deve-se ressaltar, no entanto que não serão utilizados dados reais para a alimentação dos parâmetros e tampouco realizada validação baseada na comparação com situações conhecidas.

${ }^{18}$ Apesar de ter sido iniciada a implementação e testes, não foi possível concluir a tempo a incorporação de realimentação (feedback) para que os agentes falem mais com os amigos que respondem que assimilaram as informações a eles enviadas. 


\section{Capítulo 7. ESTUDOS DE CASO E RESULTADOS}

Nos resultados das simulações desenvolvidas pode ser analisado tanto 0 comportamento de um único agente como do conjunto global dos agentes no ambiente. Em todos os casos são apresentados resultados referentes a quais assuntos são conhecidos e à quantidade de agentes que sabe de cada um dos assuntos. Isto é feito para a avaliação do conhecimento dos agentes e do fluxo de informações na sociedade. Na primeira versão da interface (lado esquerdo na Figura 32) é possível visualizar os 9 últimos passos de simulação e o atual, em cinza, de um número pequeno de agentes (10 na figura). Já no lado direito da mesma figura tem-se um gráfico onde se acompanha o número total de agentes que sabe de cada um dos assuntos (representados por cores) nos últimos 150 frames de simulação. Trata-se, portanto de uma visualização da sociedade.
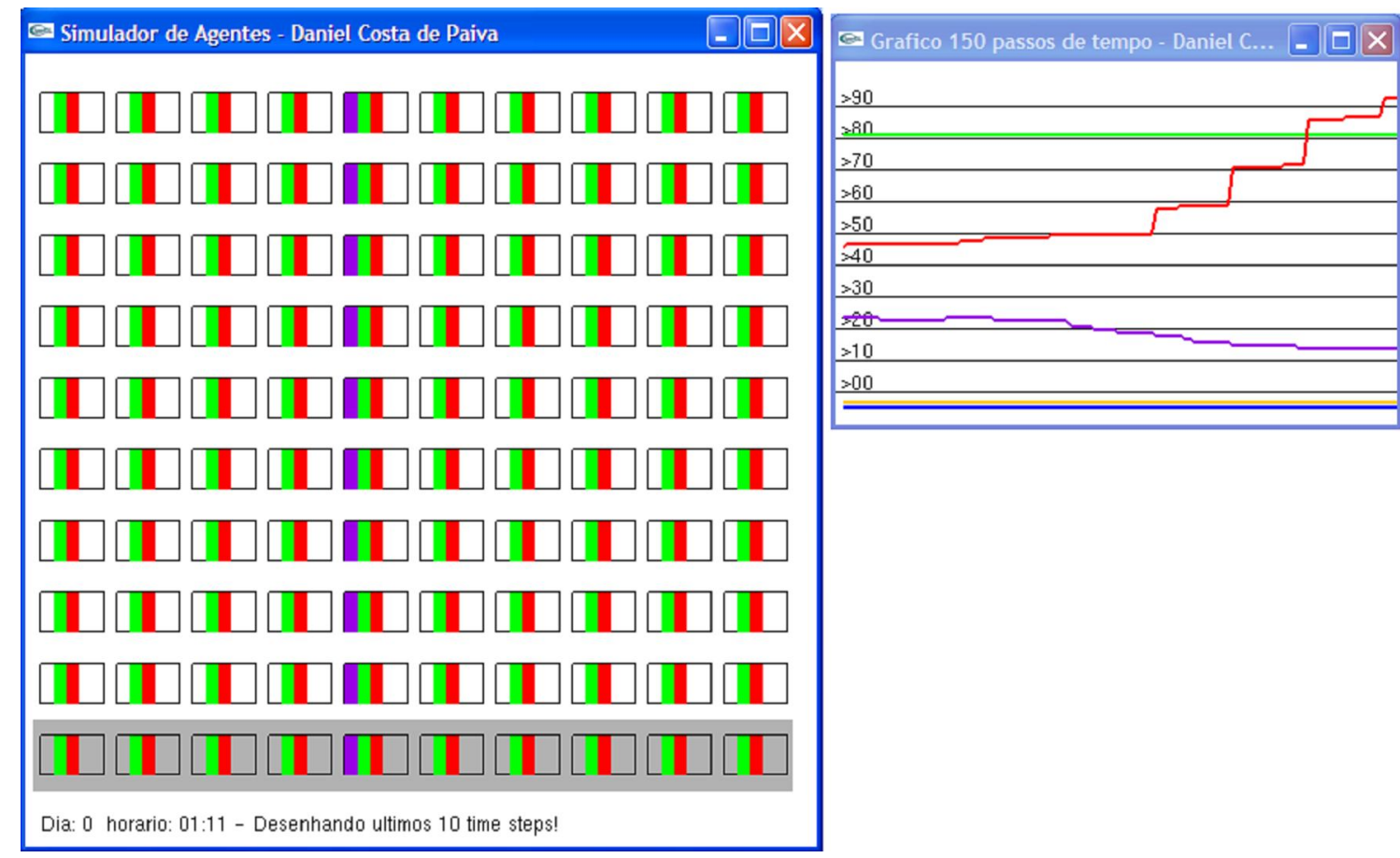

Figura 32: Visualização do andamento da simulação (100 agentes)

a) Interface: últimos 10 frames (linhas) dos primeiros 10 agentes.

b) Gráfico: quantidade de agentes que sabe de cada um dos assuntos nos últimos 150 frames de simulação. 
Já na segunda versão (Figura 33) tem-se apenas o passo atual, mas para todos os 100 agentes. Em ambos os casos os agentes são representados por retângulos e cada um dos assuntos trocados durante a simulação possui uma cor específica (0: roxo, 1: verde, 2: vermelho, etc.). Desta forma é possível visualizar a evolução do conhecimento (cores) de cada um dos agentes e a dinâmica do fluxo de informações.

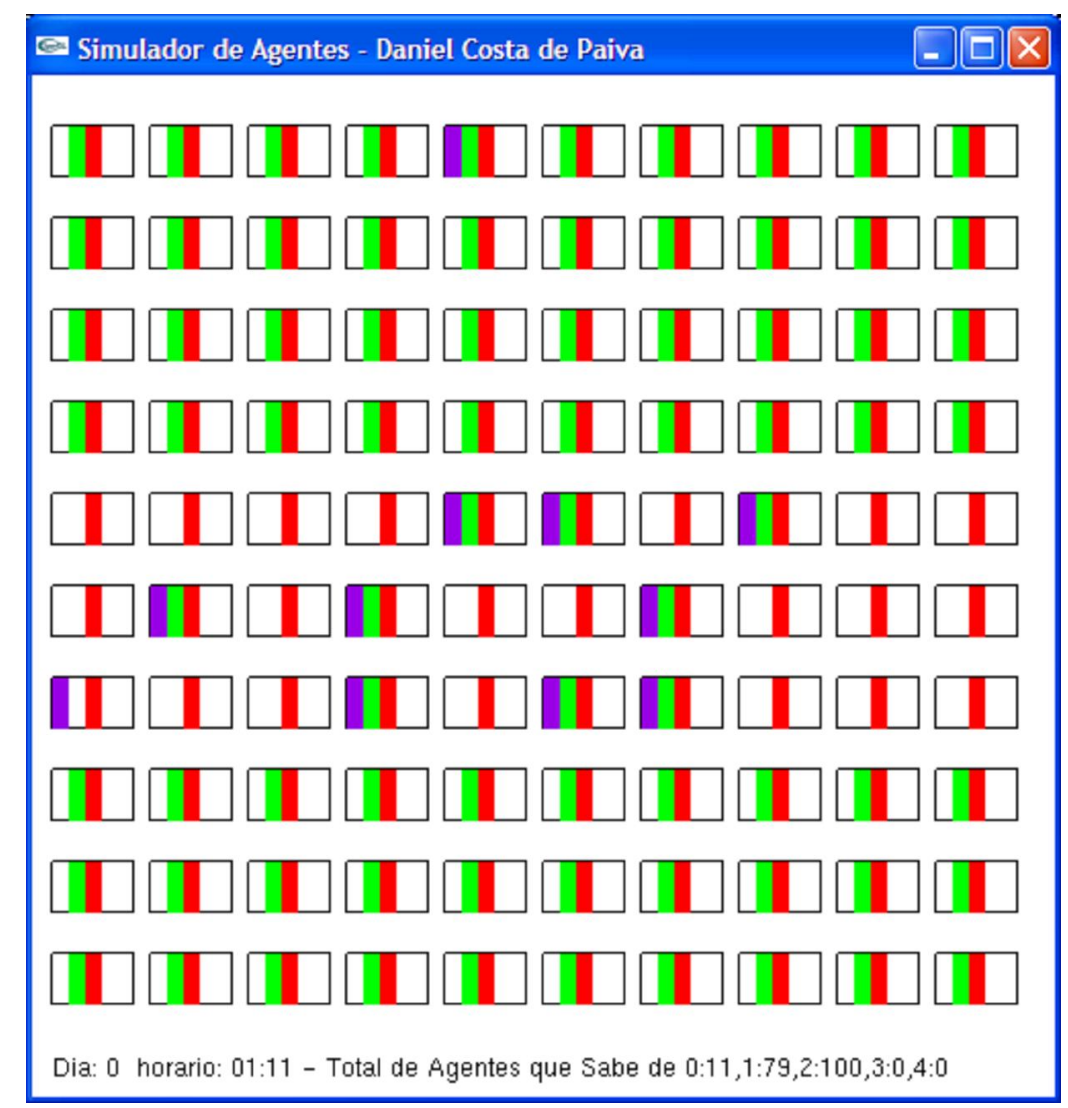

Figura 33: Visualização do andamento da simulação (100 agentes) - interface: frame atual de todos os agentes.

Após esta breve apresentação da interface gráfica, deve-se ressaltar que os resultados estão ordenados de forma a contemplar as abordagens descritas na seção 5.1.1, do capítulo que descreve o modelo, ou seja, (1) quando as informações são divulgadas pelos meios de comunicação em massa e os agentes podem ficar sabendo delas e (2) a dinâmica do fluxo de informações que ocorre nas redes sociais (entre os agentes). 
Estas abordagens podem ser identificadas tanto no âmbito da sociedade multiagentes como no funcionamento interno dos agentes. Quando a observação é realizada no nível mais geral, Figura 34, tem-se a divulgação de informações através dos meios de comunicação em massa, a possibilidade de assimilação por parte dos agentes e a dinâmica na rede social.

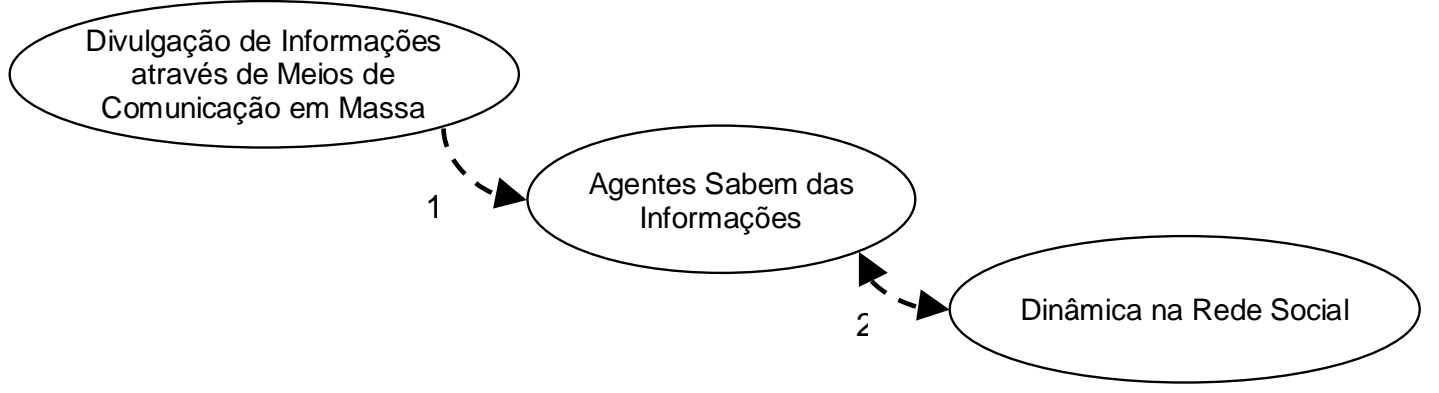

Figura 34: Divisão dos Estudos de Caso - Nível da Sociedade.

Acompanhando o que ocorre internamente em um agente, identifica-se na Figura 35 o acesso a algum meio de comunicação em massa, a assimilação de informações e também a troca de mensagens com outros agentes.

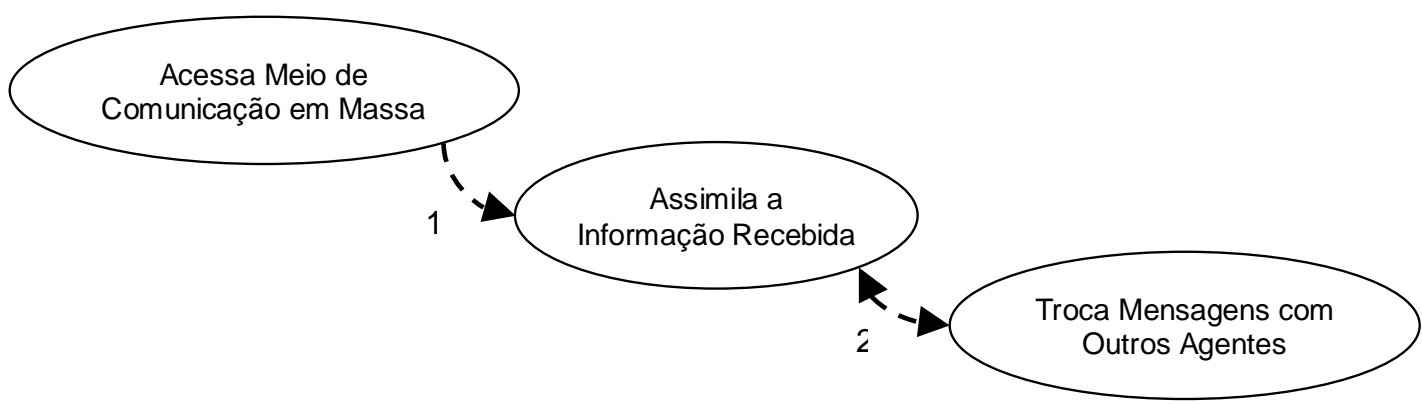

Figura 35: Divisão dos Estudos de Caso - Nível do Agente.

Optou-se então por apresentar na seção 7.1 os estudos relativos à primeira abordagem (transição 1 na Figura 34 e na Figura 35). Em 7.2 estão os resultados da combinação das transições 1 e 2, ou seja, considerando tanto a comunicação broadcast quanto diretamente entre agentes.

A seguir, foi definida uma função adaptativa com base na regra de que os agentes devem saber sempre do assunto 0 e os resultados estão na seção 7.3. Esta função se encarrega de definir qual máquina de estados o agente vai utilizar para 
satisfazer o estabelecido na regra e trocar a forma utilizada por eles para avaliação se assimilam ou não uma informação, caso necessário.

Por fim, na seção 7.4 estão apresentados os resultados de uma versão combinada onde são considerados três grupos de agentes, dois meios de comunicação em massa, dois assuntos e a possibilidade de comunicação entre alguns destes agentes.

\subsection{A Influência dos Meios de Comunicação em Massa nas Informações Conhecidas pelos Agentes}

Nesta seção estão apresentados os estudos realizados considerando apenas a divulgação de informações através dos meios de comunicação em massa e sua influência no conhecimento dos agentes.

Para a geração destes resultados, se optou por definir um grupo com 50 agentes. Este grupo tem perfil 0 e acessa o único meio de comunicação em massa disponível. Este acesso ocorre 10 minutos após o início da simulação (00:10), com 30 minutos de tempo médio e 5 minutos de desvio padrão.

Neste meio de comunicação em massa existem apenas um programa e um anúncio que se referem ao mesmo assunto ( 0 , no caso) e são veiculados entre 00:10 e 00:40 (10 e 40 nos gráficos).

Com o intuito de privilegiar a dinâmica, foi definido o limiar para assimilação igual a zero. Além disto, em caso de assimilação, o tempo que o agente se lembra do assunto é incrementado em (INT * IMP) + DMT, onde DMT é 1, o impacto 4 e o interesse sofreu variação em cada simulação visando avaliar sua influência.

Para a geração dos gráficos foram consideradas as possíveis combinações de valores para estado emocional (deprimido, normal ou ansioso) e nível de interesse (baixo, médio ou alto). Cada sub-seção apresenta os resultados obtidos quando os agentes utilizam uma das formas de avaliação de informações para assimilar algum assunto ao qual têm acesso. Estas foram descritas na seção 
6.1 e são quatro, sendo a primeira uma função e as demais três máquinas de estado de complexidade crescente.

Para a comparação dos resultados obtidos com a utilização de cada uma destas formas, todas as máquinas de estado descritas foram definidas com tamanho 6 estados. Além disto, todas as simulações compreendem o intervalo entre 00:00 e 08:00 horas, totalizando 480 minutos, tendo sido realizadas 10 repetições para a geração de cada um dos resultados.

\subsubsection{Estudo de Caso MCM - 1: Função Limiar}

Neste primeiro caso, o estado emocional dos agentes não interfere na assimilação de informações quando eles estão usando a função limiar. Desta forma o Gráfico 2 resume os possíveis resultados e se pode perceber que a diferença demonstrada é diretamente relacionada com o nível de interesse, o qual é utilizado para incrementar quanto tempo cada agente ainda se lembra do assunto assimilado.

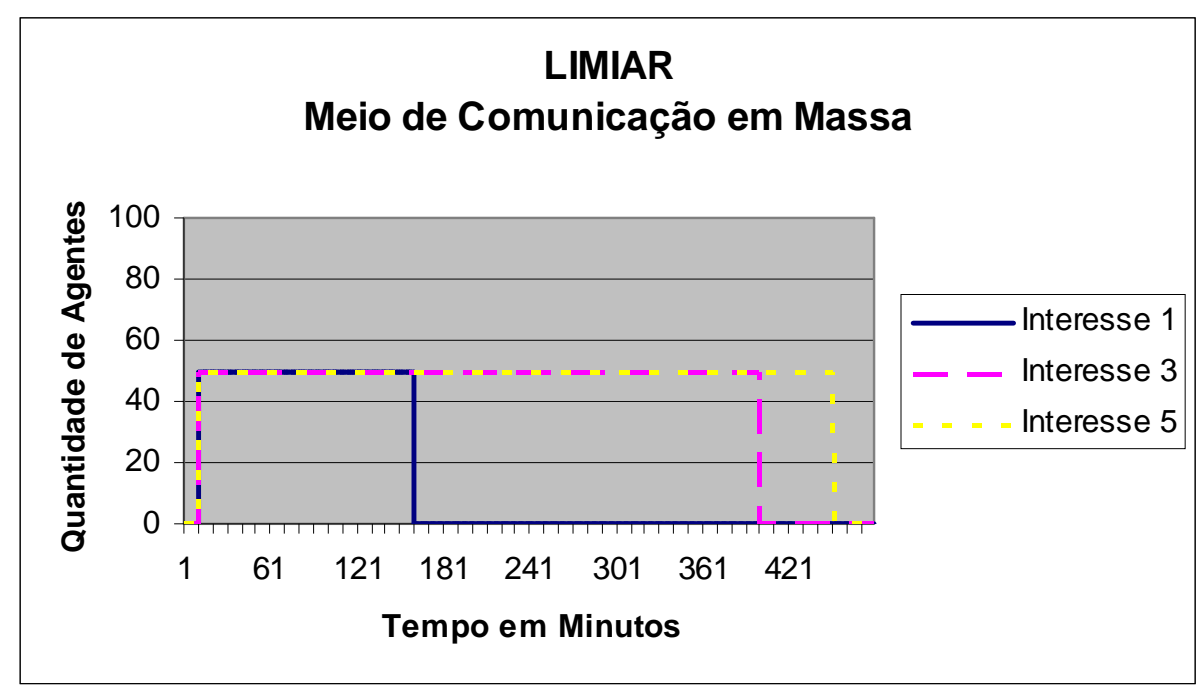

Gráfico 2: Resultados com o uso pelos agentes da função de assimilação (INT * IMP) > Limiar. 


\subsubsection{Estudo de Caso MCM - 2: Máquina de Estados Um}

De forma similar, na máquina um (Gráfico 3), os valores de estado emocional também não interferem nos resultados. Apesar disto, na forma anterior, cada vez que o agente tem acesso a um assunto ele realiza a avaliação. Já a máquina um requer que o mesmo assunto seja recebido cinco vezes para que seja assimilado, pois o tamanho definido para cada máquina é seis.

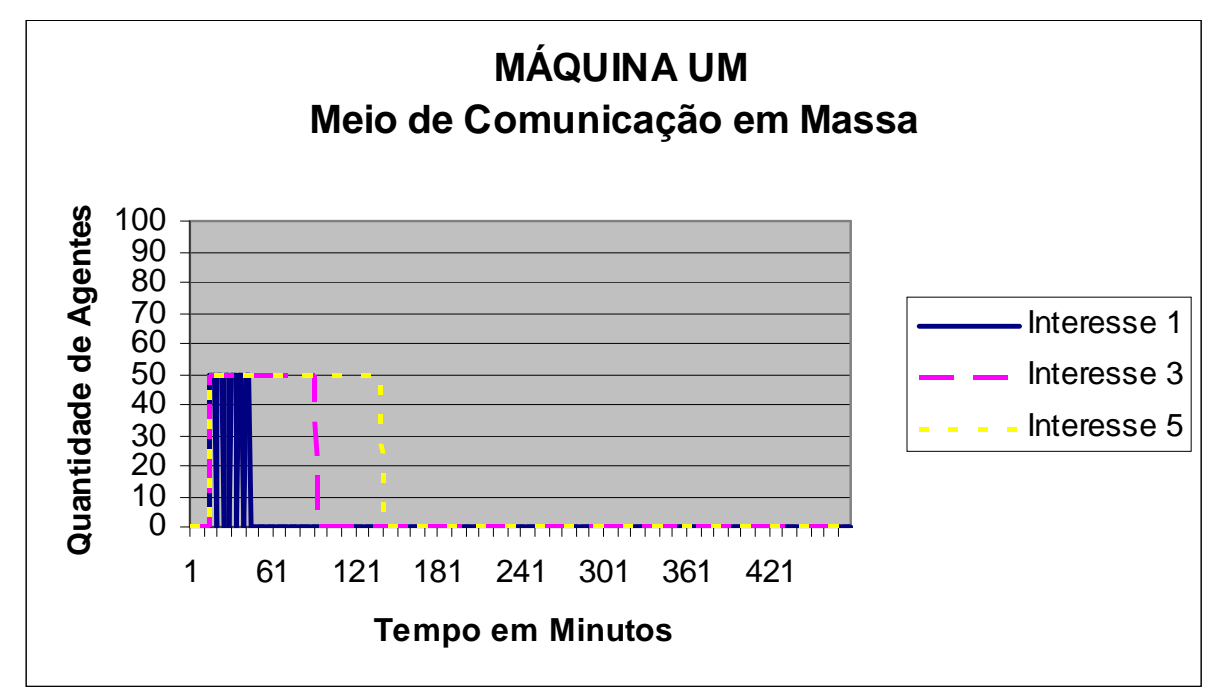

Gráfico 3: Resultados com o uso pelos agentes da máquina de estados que leva em consideração ((INT * IMP) > Limiar) para a progressão de estado.

\subsubsection{Estudo de Caso MCM - 3: Máquina de Estados Dois}

No terceiro caso, quando os agentes utilizam a máquina dois o nível de interesse interfere no estado emocional. Desta forma, no Quadro 16 podem ser vistas todas as possíveis combinações destes parâmetros e a relação deles com os resultados que serão apresentados no Gráfico 4.

Se os agentes começam como deprimidos, normais ou ansiosos, tendo interesse 1, todos ficam deprimidos e tendo interesse 5 todos ficam ansiosos, conforme o estabelecido na seção 6.1.3, Quadro 14. Estes dois casos foram 
resumidos pela legenda 1 e 4 no Gráfico 4 . Já o nível de interesse 3 (médio) não afeta o estado emocional dos agentes, e estes completam os resultados passíveis de serem gerados.

\begin{tabular}{|l|l|l|l|}
\hline \multicolumn{1}{|c|}{$\begin{array}{c}\text { Estado Emocional } \\
\text { Interesse }\end{array}$} & Deprimido & Normal & Ansioso \\
\hline Baixo & Legenda 1* $^{*}$ & Legenda 1* & ${\text { Legenda }{ }^{*}}^{*}$ \\
\hline Médio & Legenda 1* $^{*}$ & ${\text { Legenda } 2^{*}}^{*}$ & Legenda 3* $^{*}$ \\
\hline Alto & Legenda 4* $^{*}$ & Legenda 4* $^{*}$ & Legenda 4* \\
\hline
\end{tabular}

Quadro 16: *Legendas que identificam no próximo gráfico os resultados referentes a cada uma das possíveis combinações de estado emocional e nível de interesse com as máquinas dois e três.

A diferença que pode ser percebida nos três casos de interesse médio (segunda linha do Quadro 16) é decorrente do estado emocional e das transições que ocorrem na máquina de estados $(0,+1,+2$, Figura 30). Já quando o estado emocional é ansioso (legenda 3 e 4 ) a variação se deve ao nível de interesse, o qual é usado para definir quanto tempo os agentes se lembram do assunto assimilado.

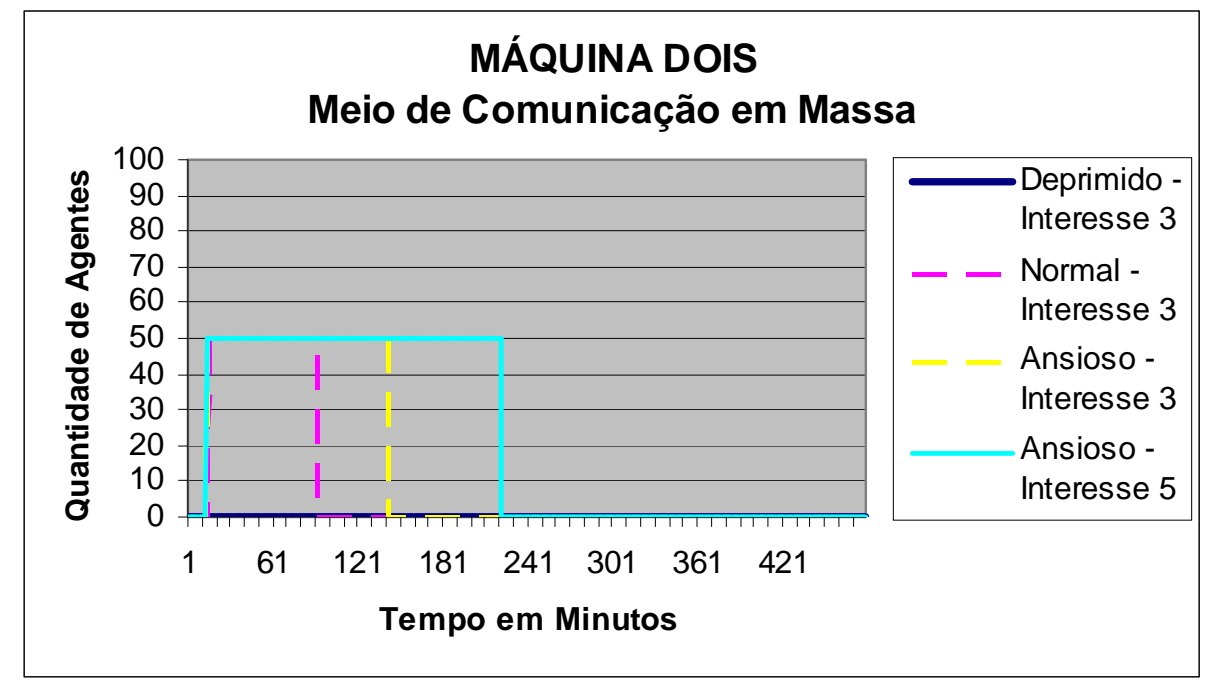

Gráfico 4: Resultados com o uso pelos agentes da máquina de estados dois (interesse afeta estado emocional e este afeta a assimilação). 


\subsubsection{Estudo de Caso MCM - 4: Máquina de Estados Três}

No quarto caso (parecido com o anterior) os agentes utilizaram a máquina três, ou seja, o interesse baixo (1) faz com que todos fiquem deprimidos e quando seu valor é alto (5) todos os agentes ficam ansiosos, uma vez que o valor do impacto definido é sempre alto. Portanto as mesmas situações apresentadas no Quadro 16, seção anterior, representam os resultados que podem ser gerados e a explicação anterior vale em ambos os casos.

A diferença que ocorre é quando os agentes estão ansiosos e com interesse nível máximo (5). Este resultado é explicado pela estrutura das máquinas de estado, pois ao se deparar com um assunto que se interessa, cada agente vai do estado I para o estado I + 2 quando utilizando a máquina dois (Figura 30) e irá para o estado I + 3 caso esteja utilizando a máquina três (Quadro 15). Desta forma, além do nível de interesse ser utilizado para definir quanto tempo o agente ainda se lembra do assunto assimilado, ele vai avaliar o mesmo assunto uma maior quantidade de vezes, considerando que está exposto a ele durante o mesmo período numa comparação da utilização da máquina dois com a máquina três.

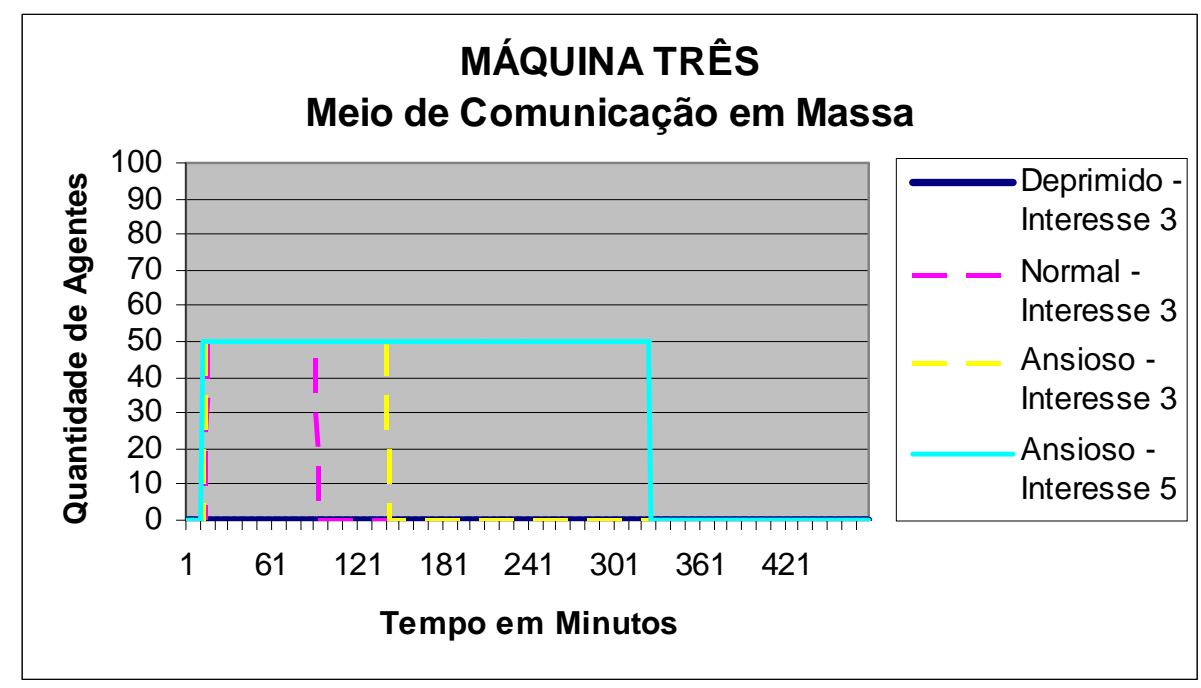

Gráfico 5: Resultados com o uso pelos agentes da máquina de estados três (interesse afeta estado emocional e ambos afetam assimilação). 


\subsubsection{Considerações Finais}

Nesta seção foram apresentados resultados de simulações considerando as formas de avaliação para assimilação de informações que os agentes podem utilizar. A diferença entre elas está diretamente relacionada com a quantidade de vezes que é necessário o recebimento de informações a respeito de um mesmo assunto para a assimilação. Assim, cada uma das formas tem influência direta no tempo que os agentes se lembram dos assuntos.

Pelos resultados apresentados, com o uso da função limiar, grande quantidade de agentes assimila informações a respeito do assunto que está sendo tratado durante a simulação, uma vez que a avaliação é feita pelos agentes a todo o momento, o que é irreal. Formas mais realistas envolvem avaliações, dependência do histórico de cada agente e principalmente as informações recebidas afetam o indivíduo e podem ser afetadas por ele. Foi por este motivo que se buscou aumentar a complexidade ao elaborar cada uma das máquinas de estado.

Até aqui, todos os resultados levaram em consideração apenas o acesso a um meio de comunicação em massa, ilustrando o efeito da comunicação broadcast que é a rápida divulgação para grande quantidade de agentes (os que tem acesso). Desta forma, não foi possível avaliar a interferência dos agentes no fluxo de informações trocadas na sociedade. Para a próxima seção foi então incluída a possibilidade de comunicação entre agentes, visando também identificar a importância da dinâmica nas redes sociais na disseminação de informações.

\subsection{Influência do Fluxo de Informações nas Redes Sociais em Comparação com a Comunicação Broadcast}

Visando avaliar a influência do fluxo de informações da rede social no conhecimento ${ }^{19}$ da sociedade e compará-lo com aquele proveniente dos meios de

\footnotetext{
${ }^{19}$ Aqui se define que um agente conhece algo ou sabe de um assunto quando ele se lembra dele por um tempo superior a 0 .
} 
comunicação em massa, foi considerado o primeiro grupo de agentes descrito na seção anterior e foi inserido um segundo grupo composto por 50 agentes, com 50 amigos cada. A diferença entre eles é que apenas membros do primeiro podem acessar o meio de comunicação em massa disponível, mas ambos podem receber informações de seus amigos e falar sobre aquilo que tiverem conhecimento.

Independente disto, a decisão de falar em todas as situações leva em consideração o descrito na seção 6.2, ou seja, o estado emocional afeta a escolha de qual assunto pode ser transmitido e a forma de assimilação de informações advindas de algum amigo leva em consideração apenas a função limiar (seção $6.1 .1)$.

Considerando a relação existente entre agentes foi elaborada a Figura 36. Para que o primeiro (agente 1) possa enviar uma mensagem, ele precisa saber do assunto, conhecer o amigo (dados que estão em sua Base de Conhecimento) e escolher sobre o que e para quem vai falar. Tomadas estas decisões, o agente 1 envia a mensagem utilizando o meio de comunicação entre agentes e ela pode ser assimilada pelo agente 2. O ouvinte deverá tratar a mensagem com o módulo de decisão (DAs) e pode atualizar sua BC. O mesmo ocorre quando o agente 2 é o falante e o 1 o ouvinte. Com este ciclo é possível perceber a influência mútua dos agentes enquanto partes de uma rede social.

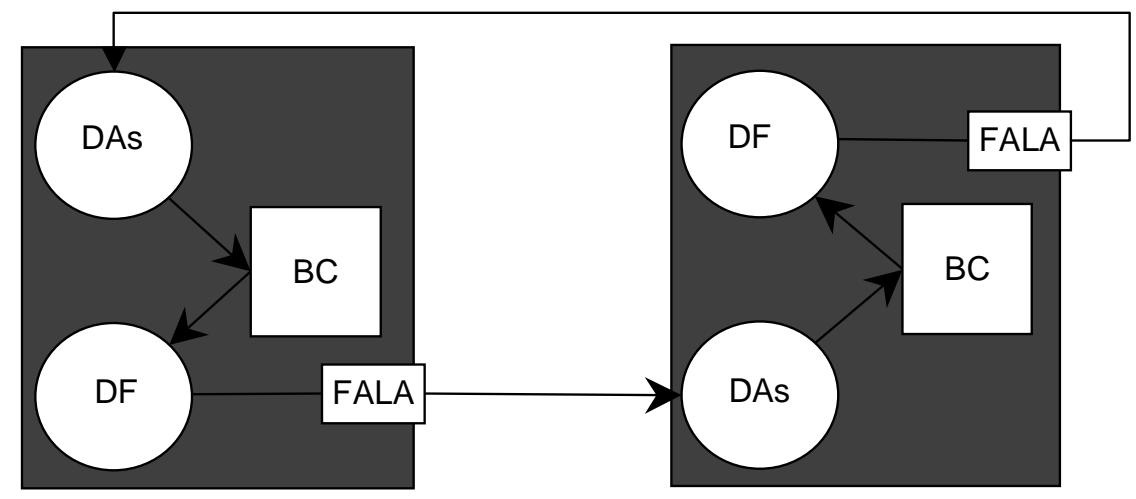

Agente 1

Agente 2

Figura 36: Acoplamento entre dois agentes ${ }^{20}$. 
A partir desta afirmação, para os resultados a seguir foi feita a simulação considerando também ${ }^{21}$ a possibilidade de troca de informações entre os agentes. Para cada uma das formas de assimilação de informações apresentadas na seção 6.1 se busca avaliar o nível de conhecimento deles quando é possível a comunicação entre amigos.

Antes, porém, de apresentar os resultados é necessário lembrar que a decisão de falar ou não sobre um assunto é interferida diretamente pelo estado emocional dos agentes. Conforme explicado na seção 6.2, um agente deprimido não fala nada, se está em seu estado normal só pode falar daqueles assuntos que sabe e pelos quais tem interesse maior que 3 (médio), já quando seu estado emocional é ansioso um assunto é escolhido (randomicamente) dentre todos os que sabe.

\subsubsection{Estudo de Caso RS - 1: Função Limiar}

Para os primeiros resultados, Gráfico 6, os agentes são ansiosos e apenas o nível de interesse sofreu variação. Esta opção resume todas as possibilidades, pois o comportamento do gráfico é o mesmo quando os agentes são normais ou ansiosos e possuem interesse 3; ou quando com estes estados emocionais o interesse é 5. Além disto, os agentes deprimidos não falam e portanto o resultado é o mesmo do Gráfico 2.

\footnotetext{
${ }^{20}$ Voltando a citar, DAs é a Decisão usada para Assimilar alguma informação; DAc é aquela usada para Acessar algum meio de comunicação em massa; DF é a Decisão que envolve a escolha sobre o que e para quem Falar e BC é a Base de Conhecimento de cada agente.

${ }_{21}$ São simulações que levam em consideração tanto a divulgação de informações através dos meios de comunicação em massa quanto a comunicação entre agentes.
} 


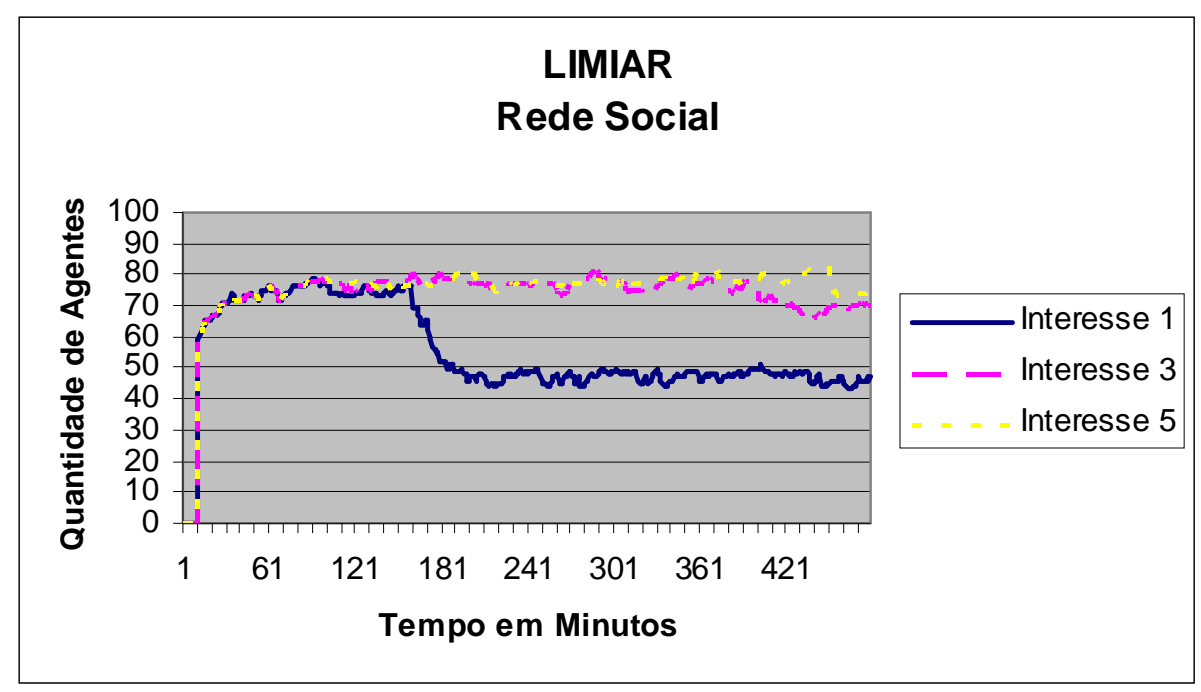

Gráfico 6: Resultados da divulgação de informações nos meios de comunicação em massa com a dinâmica na rede social quando os agentes utilizam a função de assimilação (INT * IMP) > Limiar.

Realizando a comparação entre o Gráfico 6 e o Gráfico 2 é possível perceber que a quantidade de agentes que sabe do assunto que está sendo divulgado pelo meio de comunicação em massa é similar. A pouca variação identificada pode ser explicada pelo fato de que os amigos podem ser do mesmo grupo que acessa o meio de comunicação em massa. No entanto, a contribuição do relacionamento entre amigos se mostra principalmente após o fim da divulgação broadcast, quando vários agentes continuam sabendo e conversando sobre o assunto que foi divulgado.

\subsubsection{Estudo de Caso RS - 2: Máquina de Estados Um}

Exatamente como descrito na seção anterior acontece com o uso da máquina um, pois mantendo o estado emocional ansioso e variando apenas o interesse se obtêm as possíveis combinações destes dois parâmetros. Isto é possível uma vez que considerando agentes normais o gráfico apresenta os mesmos resultados dos obtidos quando os agentes estão ansiosos. 


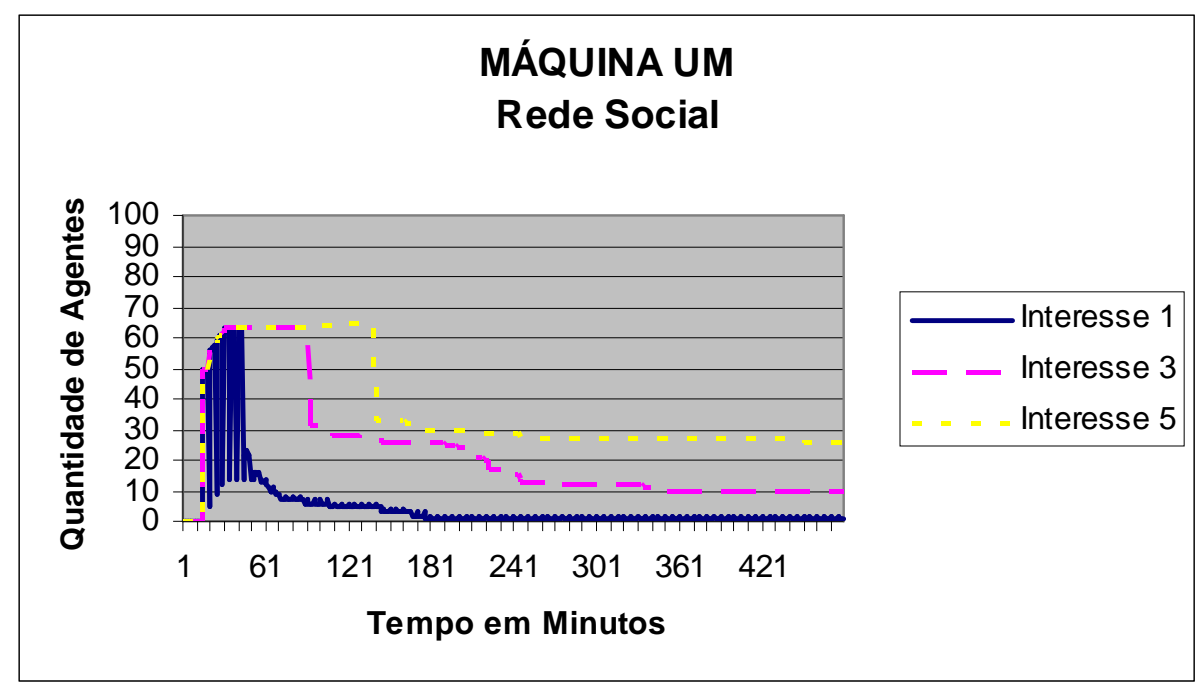

Gráfico 7: Resultados da divulgação de informações nos meios de comunicação em massa com a dinâmica na rede social quando os agentes utilizam a máquina de estados que leva em consideração ((INT * IMP) > Limiar) para a progressão de estado.

De forma similar, comparando o Gráfico 7 com o Gráfico 3 (apenas MCM), é possível identificar a queda na quantidade de agentes que sabe do assunto em questão. Esta ocorre devido ao fim da divulgação através do meio de comunicação em massa. O que se identifica de diferente entre os gráficos é a contribuição da dinâmica na rede social, por exemplo, após esta queda, durante o restante da simulação alguns agentes por ainda "saberem" do assunto, "conversam" sobre ele com seus amigos.

\subsubsection{Estudo de Caso RS - 3: Máquina de Estados Dois}

Considerando a máquina dois, o nível de interesse dos agentes tem interferência direta no estado emocional deles. Assim, em todos os resultados gerados quando com interesse 1 (baixo) nenhum agente fica sabendo do assunto. Já quando o interesse é 5 (alto) todos os agentes ficam ansiosos e o comportamento do gráfico pode ser visto na figura a seguir (legenda Ansioso - Interesse 5). 


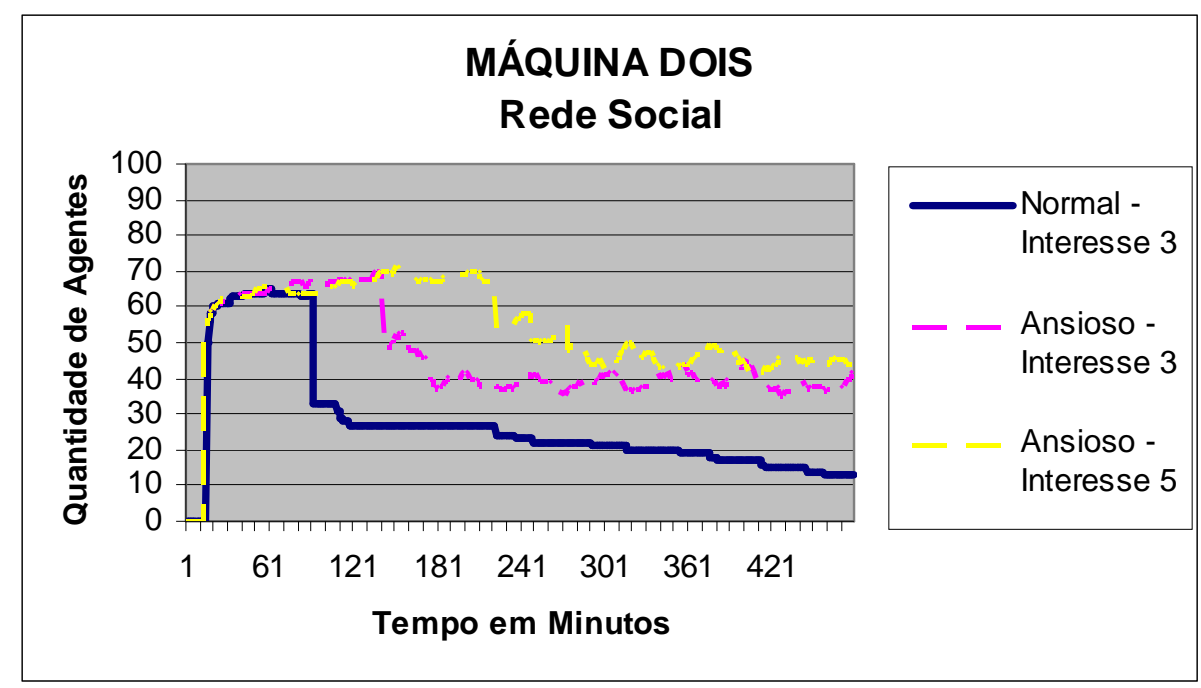

Gráfico 8: Resultados da divulgação de informações nos meios de comunicação em massa com a dinâmica na rede social quando os agentes utilizam a máquina de estados dois (interesse afeta estado emocional, EE afeta a assimilação).

Apesar de ser possível novamente identificar as quedas decorrentes do final da divulgação no meio de comunicação em massa, nas três opções apresentadas no interesse e estado emocional a diferença existente é explicada, pois quando o nível de interesse é 3, agentes ansiosos assimilam mais frequentemente o assunto ao qual têm acesso do que os normais. Comparando então a variação que ocorre quando se tem apenas agentes com estado emocional ansioso, percebe-se a interferência do nível de interesse ( 3 ou 5, nestes casos) no tempo que os agentes se lembram de um assunto assimilado.

\subsubsection{Estudo de Caso RS - 4: Máquina de Estados Três}

Conforme explicado na seção 7.1.4, as mesmas situações representam todos os resultados passíveis de serem gerados para a máquina dois ou três. A diferença é novamente identificada quando o estado emocional é ansioso e o nível de interesse 5 (alto), como pode ser visto comparando o Gráfico $8 \mathrm{com} \circ$ Gráfico 9. Esta é decorrente da estrutura de ambas as máquinas o que faz com que um agente avalie 
mais vezes (transição +2 ou +3 nas máquinas) as informações que receber quando estiver utilizando a máquina três.

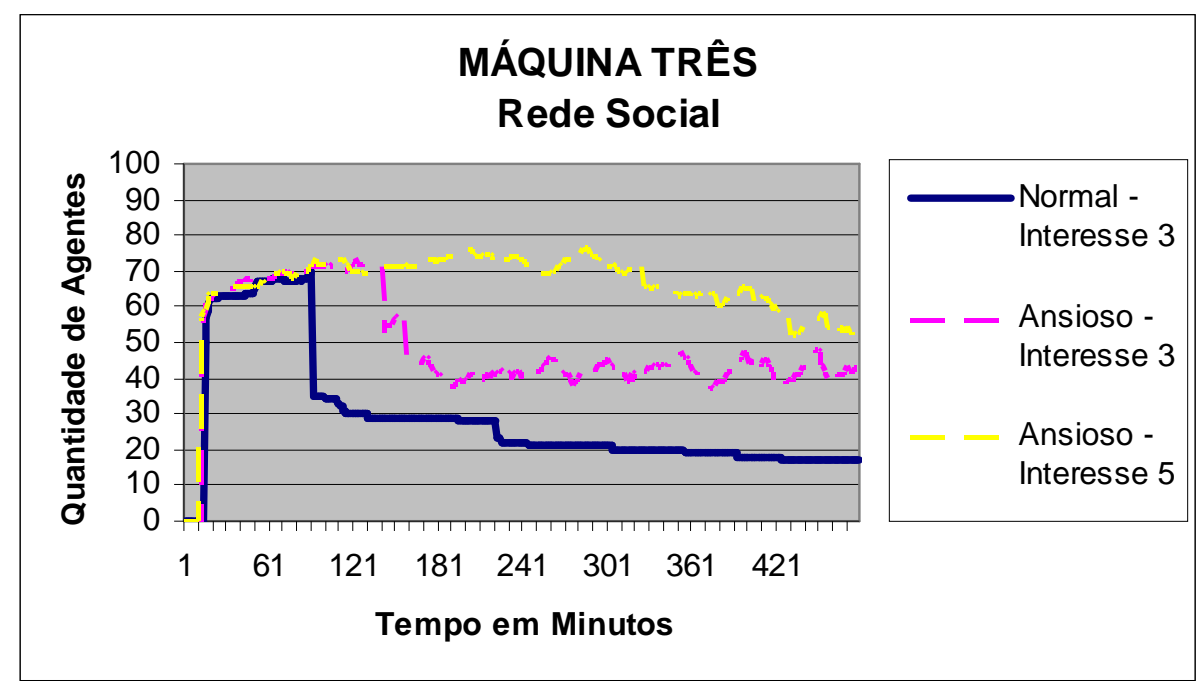

Gráfico 9: Resultados da divulgação de informações nos meios de comunicação em massa com a dinâmica na rede social quando os agentes utilizam a máquina de estados três (interesse afeta estado emocional e ambos afetam assimilação).

\subsubsection{Considerações Finais}

Finalmente, comparando os gráficos apresentados até aqui, o que se percebe é que os resultados são condizentes com a realidade e que a comunicação broadcast é um "amplificador" da quantidade de agentes que fica sabendo de algo, afinal durante um tempo eles têm acesso às informações sobre um mesmo assunto. Apesar disto, o conhecimento corre o risco de ser esquecido rapidamente se não for reforçado (gráficos apresentados na seção 7.1).

Este reforço ocorre nos resultados aqui apresentados exatamente na rede social, cujo fluxo de informações proporciona uma estabilização da quantidade de agentes que sabe do assunto em questão, quando analisada apenas a dinâmica da comunicação entre agentes.

Com estes experimentos foi possível realizar a comparação entre as duas formas de comunicação existentes. No entanto, percebeu-se que cada uma das 
formas de assimilação de informações que os agentes podem utilizar apresenta características e comportamentos diferentes, o que representa pontos positivos e negativos que dependem da aplicação pretendida.

Tendo isto como base e buscando cumprir um dos objetivos iniciais deste projeto de doutorado, foi elaborada uma função adaptativa, responsável por definir qual máquina de estados cada agente deve utilizar para que ele cumpra uma regra definida pelo usuário ou programador. Esta função está apresentada na próxima seção.

\subsection{Os Agentes Devem Agir Assim! - Função Adaptativa}

É fato que uma máquina de estados proporciona resultados melhores que outra em alguns aspectos, mas certamente piores em outros. Ciente disto se optou por definir uma função adaptativa ${ }^{22}$, a partir de uma regra de comportamento que os agentes precisam cumprir. Para os resultados a seguir, foram utilizados os mesmos dois grupos da seção anterior e foi estabelecido que os agentes devem sempre saber do assunto 0 , e que vai ser trocada a máquina de $\operatorname{estados}^{23}$ que eles estão utilizando se ela não estiver proporcionando resultados satisfatórios.

O funcionamento da função adaptativa se resume a definir qual máquina de estados o agente vai utilizar a cada momento. Inicialmente, foi definido que cada um começa utilizando a Máquina Um e que a cada passo da simulação ele busca assimilar 0 assunto 0 se tiver acesso a ele, cumprindo a regra. Caso a máquina que o agente está utilizando mude de estado, então "ela" receberá um bônus igual à quantidade de estados que ocorreu a transição $(-1,0,+1,+2,+3)$, privilegiando desta forma a máquina que proporcione assimilação mais rápida. Esta pontuação é decrementada a cada vez que o agente tentar assimilar um assunto, mas a máquina não realizar transições. Com base nisto, ao ter pontuação zero, é realizada a troca da máquina obedecendo à ordem circular (um, dois, três).

\footnotetext{
${ }^{22}$ Conceito utilizado com base no definido em (Pchelkin, 2004, Neto, 2009, 2009a).
} 
Para os gráficos a seguir estão apresentados os resultados da máquina um, dois, três e da função adaptativa visando identificar as vantagens e desvantagens de cada uma das formas de assimilação que os agentes podem utilizar. Em todos os casos é considerada tanto a divulgação broadcast quanto a possibilidade de comunicação entre os agentes.

Quando os agentes começam com nível de interesse 1 (baixo) é a situação dentre todas as possíveis variações de interesse e estado emocional onde eles ficam sabendo do assunto 0 pelo menor tempo. Trata-se inclusive de um ponto crítico das máquinas dois e três, pois nenhum agente fica sabendo de nada durante a simulação, Gráfico 10. No entanto quando os agentes utilizam a função adaptativa o gráfico mostra que a máquina um contribuiu para um resultado positivo.

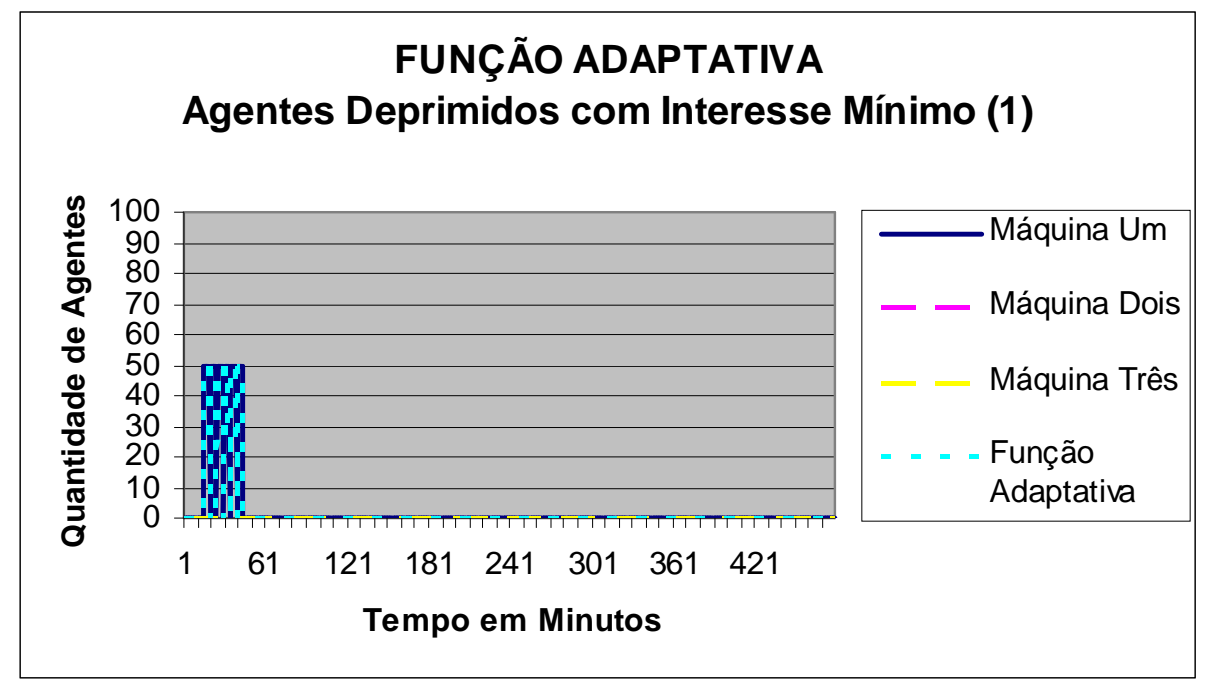

Gráfico 10: Comparativo entre as máquinas de estado com quando os agentes usam função adaptativa. Nível de Interesse: baixo / Estado Emocional: deprimido.

Similar a isto, quando os agentes são deprimidos e possuem nível de interesse médio (3), tanto usando a máquina dois quanto a três ninguém fica sabendo de nada. Novamente então o que se percebe na aplicação da função adaptativa é o benefício decorrente da possibilidade deles usarem a máquina um, Gráfico 11.

\footnotetext{
${ }^{23}$ Nestes casos não se considera a função LIMIAR como possibilidade de forma de assimilação pelos agentes, pois apesar dos resultados dela serem melhores, ela não reproduz minimamente o que acontece na realidade (frequência de avaliação e velocidade de assimilação). Assim eles alternam apenas entre a máquina um, dois ou três.
} 


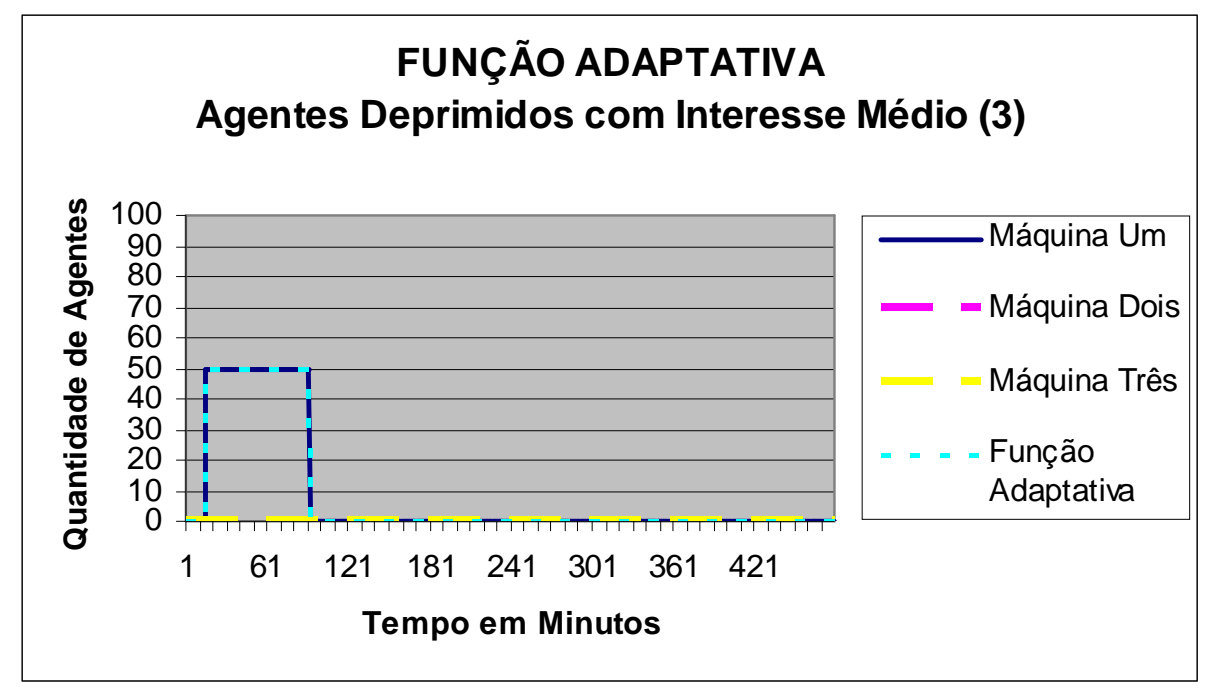

Gráfico 11: Comparativo entre as máquinas de estado com quando os agentes usam função adaptativa. Nível de Interesse: médio / Estado Emocional: deprimido.

Mantendo o nível de interesse (3) e mudando apenas o estado emocional inicial para normal, os resultados são similares (Gráfico 12) quando são comparadas as quatro formas que os agentes podem usar para avaliar se assimilam uma informação a qual têm acesso (máquinas um, dois, três ou função adaptativa). Isto ocorre, pois o interesse 3 não afeta o estado emocional e, além disto, estando normais, os agentes falam sobre os assuntos que tem interesse médio ou alto, o que é o caso.

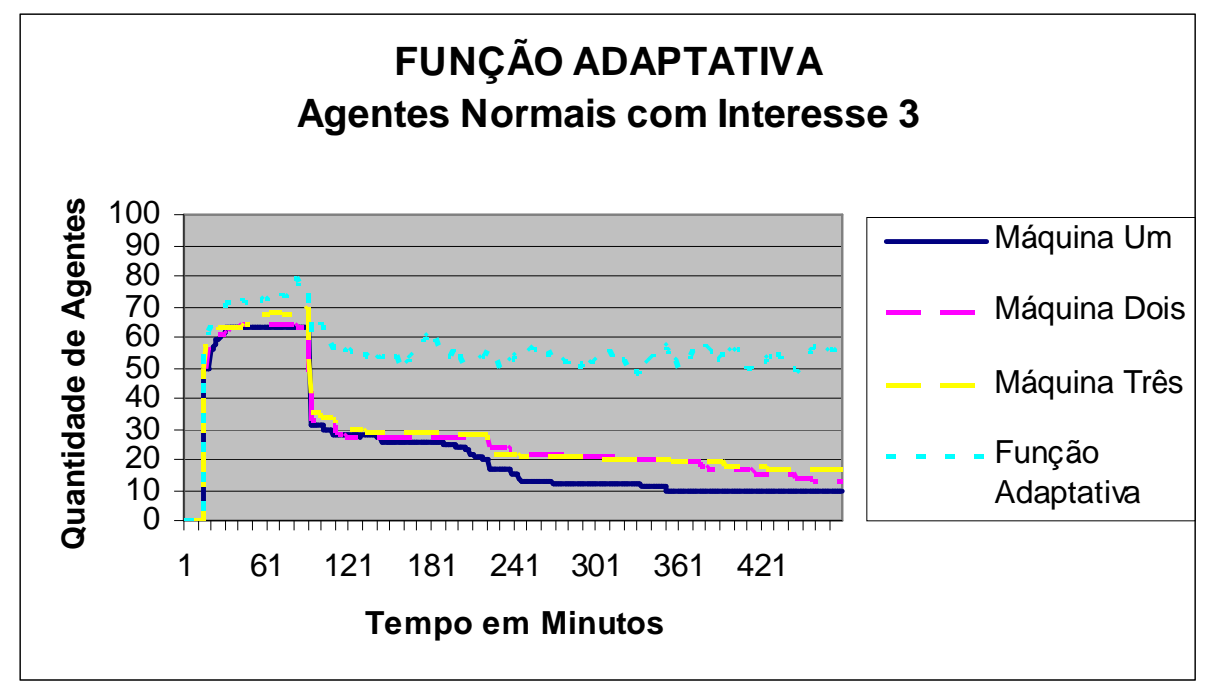

Gráfico 12: Comparativo entre as máquinas de estado com quando os agentes usam função adaptativa. Nível de Interesse: médio / Estado Emocional: normal. 
A diferença entre o Gráfico 12 e o Gráfico 13 é decorrente da velocidade de mudança de estados existente na máquina dois $(+1)$, três $(+2)$ e por consequência, na função adaptativa. Assim a assimilação se dá mais vezes e o tempo que os agentes se lembram do assunto é maior.

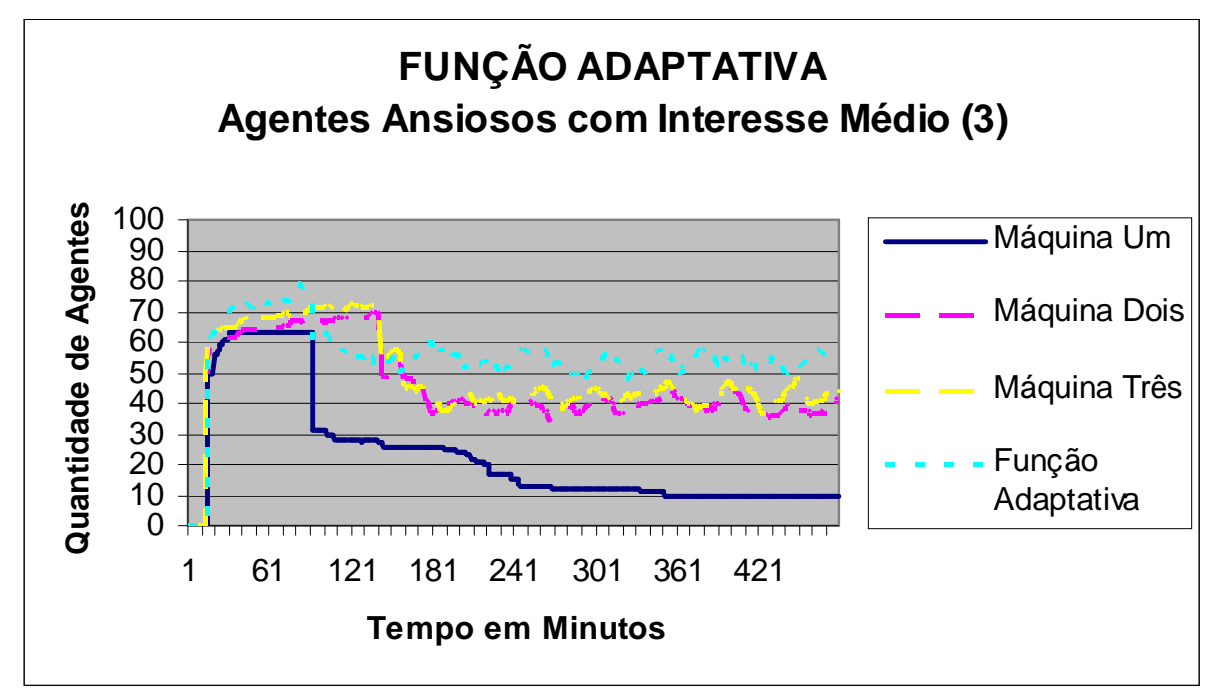

Gráfico 13: Comparativo entre as máquinas de estado com quando os agentes usam função adaptativa. Nível de Interesse: médio / Estado Emocional: ansioso.

$\mathrm{Na}$ última configuração avaliada os agentes foram definidos com estado emocional ansioso e nível de interesse 5. Esta opção privilegia a velocidade de assimilação e é quando os agentes se lembram por mais tempo.

No Gráfico 14 pode-se perceber que o resultado do uso da função adaptativa se igualou àquele obtido com a máquina três, o melhor dentre as disponíveis. 


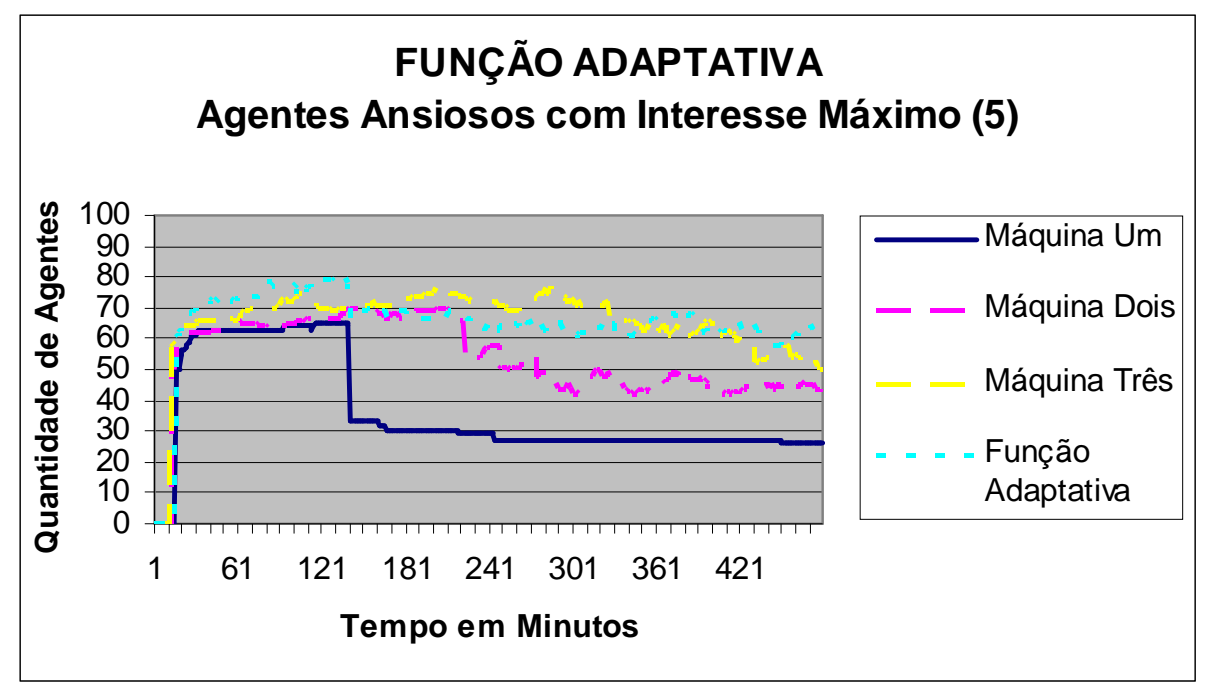

Gráfico 14: Comparativo entre as máquinas de estado com quando os agentes usam função adaptativa. Nível de Interesse: alto / Estado Emocional: ansioso.

Situação onde a maior quantidade de agentes sabe de algo por um maior período de tempo.

Analisando os últimos três gráficos é possível perceber que a quantidade de agentes que sabe do assunto e o tempo que se lembram dele são diretamente relacionados à velocidade máxima de mudança de estados em cada máquina. No Gráfico 12 ocorre a transição para o próximo estado (quando usada a máquina dois ou a três), já para o Gráfico 13 a mudança pode ser para o segundo estado subseqüente (considerando as mesmas máquinas). No terceiro caso, o Gráfico 14, como citado anteriormente, representa a situação com maior dinâmica e é onde pode ocorrer a transição +3 (máquina três).

Finalmente é preciso ressaltar que, sem que seja necessário um período de treinamento para avaliação das máquinas de estados existentes, com a definição de regras simples é possível chegar ao melhor funcionamento interno dos personagens (dentre aqueles que eles dispõem), ou seja, a resultados mais próximos do identificado no mundo real, ou do objetivo da simulação. 


\subsection{Versão Combinada}

Para a geração dos próximos resultados foram tratados três grupos, cada um com 30 agentes, totalizando 90 , todos ansiosos e com interesse máximo por todos os assuntos. Cada um dos agentes com 30 amigos.

Para a configuração, foram mantidos os dois grupos utilizados nas seções 7.2 e 7.3 e o terceiro grupo incluído é similar ao primeiro (descrito na seção 7.1), pois pode acessar um meio de comunicação em massa e trocar mensagens com seus amigos. A diferença é que este grupo tem acesso ao meio que veicula o assunto 1 e o perfil destes agentes define que eles acessam a este meio após as 00:50, com tempo médio de 30 minutos e desvio padrão 5 , indo ao encontro do intervalo no qual ocorre a veiculação das notícias e anúncios, entre 00:50 e 01:20.

O primeiro resultado gerado seguindo esta configuração está no Gráfico 15 , quando foi considerada apenas a divulgação de notícias através dos meios de comunicação em massa. Neste caso, todos os agentes dos dois grupos que recebem informações divulgadas desta forma ficaram sabendo dos assuntos. No entanto, como não é possível à comunicação entre amigos, um grupo de 30 agentes ficou sem saber nenhum dos assuntos durante todo o tempo.

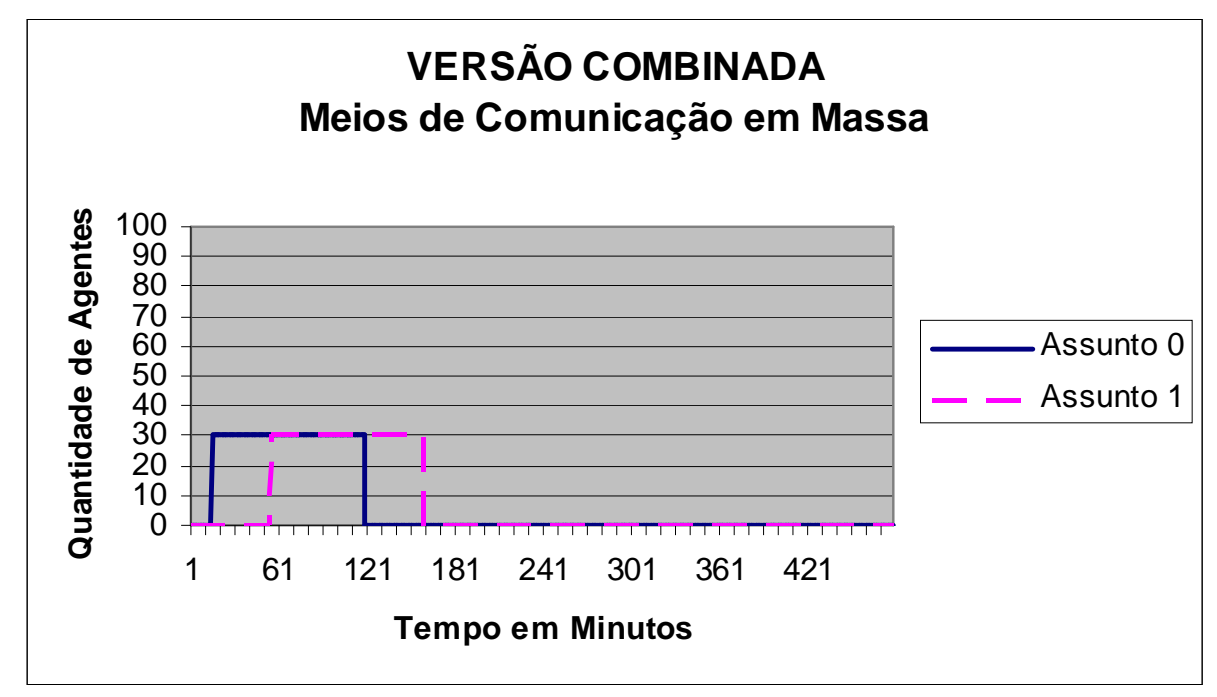

Gráfico 15: Versão combinada, apenas meios de comunicação em massa. 
Dando prosseguimento foi incluída a possibilidade da comunicação na rede social, a qual tem sua influência ressaltada comparando o Gráfico 15 com o Gráfico 16. Percebe-se neste último caso que o grupo de agentes que não acessa nenhum meio de comunicação em massa ficou sabendo de algum assunto (um ou mais) e, além disto, mesmo depois de terminada a veiculação, diversos agentes continuam sabendo e trocando mensagens sobre os assuntos divulgados.

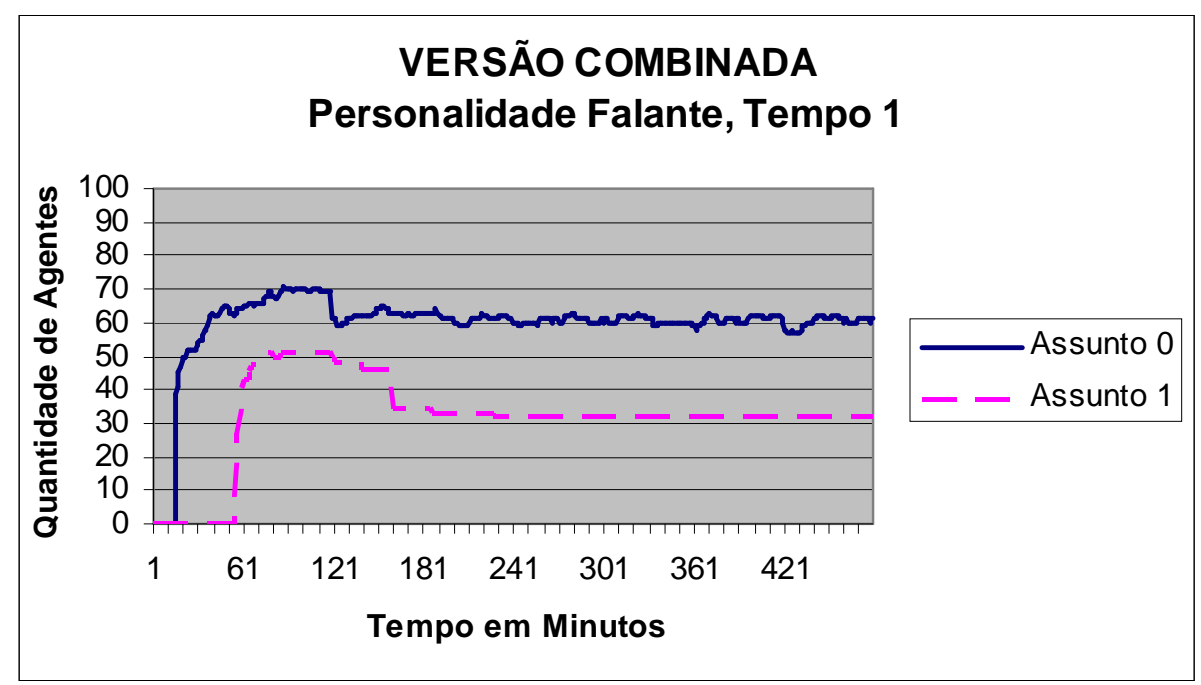

Gráfico 16: Versão combinada comunicação através dos meios de comunicação em massa e na rede social. Agentes com personalidade falante tentam falar a todo minuto.

Outro resultado que foi possível avaliar se refere a frequência que os agentes tentam falar com seus amigos (personalidade). Para isto, na situação retratada no Gráfico 16 eles tentam enviar alguma mensagem a cada minuto de simulação, já no caso do Gráfico 17 o intervalo usado foi de 10 minutos. A comparação mostra que a dinâmica na rede social afetou diretamente a quantidade de agentes que sabe de um assunto e também no tempo que se lembram dele. 


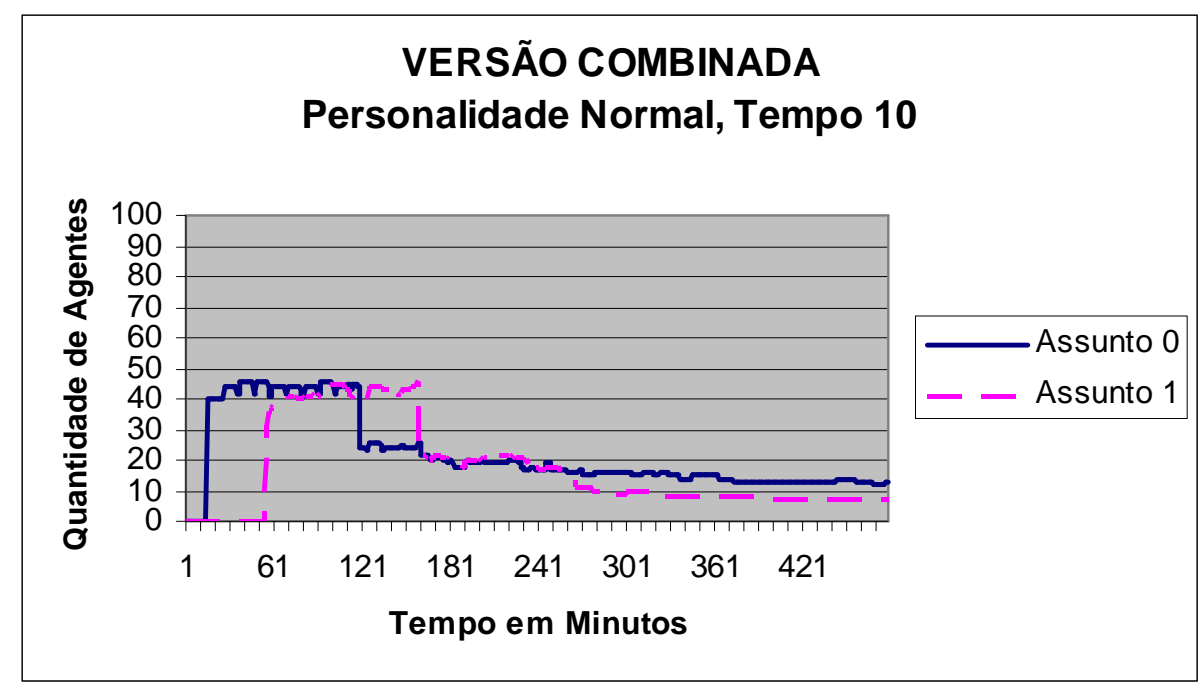

Gráfico 17: Versão combinada comunicação através dos meios de comunicação em massa e na rede social. Agentes com personalidade normal tentam falar a cada 10 minutos.

Os exemplos a seguir visam ilustrar histórias individuais geradas para quatro agentes específicos:

- Agente 29 (primeiro grupo, acessa o meio de comunicação em massa que divulga o assunto 0). Este agente não conversou com nenhum de seus amigos durante a simulação. Sua rotina foi de acessos ao meio de comunicação, tendo sua primeira assimilação do assunto 0 ocorrida aos 00:14 minutos. Ele se esqueceu do assunto à 01:58.

- Agente 37 (segundo grupo, acessa o meio de comunicação em massa que divulga o assunto 1). Este agente ouviu o assunto 0 aos 00:37 minutos, recebeu novamente informações a respeito deste assunto aos 00:47 minutos, até que à 01:18 se esqueceu dele. No entanto, seguindo o definido em seu perfil, acessou o meio de comunicação em massa 1 aos 00:50 minutos e aos 00:54 assimilou pela primeira vez o assunto 1. Após isto sua rotina foi de acesso e assimilação do assunto 1 , até que às 02:38 se esqueceu dele. Sua rotina incluiu ainda conversas com seus amigos, tendo ouvido o assunto 0 por diversas vezes entre 01:22 e 03:59, por exemplo, e se esqueceu dele às 04:49 horas.

- Agente 51 (segundo grupo, acessa o meio de comunicação em massa que divulga o assunto 1). Assim como o agente 29, este não 
conversou com nenhum de seus amigos durante a simulação. Sua rotina foi aos 00:50 minutos acessar o meio de comunicação 1. Após isto, teve conhecimento do assunto 1 de 00:54 minutos até às 02:38, quando se esqueceu.

- Agente 89 (terceiro grupo, apenas pode receber informações através da rede social): aos 00:59 minutos este agente ouviu o assunto 0 pela primeira vez. Esta atividade foi repetida entre 01:06 e 06:24 horas, e ele só se esqueceu do assunto às 06:59 horas.

Estes resultados apresentam estórias de agentes individualmente diferentes, sem que para isto exista a definição explícita do usuário quanto ao modo de agir de cada um deles. 


\section{Capítulo 8. CONCLUSÕES}

Nesta tese foi realizado o estudo de quatro áreas de pesquisa, o qual engloba: agentes inteligentes, aspectos cognitivos, redes sociais, meios de comunicação em massa e formas / objetivos de publicação de informações. Isto foi possível pelo contato com pesquisadores ligados à Escola de Comunicação e Artes (ECA) e Escola Politécnica (EP) da Universidade de São Paulo (USP), além da Faculdade Cásper Líbero.

Após a abordagem dos conceitos relevantes para o entendimento deste trabalho e de pesquisas importantes para delimitar e situar o que foi desenvolvido, apresentou-se o modelo composto por partes das quatro áreas. Concomitante com sua elaboração foram desenvolvidos trabalhos preliminares, alguns dos quais geraram as publicações que estão apresentadas no apêndice A.

Voltando ao modelo, este contempla tanto características relacionadas ao ambiente quanto à "mente" do agente, ou seja, contém não só uma visão global da sociedade, mas também uma arquitetura e características que os agentes possuem e que dão a eles a possibilidade de participar ativamente das simulações.

A modelagem foi realizada utilizando ontologias que como um modelo para descrever o mundo, buscam assegurar a interoperabilidade do sistema e a padronização conceitual. Foi então desenvolvido um simulador tomando tal simulador como base, onde se pretendeu então definir e aprimorar o funcionamento de cada um dos agentes, inserindo características relacionadas ao estado emocional e inter-relações entre os parâmetros considerados (interesse, impacto, etc.) para dar suporte às decisões por eles tomadas.

Os agentes possuem três módulos de decisão, podendo acessar meios de comunicação em massa, assimilar informações recebidas e também falar com seus amigos. Além disto, foram apresentadas quatro formas que eles podem usar para avaliar se assimilam as informações que recebem. Tais formas foram aprimoradas subseqüentemente, fato motivado pelo reuso e extensibilidade. Primeiramente foi elaborada uma função para avaliação a cada informação recebida ou acessada, e depois foram definidas três máquinas de estados finitos, através das quais os agentes precisam receber algumas vezes informações a respeito do 
mesmo assunto para que este seja assimilado. Além disto, para a elaboração da máquina dois foi considerada uma maior complexidade em relação à anterior, de forma que as informações recebidas interferem no estado interno dos agentes e afetam os assuntos sobre os quais eles podem escolher para falar. Dando prosseguimento, na máquina três, além da informação afetar os agentes ocorre uma dependência com relação ao seu histórico e seus interesses na decisão sobre o que cada um pode falar.

Para os estudos de caso e resultados foram isolados alguns parâmetros, como interesse, estado emocional e personalidade, comparando cada uma das formas que os agentes podem usar para assimilar. Com as simulações foram identificados pontos positivos e negativos, como o fato da avaliação a cada instante proporcionar resultados melhores, mas não reproduzir minimamente o que acontece em situações reais. Foi também identificado um ponto crítico no uso das máquinas dois e três que está relacionado com a situação onde os agentes estão deprimidos e possuem interesse baixo pelo assunto. Neste caso, nestas máquinas nenhum agente ficou sabendo de algo.

Após estas comparações foi apresentada uma função adaptativa, a qual realiza a avaliação e troca da máquina de estados finitos que os agentes estão utilizando para assimilar informações a fim de que cumpram uma regra definida pelo usuário ou programador. Neste caso, definiu-se que os agentes devem sempre saber de um assunto específico e, combinando as possíveis formas de assimilação que eles têm disponível, se chegou a resultados melhores analisando o aspecto geral do que o uso de uma das três formas de avaliação em separado.

É preciso também salientar que tanto a inclusão de novas formas de avaliação para assimilação de informações, quanto a definição de novas regras que guiem a função adaptativa é simples e permitida no simulador. Isto é possível pois todo o desenvolvimento foi realizado de forma modular. 


\subsection{Contribuições}

A contribuição principal aqui se dá, portanto, no cumprimento do objetivo de definir agentes minimamente cognitivos que participam ativamente na dinâmica do fluxo de informações, tanto acessando meios de comunicação em massa quanto conversando com seus amigos. Além disto, tanto as informações às quais eles têm acesso afetam seu estado interno quanto as características e histórico individual interferem na decisão sobre o que cada agente irá falar.

O funcionamento destes agentes foi sendo complexificado e acredita-se que com o uso da função adaptativa se possa reproduzir situações similares àquelas identificadas no mundo real. Visando ilustrar isto, foram apresentados resultados de uma versão combinada (definida pelo autor) onde estão considerados três grupos e tanto a possibilidade de acesso a meios de comunicação em massa e recebimento das informações ali veiculadas quanto troca de mensagens entre membros do mesmo grupo social.

Outro ponto a ser ressaltado refere se à facilidade para se definir regras que os agentes devem cumprir, o que certamente possibilita a obtenção de melhores resultados, sem que sejam necessários testes com cada uma das formas de avaliação para assimilação (máquinas de estado como as definidas aqui, por exemplo), em uma fase de treinamento e a avaliação a posteriori para se definir qual o melhor funcionamento interno dos agentes para uma determinada situação.

Em todos os resultados apresentados foram utilizados até 100 agentes, no entanto, é possível extrapolar o número de pessoas no ambiente estudado, assim como combinar notícias e anúncios a fim de reproduzir a programação de meios de comunicação em massa reais.

\subsection{Possíveis Aplicações}

Como decorrência dos resultados obtidos neste projeto considera-se 0 desenvolvimento de aplicações comerciais onde seja tratada tanto a relação entre 
agentes como a transmissão e publicação de informações. Por exemplo, em (GLOBO, 2011) tem-se um boletim informativo que auxilia empresas na escolha da melhor forma e época do ano para divulgação de seus produtos e marca. A ferramenta que foi apresentada poderia, por exemplo, ser estendida e então utilizada para uma avaliação antes de se iniciar uma campanha publicitária, já que grande parte das avaliações atuais ocorrem quando a campanha já está "no ar" e já teve custos. Neste sentido, com aprimoramentos no desenvolvimento e a configuração apropriada, futuramente deverá ser possível, por exemplo, que:

- Os profissionais de agências de publicidade e propaganda avaliem diferentes possibilidades de divulgação de um produto em determinado (um ou mais) meio de comunicação em massa, identificando a melhor combinação de distribuição de anúncios em qual veículo;

- As emissoras avaliem diferentes grades de programação, uma vez que sejam configuradas corretamente as informações relativas à audiência, podendo realizar alterações e avaliações sem custo de produção e veiculação de programas e/ou anúncios;

- As emissoras avaliem diferentes possibilidades para inclusão de um novo programa na grade de programação, identificando dia, horário, duração mais aconselháveis.

Ao citar estas aplicações, se busca aqui não uma ferramenta perfeita e que apresente resultados que certamente darão retorno, mas sim que, tendo desenvolvimento contínuo, facilite cada vez mais o trabalho de profissionais ligados aos meios de comunicação em massa e que proporcione uma diminuição dos custos.

\subsection{Trabalhos Futuros}

Com relação a trabalhos futuros, muitas são possibilidades, por exemplo, com relação à (aos): 
- Sociedade - definir perfis de agentes com base em informações reais, buscando comparar os resultados do simulador com situações conhecidas;

- Agentes - aprimorar e evoluir a arquitetura de funcionamento de cada um, buscando reproduzir individualidades. Incluir novas formas de avaliação de informações e o vínculo entre amigos de forma que a decisão a respeito do que falar tenha dependência direta de quem é o destinatário;

- Meios de Comunicação em Massa - definir maior granularidade de assuntos, inserir detalhes de grades de programação mais próximas do real. Diferenciar uma emissora de rádio, televisão, transmissão via internet, incluindo peculiaridades de cada situação;

- Rede Social - definição da conectividade de forma dinâmica, ou seja, ao receber uma mensagem o ouvinte deve retornar ao emissor uma avaliação daquilo que recebeu e isto fará com que uma rede totalmente conectada (no início da simulação) se transforme em uma distribuição mais realista, onde grupos com interesses semelhantes se encontrem. A partir disto, identificar os agentes mais importantes naquele contexto e identificar características que o fazem ser assim. Realizar avaliações da quantidade de amigos na dinâmica do fluxo de informações.

Estas são algumas possibilidades de continuação para este trabalho multidisciplinar que visa desenvolver uma aplicação que, pelas entrevistas realizadas com profissionais da Faculdade Cásper Líbero e que trabalham com pesquisa de campo, poderá trazer benefícios comercialmente.

Por fim, agradecimento especial à FAPESP, pois através da bolsa concedida foi possível a realização deste trabalho até aqui. 


\section{REFERÊNCIAS}

AGUIAR, S. (2006) Redes sociais e tecnologias digitais de informação e comunicação - Relatório final de pesquisa. NUPEF rits - Núcleo de Pesquisas, Estudos e Formação da Rede de Informações para o Terceiro Setor. mar-ago.

AHEARN, L. M. (2001) Language and Agency. Annual Review of Anthropology 30 : 109-37.

ALEXANDRE, M. (2001) O papel da mídia na difusão das representações sociais. COMUM, Rio de Janeiro, v. 6, n. 17, p. 111-125, jul./dez.

ALMADA, V. C.; OLIVEIRA, R. F. (1997) Sobre o uso de estatística de simulação em estudos de comportamento. Análise Psicológica, 1 (XV): 97-109.

ALMEIDA, M. B.; BAX, M. P. (2003) Uma visão geral sobre ontologias: pesquisa sobre definições, tipos, aplicações, métodos de avaliação e de construção. Ci. Inf., Brasília, v. 32, n. 3, p. 7-20, set/dez.

ALT, J. K.; LIEBERMAN, S. (2010) Developing Cognitive Models for Social Simulation from Survey Data. Modeling, Virtual Environments and Simulation (MOVES) Institute, Monterey, California.

ALVARES, L. O.; SICHMAN, J. S. (1997) Introdução aos Sistemas Multiagentes. Jornadas de Atualização em Informática. XVII Congresso da SBC, Brasília.

ARANDA, A. L. V. (2005) Televisión y telespectadores. COMUNICAR - Revista Científica de Comunicación y Educación, n. 25, p. 203-210.

AZAMBUJA, P. (2007) Interface e TV Digital: ação e simulação. XXX Congresso Brasileiro de Ciências da Comunicação. Santos, ago. Disponível em: http://www.intercom.org.br/papers/nacionais/2007/.../R0218-1.pdf. Acesso em: 29/09/2010.

BAARS, B. J.; GAGE, N. M. (2007) Cognition, Brain, and Consciousness. Academic Press - Elsevier.

BAPTISTA, L. S. D. P. (2007) Estudo dos Agentes Cognitivos Baseados na Arquitetura BDI e suas Aplicações. Monografia. Faculdade Ubaense Governador Ozanam Coelho, Ubá.

BARBOSA, J. N. (2008) Raciocínio e resolução de problemas. Disponível em http://web.mac.com/jbarbo00/.Public/JuizoPsic-.Mac.pdf.

BARBOSA, G.; RABAÇA, C. (1987) Dicionário de Comunicação. São Paulo: Ática.

BARROS, L.; SILVA, A. T.; MUSSE, S. R. (2004) PetroSim: An Architecture to manage Virtual Crowds in Panic Situations. In: Computer Animation and Social Agents, Genebra. Proceedings of CASA. v. 1. p. 111-120. 
BATISTA, L. L.; CAVALHEIRO, R. F.; LEITE, F. (2008) Mídia e referências: um estudo sobre interações e efeitos. Ciências \& Cognição, vol. 13, n. 3, p. 151-161. dez.

BATISTA, L. L.; RODRIGUES, C. D. R.; BRIZANTE, J. G.; FRANCHESCI, R. (2008) Aspectos cognitivos da percepção na propaganda. Ciências \& Cognição, vol. 13, n. 3, p. 137-150. dez.

BELTRÃO, L.; QUIRINO, N. O. (1986) Subsídios para uma teoria da comunicação de massa. Editora Summus, São Paulo, v. 13.

BEZEK, A.; GAMS, M. (2003) Agent-Oriented Software Engineering: A Comparison of Agent and Non-Agent Version of a Cluster Server. Second International Conference on Autonomous Agents and Multiagent Systems, Melbourne, Australy.

BILLE, W.; PELLENS, B.; KLEINERMANN, F.; TROYER, O. de; (2004) Intelligent Modeling of Virtual Worlds Using Domain Ontologies. In Proceedings of the Workshop of Intelligent Computing (WIC), Mexico City, Mexico, pp. 272-279

BILLE, W.; TROYER, O. de; KLEINERMANN, F.; PELLENS, B.; ROMERO, R. (2004a) Using ontologies to build virtual worlds for the web. Proceedings of the International Conference on WWW/Internet. Madri, oct.

BOND, A. H.; GASSER, L. (1988) A Survey of Distributed Artificial Intelligence. 57 pags. Aug. Disponível em skripta.gootik.net/src/SWI/084/BondGasser.pdf, acessado em 30-03-2011.

BORDENAVE, J. E. D. (2007) O que é Comunicação. São Paulo: Brasiliense, 34ํำ reimpressão da $1^{\underline{a}}$ ed. de 1982. Coleção primeiros passos; 67.

BORDINI, R. H.; VIEIRA, R. (2003) Linguagens de programação orientadas a agentes. Um introdução baseada em AgentSpeak. RITA. v. 10, n. 1. Disponível em http://200.201.81.50/ jorge/LINGUAGENS\%20DE\%20PROGRAMA\%C7\%C3O/ANO \%202010/ARTIGOS\%20 \%20LINKS\%20INTERESSANTES/LP\%20orientada\%20a \%20Agentes\%20Computacionais.pdf.

BOUYER, G. C. (2008) Embodiment: Cognição Incorporada e Comunicação na Atividade de Trabalho. V Jornada de Ergonomia: Trabalho Cooperativo, Confiabilidade Humana e Cognição.

BRAGA, G. M. (1995) Informação, Ciência da Informação: breves reflexões em três tempos. Ciência da Informação, Brasília, vol.24, n.1, pp. 84-88.

BRAGA, B. T. R.; PEREIRA, J. L. A. (2001) Agentes Inteligentes - Conceitos, Características e Aplicações. Trabalho de conclusão de curso. Universidade da Amazônia. Orientador: Prof. Cláudio Alex Rocha.

BRAUN, A. (2004) Modelagem e simulação de multidões humanas em situações de emergência. Dissertação (Mestrado em Computação Aplicada) - UNISINOS Universidade do Vale do Rio dos Sinos, São Leopoldo, RS, Brasil. Orientadora: Soraia Raupp Musse. 
BRAZDIL, P.; GAMS, M.; SIAN, S.; TORGO, L.; VAN DE VELDE, W. (1996)

Learning in Distributed Systems and Multi-Agent Environments. Disponível em http://www.up.pt/ itorgo/papers/ldsme/ldsme.html acessado em 08/10/2010.

BREITMAN, K. K. (2005) Web Semântica: A Internet do futuro. Rio de Janeiro. LTC Editora - Livros Técnicos Científicos.

BRITTOS, V. C.; MIGUEL, J. (2005) Comunicação e mercado: a lógica televisiva moçambicana. In Economia e Políticas da Comunicação. Actas do III SOPCOM, VI LUSOCOM e II IBÉRICO. Vol III.

BURDELIS, M. A. P.; ANDRADE, M. T. C. (2009) Análise, Sob o Ponto de Vista de Adaptatividade, de Sistemas Híbridos em Inteligência Computacional: Algoritmos Genéticos \& Sistemas Nebulosos. In: 3ํWorkshop de Tecnologia Adaptativa - WTA, pg 39 - 45, São Paulo, SP.

CAMPOS, M. L. A. (2004) Modelização de domínios de conhecimento: uma investigação de princípios fundamentais. Ci. Inf. Braília, v. 33, n. 1, p. 22-32, jan/abr.

CARNEIRO, F. F. (2008) Um modelo de rede social on-line para instituições de ensino superior. Trabalho de graduação em Ciência da Computação. Faculdade Governador Ozanam Coelho, Orientador Prof. Clayton Vieira Fraga Filho.

CARRINGTON, P. J.; SCOTT, J.; WASSERMAN, S. (2005) Models and methods in social network analysis. Cambridge: Cambridge University Press. 329p. (Structural analysis in the social sciences, v.27). Notas de Leitura, p. 113.

CARVALHO, A. A. A. (2000) A representação do conhecimento segundo a teoria da flexibilidade cognitiva. Revista Portuguesa de Educação, v. 13, n. 1, Universidade do Minho.

CASARE, S. J. (2005) Uma ontologia funcional de reputação para agentes. Dissertação (Mestrado em Engenharia Elétrica) - USP Universidade de São Paulo, São Paulo, SP, Brasil. Orientador: Jaime Simão Sichman.

CASTELFRANCHI, C. (1998) Modelling Social Action for Al Agents. Artificial Intelligence, 103 (1-2) : 157-182.

CESCON, E. (2009) The interdisciplinary method of research on the consciousness conscious of itself. Ciências \& Cognição 2009; Vol 14 (1): 14-25

CHAUHAN, D.; BAKER, A. D. (1997) JAFMAS - A java-based agent framework for multiagent systems: Development and Implementation. Doctoral Thesis. Department of Electrical \& Computer Engineering and Computer Science University of Cincinnati.

CHAUI, M. (2003) Filosofia volume único. Editora Ática, $1^{\underline{a}}$ edição, 6 $6^{\underline{a}}$ impressão. São Paulo.

CHUNG, K. S. K.; HOSSAIN, L. (2010) Towards a social network model for understanding information and communication technology use for general practitioners in rural Australia. Computers in Human Behavior vol. 26, p. 562-561. 
COMUNICAÇÃO (2008) Comunicação entre personagens. Disponível em www2.dbd.pucrio.br/pergamum/tesesabertas/0210488_04_cap_06.pdf acessado em abril de 2008. Capítulo 06 de uma tese aberta que está inacessível em 08/10/2010.

CONY, C. A. (2007) Simulação de agentes virtuais dotados de percepção sintética em situações de emergência. Dissertação (Mestrado em Computação Aplicada) UNISINOS Universidade do Vale do Rio dos Sinos, São Leopoldo, RS, Brasil. Orientadora: Soraia Raupp Musse.

CONY, C. A.; BICHO, A. L.; JUNG, C. R.; MAGALHÃES, L. P.; MUSSE, S. R. (2007) A perceptive model for virtual agents in crowds. In: Computer Graphics International (CGI), Itaipava. Proceedings of Computer Graphics International, v. 1. p. 141-150.

CORRÊA, C. C. (2009) Decisão. 1ํㅡㄹ Curso de Neurociências e Comportamento do IB - USP.

COURTY, N.; MUSSE, S. R. (2004) Fastcrowd: Real-time simulation and interaction with large crowds based on graphics hardware. IN EUROGRAPHICS/ACM SIGGRAPH SYMP. ON COMPUTER ANIMATION (POSTER SESSION), SCA 04, Grenoble, France, p. 1-9.

COURTY, N.; MUSSE, S. R. (2005) Simulation of large crowds in emergency situations including gaseous phenomena. Computer Graphics, Stony Brook, New York, USA, June 22-24.

CRUZ, E. M. K.; SEGATTO, A. P. (2009) Processos de comunicação em cooperações tecnológicas Universidade-Empresa: estudos de caso em universidades federais do Paraná. RAC, Curitiba, v. 13, n. 3, art. 5, p. 430-449, jul/ago. Disponível em http://www.anpad.org.br/rac.

DEL NERO, H. S. (1998) O Equilíbrio Necessário. (Ed. Collegium Cognitio)

DEMAZEAU, Y. (1995) From interactions to collective behaviour agent-based system. In Proceedings of the 1st European Conference on Cognitive Science, St. Malo.

DEUS, I. M. I. de., (2006) Jornal on-line: personalização do conteúdo através da tecnologia de agentes inteligentes - Dissertação (Mestrado). - Faculdade de Comunicação, Educação e Turismo, Universidade de Marília, Unimar.

DOMINGOS, A. A. (2006) O processo natural de comunicação humana: a emergência da linguagem. XXIX Congresso Brasileiro de Ciências da Comunicação. Universidade de Brasília, setembro.

DRIGO, M. O. (2007) Comunicação e cognição - semiose na mente humana. Porto Alegre: Sulina, Sorocaba: eduniso.

DURFEE, E. H.; LESSER, V. R. (1989) Negotiation Task Decomposition and Allocating Using Partial Global Planning. Distributed Artificial Intelligence, PitmanLondon, Vol. 2, pp. 229-243. Disponível em ftp://dis.cs.umass.edu/pub/lesser/Durfee_DAl_Ch10.pdf, acessado em 30-03-2011. 
FERBER, J. (1999) Multi-Agent Systems: An Introduction to Distributed Artificial Intelligence. Addison-Wesley, New York. Revisão disponível em http://jasss.soc.surrey.ac.uk/4/2/reviews/rouchier.html, acessado em 30-07-2011.

FERNANDES, A. M. R. (2005) Inteligência Artificial: noções gerais, VisualBooks $2^{a}$ impressão, Florianópolis, 160 p.

FERREIRA, S. L. C.; GIRARDI, R. (2002) Arquiteturas de Software Baseadas em Agentes: Do Nível Global ao Detalhado. Revista Eletrônica de Iniciação Científica, v. 2, n. 2, Junho. Disponível em http://www.sbc.org.br/reic/edicoes/2002e2/tutoriais/ArquiteturasDeSoftware BaseadasEmAgentes.pdf.

FITZGERALD, H. E. (1986) Psicologia do desenvolvimento. Ed. Campus. V. 1 e 2, Rio de Janeiro.

FLEISCHHAUER, L. I. A. (1996) O uso da tecnologia de agentes na integração da programação da produção. Dissertação (Mestrado em Engenharia) Universidade Federal de Santa Catarina. Orientador Prof. Fernando Álvaro Ostuni Gauthier.

FRANCISCATO C. E. (2003) A Atualidade no Jornalismo: Bases para sua delimitação teórica. Tese de Doutorado em Comunicação e Cultura Contemporâneas. Salvador.

FRANKLIN, S. (1997) Autonomous agents as embodied Al. Cybernetics and Systems, n. 28, vol. 6, pp. 499-520.

FREITAS, M. C.; PEREIRA, H. B. de B. (2005) Contribuição da análise de redes sociais para o estudo sobre os fluxos de informações e conhecimento. In Proceedings CINFORM - Encontro Nacional de Ciência da Informação VI, Salvador.

FREITAS FILHO, P. J. (2001) Introdução à modelagem e simulação de sistemas. Cap. 1. In: 1Ed. Florianópolis, SC, Brasil: [s.n.].

FUENTE, F. V. (1997) El Poder de la Información (II). In Teoría general de la Información. Madrid: Noesis.

GAO, Z.; REN, L.; QU, Y.; ISHIDA, T. (2005) Virtual space ontologies for scripting agents. MMAS, LNAI 3446, p. 70-85.

GARDNER, H. (1996) A nova ciência da mente. São Paulo: Editora da Universidade de São Paulo. Disponível em http://books.google.com.br/books? id=HTj4CUAy5qoC\&printsec=frontcover\&hl=ptbr\&source=gbs_ge_summary_r\&cad=0\#v=onepage\&q\&f=false, acessado em 30-032011.

GAZZANIGA, M. S. (Editor-in-chief) (1999) The New Cognitive Neurosciences. Second Edition, Massachusetts Institute of Technology.

GIBSON, D. (2000) Making simple work of complex functions. SPLat Controls. Disponível em: http://www.microconsultants.com/tips/fsm/fsmarticl.pdf. Acesso em: 16/09/2010. 
GILBERT, N. (1998) Agent-based social simulation: dealing with complexity. University of Surrey, Guildforr, UK, December.

GLOBO. (2011) Mapa da Mina. Rede Globo, Direção Geral de Comercialização. Disponível em http://comercial.redeglobo.com.br/mapadamina/, acessado em 30-032011.

GOMES, F. S. (2007) Gênesis Habermasiana e o caso de catende: pragmática universal e a economia solidária. Dissertação (Mestrado). Orientador: Prof. Dr. Fernando Guilherme Tenório. Fundação Getúlio Vargas.

GOMIDE, P. I. C. (2000) Crianças e adolescentes em frente à TV: O que e quanto assistem de televisão. Revista Igualdade. Publicação Oficial do Ministério Público do Paraná, Curitiba, v. 8, n. 27, Abril/Junho, p. 35-36.

GREEN, D. W. (1996) Cognitive Science an introduction. Blackwell Publishers.

GRUBER, T. R. (1993) Toward principles for the design of ontologies used for knowledge sharing. International Journal of Human-Computer Studies, v. 43, n. 5/6, p. 907-928.

GUDWIN, R. R. (2010) Introdução à Teoria de Agentes. DCA-FEEC-UNICAMP. Disponível em http://www.dca.fee.unicamp.br/ gudwin/courses/lA009/Aulas.html acessado em 08/10/2010.

GUTIÉRREZ, A. G. (1999) Apoximación al concepto y al objeto de la Información/Documentación. Capítulo I. Do livro introducción a la documentación informativa y periodística. Colección universitaria: ciencias de la información de Juan Carlos Suárez Villegas, p. 23-61.

GUTIÉRREZ, M. A. A. (2005) Semantic Virtual Environments. Tese (doutorado em Ciências) na Escola Politécnica Federal de Lausanne. Orientadores Prof. Dr. Daniel Thalmann e Prof. Dr. Frédéric Vexo.

HAN, S.; LERNER, J. S. (2009) Decision Making. In D. Sander and K. Scherer (Eds.), The Oxford Companion to the Affective Sciences. New York: Oxford University Press. p. 1-12.

HEILMAN, K. D.; LIGHT, A.; MUSEMBWA P. (1995) Intelligent Agents: A Technology and Business Application Analysis. http://www.mines.unancy.fr/ gueniffe/CoursEMN/I31/heilmann/heilmann.html

HEINEN, F. (2002) Sistema de Controle Híbrido para Robôs Móveis Autônomos. 2002. 130 f. Dissertação (Mestrado em Computação Aplicada) - Universidade do Vale do Rio dos Sinos - UNISINOS. Orientador: Fernando Santos Osório.

HELBING, D.; FARKAS, I.; VICSEK, T. (2000) Simulating dynamical features of escape panic. NATURE, v. 407, n. 6803, p. 487-490, September 28.

HELBING, D.; MOLNAR, P. (1995) Social force model for pedestrian dynamics. In: PHYSICAL REVIEW. V. 51, n. 5, p. 4282-4286. 
HELBING, D.; MOLNAR, P. (1998) Self-organization phenomena in pedestrian crowds. In: SELF-ORGANIZATION OF COMPLEX STRUCTURES: FROM INDIVIDUAL TO COLLECTIVE DYNAMICS. Gordon and Breach, London: F. Schweitzer (Ed.), p. 569-577.

HRUSCHKA, D. J.; CHRISTIANSEN, M. H.; BLYTHE, R. A.; CROFT, W.; HEGGARTY, P.; MUFWENE, S. S.; PIERREHUMBERT, J. B.; POPLACK, S. (2009) Building social cognitive models of language change. Cell Press, Elsevier. oct.

HUHNS, M. N.; SINGH, M. P. (1997) Ontologies for agents. IEEE Internet Computing. nov/dec.

HURFORD, J. R.; STUDDERT-KENNEDY, M.; KNIGHT, C. (1998) Evolution of Language. Cambridge University Press.

HÜSKES, M.; SILVEIRA, A.; TONTINI, G. (2003) O marketing de relacionamento e os programas de fidelização de clientes em supermercados da região sul do Brasil. Iberoamerican Academy of Management Third International Conference, v. 3, p. 127. São Paulo.

IBOPE (2010) WebRF. Revista GIRO, ed. 10, ano 3, jul/ago/set. Disponível em http://www.ibope.com.br/giroibope/10edicao/webrf.html acessado em 16/10/2010.

ITO, M. (1997) Uma análise do fluxo de comunicação em organizações dinâmicas de agentes. Dissertação (Mestrado) apresentada à Escola Politécnica da Universidade de São Paulo. Orientador: Jaime Simão Sichman.

IZQUIERDO, I. (2007) A Arte de Esquecer. VII São Paulo Research Conferences Cérebro e Pensamento, agosto.

JACKENDOFF, R. (2002) Foundations of Language: Brain, Meaning, Grammar, Evolution. Oxford University Press.

JENNINGS, N. R. (2001) An agent-based approach for building complex software systems, Communications of the ACM vol. 44 (4).

JENNINGS, N. R.; WOOLDRIDGE, M. (1996) Software Agents. In: IEEE Review, p. 17-20.

JOHNSON-LAIRD, P.N. (1988) The computer and the mind: an introduction to cognitive science. Cambridge, MA: Harward Press. Disponível em http://books.google.com.br/books?id=Tf5gRFgVuegC\&printsec=frontcover\&source=g bs_ge_summary_r\&cad=0\#v=onepage\&q\&f=false acessado em 30-03-2011.

JURAFSKY, D.; MARTIN, J. H. (2000) Speech and Language Processing: an introduction to natural language processing, computational linguistics, and speech recognition. Prentice Hall.

KABBAJ, A. (2009) A (sequential) map for a visit of Amine Platform. Versão 6.0 INSEA, Rabat, Morocco. Disponível em: http://amineplatform.sourceforge.net/intro.htm\#A (sequentiel) map. Acesso em nov. 2010. 
KAY, A. (1984) Computer Software. Scientific American, v. 3, n.251, p.41-47.

KIHLSTROM, J. F.; PARK, L. (2002) Cognitive Psychology, Overview. Encyclopedia of the Human Brain, Elsevier Science (USA), vol. 1, p. 839-853.

KRISTENSEN, C. H.; ALMEIDA, R. M. M.; GOMES, W. B. (2001) Desenvolvimento histórico e fundamentos metodológicos da neuropsicologia cognitiva. Psicologia: Reflexão e Crítica, 14 (2), p. 259-274.

LABNEC (2009). 1ํㅡㄹ Curso de Neurociências e Comportamento, Instituto de Biociências, Universidade de São Paulo.

LABROU, Y.; FININ, T.; PENG, Y. (1999) Agent Communication Languages: The Current Landscape. IEEE Intelligent Systems, 14(2), 45-52.

LAGE, L. (2000) Publicidade e Propaganda Comunitária - Polígrafo Acadêmico,.

LAPPIN, S. (1997) The Handbook of contemporary semantic theory. Edited by Shalom Lappin. Blackwell Publishers.

LAW, A. M.; KELTON, W. D. (1991) Simulation modeling and analysis. In: McgrawHill, Inc. New York, London: Second Edition. Com partes disponíveis em http://www.mhhe.com/engcs/industrial/lawkelton/, acessado em 30-03-2011.

LEÃO, A. L. M. S.; MELLO, S. C. B. (2009) Atividades marcárias na vida cotidiana dos consumidores: descoberta de uma nova forma de pensar as marcas? RAC. Curitiba, v. 13, n. 1, art.6, p. 92-116, jan-mar. Disponível em http://www.scielo.br/scielo.php?pid=S1415-65552009000100007\&script=sci_arttext.

LE COADIC, Y. F. (2004) A ciência da informação. 2. ed. Brasília: Briquet de Lemos.

LIMA, G. A. B. (2003) Interfaces entre a ciência da informação e a ciência cognitiva. Ciência da. Informação, Brasília, vol. 32, n. 1, p. 77-87.

LIMA JUNIOR, W. T. (2009) Mídia social conectada: produção colaborativa de informação de relevância. LíBERO. V. 12, n. 24, p. 95-106, São Paulo.

LORENZI, F.; SANTOS, D. S.; BAZZAN, A. L. C. (2005) Case-based recommender system inspired by social insects. XXV Congresso da Sociedade Brasileira de Computação, São Leopoldo. Disponível em: http://www.sbc.org.br/bibliotecadigital/download.php\%3Fpaper\%3D327+Casebased+recommender+system+inspired+by+social+insects. Acesso em 2010.

LUIZ, R. R. (2006) Avaliação de produtividade acadêmica: uma proposta de quantificação. RBPG, Brasília, v. 3, n. 6, p. 300-312, dez.

LUPETTI, M. (2006) Administração em Publicidade: A Verdadeira Alma do Negócio. Pioneira Thomson Learning, São Paulo.

MAES, P. (1994) Modeling Adaptive Autonomous Agents. Artificial Life I, vol. I \& 2, n. 9. 
MAES, P. (1995) Artificial life meets entertainment: lifelike autonomous agents. Comunications of ACM, v. 38, n. 11, p. 108-114.

MAGLIO, P.; BARRET, R. (2000) Intermediaries Personalize Information Streams. Communications of the ACM, v. 43, n. 8, p. 96-101. Disponível em http://delivery.acm.org/10.1145/350000/345158/p96maglio.pdf?key $1=345158 \&$ key $2=9109756821 \&$ coll=GUIDE\&dl=GUIDE\&CFID $=10792$ 7615\&CFTOKEN=58401269, acessado em 08/10/2010.

MALANGA, E. (1979) Publicidade uma introdução. Editora Atlas, terceira edição.

MARCHELLI, L. B. (2009) Memória. $1^{\circ}$ Curso de Neurociências e Comportamento do IB - USP.

MARTELETO, R. (2001) Análise de redes sociais - aplicação nos estudos de transferência da informação. Ci. Inf. vol.30, no.1, p. 71-81. Brasília Jan./Apr.

MARTINO, L. C. (2001) De qual comunicação estamos falando? Em Teorias da Comunicação - Conceitos, escolas e tendências. Rio de Janeiro: Ed. Vozes.

MEDNICK, S. A. (1973) Aprendizagem. Curso de psicologia moderna, quarta edição, Zahar editores, Rio de Janeiro.

MELLO, M. (2003). Reflexões sobre Linguística e cognição musical. Dissertação (Mestrado realizado no Instituto de Estudos da Linguagem), Universidade Estadual de Campinas. Disponível em http://www.marcelomelloweb.kinghost.net/mmreflexoes.html acessado em 08/10/2010.

MENEGUZZI, F. R. (2004) Planejamento Proposicional em Agentes BDI. Porto Alegre. 138 p. Dissertação (Mestrado) Fac. de Informática, PUCRS. Disponível em http://www.pucrs.br/inf/pos/mestdout/dissertacoes/arquivos/fmeneguzzi.pdf, acessado em 30-03-2011.

MENESES, E. X. (2001) Jornada de Atualização em Inteligência Artificial Integração de Agentes de Informação. Disponível em:

http://www.ime.usp.br/ eudenia/jaia/. Acesso em: 09/09/2010

MERLO-FLORES, T. (1999) Por que assistimos à violência na televisão? Pesquisa de campo argentina. Em Ulla Carlsson \& Cecilis von Feilitzen (orgs.) A criança e a violência na mídia. Cortez Editora: Brasília: Brasil.

MEUNIER, J. P.; PERAYA, D. (2008) Introdução às Teorias da Comunicação. Vozes, Petrópolis.

MIKA, P. (2007) Social Network and Semantic Web. Barcelona: Springer.

MOURA, S. A. De. (2002) Teorias Cognitivas da Aprendizagem. Apresentação realizada na UFRJ, disponível em http://www.api.adm.br/ufrj/conhecimento/aprendizagemporassociacao.ppt, acessada em 30-03-2011. 
MOYA, L. J.; TOLK, A. (2007) Towards a Taxonomy of Agents and Multi-Agent systems. In. springsim '07: Proceedings of the Spring Simulation Multiconference.

MUELLER, S. P. M. (2007) Métodos para pesquisa em Ciência da Informação / Suzana Pinheiro Machado Mueller, organizadora - Brasília : Thesaurus, 192 p. Cap. 5.

MUNIZ, E. (2004) Publicidade e Propaganda: origens históricas. Cadernos Universitários - Introdução. À Publicidade e Propaganda, Canoas, v. 1, n. 148, p. 5163.

MUSSE, S. R. (2001) Behavioral Modeling of Virtual Human Actors, Revista de Informática Teórica e Aplicada, Vol. 8, No. 2. Disponível em <http://www.inf.ufrgs.br/ revista/docs/rita08/rita_v8_n2_p125a141.pdf>. Acesso em 06 jun 2008.

MUSSE, S. R.; THALMANN, D. (2001) Hierarchical Model for Real Time Simulation of Virtual Human Crowds, IEEE Trans. on Visualization \& Computer Graphics, 7(2), pp. 152-164.

NARDIN, L. G. (2009) Uma arquitetura de apoio à interoperabilidade de modelos de reputação de agentes. Dissertação (Mestrado em Engenharia Elétrica) - USP Universidade de São Paulo, São Paulo, SP, Brasil. Orientador: Jaime Simão Sichman.

NETO, A. F. B. (2009a) Uma arquitetura para o desenvolvimento de agentes cognitivos com personalidade e emoção. Dissertação (Qualificação de Mestrado em Ciência da Computação). Instituto de Matemática e Estatística da Universidade de São Paulo. Orientador Prof. Dr. Flávio Soares Corrêa da Silva.

NETO, J. J. (2009b) Adaptatividade: generalização conceitual. 3o Workshop de tecnologia Adaptativa - WTA, São Paulo.

NETO, J. J. (2009c) Um glossário sobre Adaptatividade. 3ํWorkshop de tecnologia Adaptativa - WTA, São Paulo.

NETTO, M. L. (2007) Computação Evolutiva e Cognitiva: simulação em vida artificial e cognição. Tese de Livre Docência. Escola Politécnica da USP - São Paulo. 208 p.

NORONHA, D. P.; SILVA, J. F. M.; FUNARO, V. M. B. O.; IGAMI, M. P. Z.; TOLEDO, S. R. P. C. S (2007) Comunicações em eventos da área da ciência da informação: contribuição dos docentes dos programas de pós-graduação.

NWANA, H. S. (1996) Software Agents: An Overview. Knowledge Engineering Review, Cambridge University Press, vol. 11, No 3, p. 1-40.

OINAS-KUKKONEN, H.; LYYTINEN, K.; YOO, Y. (2010) Social networks and information systems: ongoing and future research streams. Journal of the Association for Information Systems. v. 11, n. 2, p. 61-68.

OLIVEIRA, F. M. (1996) Inteligência Artificial Distribuída. In: IV Escola Regional de Informática, pp 54-73, Abril. 239 p. 
PAIVA, D. C. (2006) Modelagem e Simulação de Multidões Humanas em Situações da Vida Cotidiana usando Ontologias. Dissertação (Mestrado em Computação Aplicada) - UNISINOS Universidade do Vale do Rio dos Sinos, São Leopoldo, RS, Brasil. Orientadora: Soraia Raupp Musse.

PAIVA, D. C. de; VIEIRA, R.; MUSSE, S. R. (2005) Ontology-based crowd simulation for normal life situations. In: Proceedings of Computer Graphics Internationa. Stony Brook, New York, USA.

PAN, X. (2006) Computational Modeling of Human and Social Behaviors for Emergency Egress Analysis. Technical Report \#165. Stanford University.

PCHELKIN, A. (2004) General Aspects of Constructing an Autonomous Adaptive Agent. International Journal on Information Theories \& Applications, vol. 11, pp. 337344. Institute for Information Theories and Applications, Sofia, Bulgaria.

PELECHANO, N.; ALLBECK, J. M.; BADLER, N. I. (2008) Virtual Crowds: Methods, Simulation, and Control. Morgan \& Claypool. 188 pags.

PELECHANO, N.; BADLER, N. I. (2006) Modeling crowd and trained leader behavior during building evacuation. IEEE Computer Graphics and Applications, Nov., pp. 8086.

PEREIRA, H. B. B.; FREITAS, M. C. e SAMPAIO, R. R. (2007). Fluxos de informações e conhecimentos para inovações no arranjo produtivo local de confecções em Salvador, DataGramaZero - Revista de Ciência da Informação vol. 8, n. 4, Bahia.

PEREIRA, L. L.; VIAPIANA, S. L. (2004) A influência do posicionamento de marca no processo decisório de compra do consumidor adolescente no município de Cascavel. VII SEMEAD - São Paulo.

PERLES, J. B. (2010) Comunicação: conceitos, fundamentos e história. Disponível em: http://www.bocc.uff.br/pag/perles-joao-comunicacao-conceitos-fundamentoshistoria.pdf. Acesso em 13/10/2010.

PINHEIRO, L. V. (2007) As redes cognitivas e a produção do conhecimento em ciência da informação: um estudo nos periódicos da área. Dissertação (Mestrado em Ciência da Informação) - Universidade Federal de Santa Catarina. Orientadora Dra. Edna Lúcia da Silva.

PINHEIRO, L. V.; SAVI, M. G. M. (2005) O fluxo de informação na comunicação científica: enfoque nos canais formais e informais. Trabalho apresentado por Liliane pinheiro na disciplina Fontes de Informação, Profa. Ursula Blattmann. Disponível em: http://www.ced.ufsc.br/ ursula/3211/liliane.ppt acessado em 08/10/2010.

PINTO, A. S. (2008) Simulação e Avaliação de Comportamentos em Sistemas MultiAgentes baseados em Modelos de Reputação e Interação. Dissertação (Mestrado em Computação Aplicada) - Universidade do Vale do Rio dos Sinos, São Leopoldo.

PLETSCH, E. (2006) Modelagem de Percepção de Humanos Virtuais baseada em dados Geométricos e Ray-Casting. Dissertação (Mestrado em Computação 
Aplicada) - Universidade do Vale do Rio dos Sinos. Orientador: Soraia Raupp Musse.

POSNER, M. I. (1998) Foundations of cognitive science. MIT press paperback edition. 6⿳⺈ $\mathrm{imp}$.

PROENÇA, H. P. M. C. (2003) MARCS - Sistema Multi-Agente para Controlo de Tráfego Ferroviário. Dissertação (mestrado) em Inteligência Artificial e Ciências da Computação. Faculdades de Ciências, Economia e Engenharia - Universidade do Porto.

QUINTANILHA, T.; ALMEIDA, M.. (2008) Redes sociais e empreendedorismo em pequenas empresas de base tecnológica no Brasil. Revista Digital - Buenos Aires Ano 13, n. 119, abr. Disponível em http://www.efdeportes.com/efd119/redes-sociaisem-pequenas-empresas-de-base-tecnologica-no-brasil.htm, acessado em 30-032011.

RADEMACHER, P. (1999) GLUI: A GLUT-Based User Interface Library. Version 2.0.

RAO, A. S.; GEORGEFF, M. P. (1991) Modeling Rational Agents within a BDIArchitecture. In Proceedings of the 2nd International Conference on Principles of Knowledge Representation and Reasoning. Morgan Kaufmann. Editors James Allen, Richard Fikes and Erik Sandewall, pages 473-484.

RECUERO, R. C. (2009) Redes sociais na internet: considerações iniciais. Núcleo de Pesquisa (NP-8) de Tecnologias da Comunicação e Informação do IV Encontro dos Núcleos de Pesquisa da XXVII INTERCOM Congresso Brasileiro de Ciências da Comunicação. Porto Alegre, Setembro.

REYNOLDS, C. W. (1987) Flocks, herds and schools: a distributed behavioral model. In: Proc. of 14Th Conf. On Computer Graphics and Interactive Techniques, Siggraph 87. Edited By Maureen C. Stone: ACM PRESS,. v. 21, n. 4, p. 25-34.

REZENDE, F. M. (2003) Utilizando padrões de comunicação entre agentes num framework de suporte à mobilidade em CLI. Monografia (Graduação em Ciência da Computação). Universidade de Tiradentes, Aracaju. Orientador Marco Antonio Costa Simões.

RHEINHEIMER, L. R. (2004) WSAgent: Um Agente Baseado em Web Services para Promover a Interoperabilidade entre Sistemas Heterogêneos no Domínio da Saúde. Dissertação de Mestrado apresentada à Universidade do Vale do Rio dos Sinos, São Leopoldo.

RIBEIRO, C. (2003) Metacognição: um apoio ao processo de aprendizagem. Psicologia: reflexão e crítica, v. 16, n.1, p. 109-116.

RICH, E.; KNIGHT, K. (1993) Inteligência Artificial. McGraw-Hill, 20 Ed. São Paulo.

RICKEL, J.; JOHNSON, W. (1997) Integrating Pedagogical Capabilities in a Virtual Enviroment Agent. Proceedings of the First International Conference on Autonomous Agents, p. 30-38. 
ROCHA, L. (1996) From Artificial Life to Semiotic Agents Models. Disponível em http://lib-www.lanl.gov/la-pubs/00460075.pdf.

ROSVALL, M. (2003) Complex Networks and Dynamics of an Information Network Model. Dissertação (Mestrado em Engenharia Física). Universidade de Umea. Sweden. Orientadores Kim Sneppen e Petter Minnhagen.

ROZADOS, H. B. F. (2003) A Ciência da Informação em sua aproximação com as Ciências Cognitivas. Em Questão, Porto Alegre, V. 9, n. 1, p. 79-94, jan/jun.

RUSSEL, S.; NORVIG, P. (2004) Inteligência Artificial. Tradução da segunda edição, Elsevier, Rio de Janeiro, RJ, Brasil.

SÁ, D. B. S. e. (2008) Telespectador: o senhor da comunicação. Dissertação (Mestrado em Cognição e Linguagem). Universidade Estadual do Norte Fluminense Darcy Ribeiro, Centro de Ciências do Homem. Orientador: Prof. Carlos Henrique Medeiros de Souza.

SANTOS, B.; CASTRO, F; BRAZ, G.; CATÃO, L.; ISRAEL, P.; ANDRADE, S.; BELCHIOR, W. (2003) Programa de Aprimoramento Discente em Modelagem Geométrica - Curso básico de OpenGL. Universidade Federal de Minas Gerais, Belo Horizonte.

SANTOS, C. L. R.; SICHMAN, J. S. (1997) Significado e representação de organizações em sistemas multiagentes: uma análise preliminar. Anais do I Encontro Nacional de Inteligência Artificial. Brasília.

SANTOS, G. (2005) Princípios da Publicidade, Editora UFMG, Belo Horizonte.

SARACEVIC, T. (1996) Ciência da Informação: origem, evolução e relações.

Perspectivas em Ciência da Informação, Belo Horizonte, v. 1, n. 1, p. 41-62, jan. /jun. Disponível em http://www.scribd.com/doc/6837453/Tefko-Saracevic-Ciencia-dainformacao-origem-evolucao-e-relacoes, acessado em 30-03-2011.

SHREINER, D.; WOO, M.; NEIDER, J.; DAVIS, T. (2007) Open GL Programming Guide - The official guide to learning. Version 2, 15 $\mathrm{Ed}$.

SICHMAN, J. S.; DEMAZEAU, Y.; BOISSIER, O. (1992) When can Knowledgebased Systems be Called Agents?. XII Congresso da Sociedade Brasileira de Computação - IX Simpósio Brasileiro de Inteligência Artificial. pp 172-185, Rio de Janeiro.

SIEMENS, G. (2005) Ciclo de desenvolvimento da aprendizagem. Disponível em http://www.webcompetencias.com/textos/cda.htm. Acessado em 21/10/2009.

SILVA, A. T. (2005) Geração automática de populações de personagens virtuais. Dissertação (Mestrado em Computação Aplicada) - UNISINOS Universidade do Vale do Rio dos Sinos, São Leopoldo, RS, Brasil. Orientadora: Soraia Raupp Musse.

SILVA, F. J. A.; SILVA, F. J. (2007) A comunicação científica e o pesquisador - um ensaio cienciométrico. Revista Tecnológica Fortaleza, v. 28, n. 1, p. 18-32, jun. 
SIMPKINS, B.; SIEK, W. R.; SMART, P. R.; MUELLER, S. T. (2010) Idea propagation in Social Networks: The Role of 'Cognitive Advantage'. In: NetworkEnabled Cognition: The Contribution of Social and Technological Networks to Human Cognition, Lulu Press, Raleigh, North Carolina, USA. (Pre-publication).

SÓLIO, M. B. (2006) O discurso gráfico como ferramenta de produção de significação na comunicação organizacional. UNIrevista. V. 1, n. 3. Junho.

STEHLÉ, J.; BARRAT, A.; BIANCONI, G. (2010) Dynamical and bursty interactions in social networks. PACS n. 89.75.-k,64.60.aq,89.65.-s.

SUGAHARA, C. (2008) Um estudo sobre fluxos de informação em redes sociais. Projeto de Doutorado submetido à Escola de Comunicação e Artes da USP.

SUGIYAMA, S.; ABE, N.; TANAKA, K.; TAKI, H.; YAGI, T. (2004) Autonomous virtual human research for dialog system. Proceedings of the IEEE Conference on Cybernetics and Intelligent Systems, Singapore, Dec.

SUTTON, R. S. (1990) Reinforcement Learning Architectures for Animats. In International workshop on simulation of adaptative behavior I, Cambridge: MIT Press. P. 288-296.

TAMANAHA, P. (2006) Planejamento de mídia. São Paulo, Prentice Hall. Revisão.

THALMANN, D.; MUSSE, S. R. (2007) Crowd Simulation. 1ed. London SpringerVerlag. v1, 245p.

THOMPSON, J. J. (1973) Anatomia da Comunicação. Editora Bloch. $2^{\underline{a}}$ edição.

TOKORO, M. (1994) Agents: Towards a Society in Which Humans and Computer Cohabitate. In: Proceedings of the 6th European Workshop on Modelling Autonomous Agents, Odense, Denmark.

TOM MICRO (2010) Software de análise, planejamento e otimização de mídia da Ipsos Marplan. Disponível sua descrição em http://www.ipsos.com.br/.

TOMAÉL, M. I. (2008) Redes de Conhecimento. DataGramaZero: revista de Ciência da Informação, Rio de Janeiro, RJ, Brasil, Vol. 9, N. 2, abr.

TORRES, J. A. R.; MACIEL, A.; NEDEL, L. P. (2002) Uma arquitetura para animação de humanos virtuais com raciocínio cognitivo. Symposium on Virtual Reality, Fortaleza.

TROIANO, J. (2009) Como cuidar e lucrar com suas marcas. BIP, n. 567, pp. 6-7, dez.

TSAMPOULATIDIS, I.; NIKOLAKIS, G.; TZOVARAS, D.; STRINTZIS, M. G. (2004) Ontology based interactive graphic environment for product presentation. Proceedings of the Computer Graphics International.

VERONEZZI, J. C. (2010) Planejamento de mídia: um roteiro básico. Revisão disponível em http://www. midianet.net. 
VIAPIANA, S. L. (2010) Estratégia e planejamento de mídia e medidas alternativas. Disponível em

http://www.fasul.edu.br/pasta_professor/downloader.php?lay=\&id=3010 acessado em 08/10/2010.

WEISS, G. (1999) Multiagent Systems A Modern Approach to Distributed Artificial Intelligence. London, The Mit Press, 580p.

WILKENS, R. S.; MORAES, M. C. (2007) Proposta de uma ontologia para representar e gerenciar emoções em agentes. Workshop - Escola de Sistemas de Agentes para Ambientes Colaborativos. Pelotas, RS. Disponível em http://www.inf.pucrs.br/ ontolp/downloads-emocoes.php acessado em 08/10/2010.

WILSON, R. A.; KEIL, F. C. (1999) The MIT encyclopedia of the cognitive sciences. Editado por Robert A. Wilson, Franck C. Keil.

WOOLDRIDGE M.; JENNINGS N. R. (1994) Formalizing the Cooperative Problem Solving Process. In M. Klein, editor, Proceedings of the Thirteenth International Workshop on Distributed Artificial Intelligence (IWDAI-93), Lake Quinalt, WA.

WOOLDRIDGE, M. (1999) Intelligent Agents. WEISS, G. (Ed.) Multiagent Systems A Modern Approach to Distributed Artificial Intelligence. MIT Press.

WOOLDRIDGE, M. (2009) An Introduction to MultiAgent Systems. 2nd edition. John Wiley \& Sons - Chichester, England. Partes do livro acessadas em http://www.csc.liv.ac.uk/ mjw/pubs/imas/imas2e.html, 11 nov. 2010.

YEPES, I. (2003) Sistemas Multi-Agentes. Projeto ISIS. Disponível em http://www.oocities.com/igoryepes/agentes.htm acessado em 11 nov. 2010.

YEPES, I.; BARONE, D. A. C. (2003) Inteligência Artificial Distribuída: Uma Abordagem ao Comportamento Social Inteligente. In: BARONE, D. (Ed.). Sociedades Artificiais. Porto Alegre: Bookman. cap. 9, p. 231-250.

ZAMBERLAM, A. O.; GIRAFFA, L. M. M. (2001) Manual do X-BDI. PUCRS, Porto Alegre, abr. Disponível em http://www.pucrs/inf/pos/mestdout/rel_tec/tr009.pdf.

ZAMBERLAM, A. O., GIRAFFA, L. M. M. (2001a) Modelagem de agentes usando a arquitetura BDI. PUCRS, Porto Alegre, abr. Disponível em http://www3.pucrs.br/pucrs/files/uni/poa/facin/pos/relatoriostec/tr008.pdf acessado em 08/10/2010. 


\section{BIBLIOGRAFIA COMPLEMENTAR}

ATKINSON, R. C.; SHIFFRIN, R. M. (1971) The Control of short-term memory. Scientific American, New York, v. 225, n. 2, p. 82-90.

BRANDSHAW, J. M. (1997) Software Agents. Cambridge: MIT.

HOUAISS, A.; VILLAR, M. S. (2001) Minidicionário Houaiss da língua Portuguesa. Rio de Janeiro, Objetiva, primeira edição.

INGEDORE, G.; VILHAÇA, K. (2002) Argumentação e Linguagem. 8 ed. São Paulo: Corteza.

MILLER, G. A. (1956). The magical number seven, plus or minus two: Some limits on our capacity for processing information. Psychological Review 63 (2): 343-355.

MINSKY, M. (1980) A framework for representing knowledge. In: HAUGELAND ed. Mind design: philosophy, psychology, Artificial Intteligence. Bradford Book.

NEGROPONTE, N. (1995) A Vida Digital. São Paulo: Companhia das Letras.

WEAVER, W. (1949) Recent contributions to the mathematical theory of communication. Mathematical Theory of Communication. Sept. Disponível em Recent contributions to the mathematical theory of communication. 


\section{APÊNDICE A - PUBLICAÇÕES REALIZADAS}

Durante o período do doutorado foram desenvolvidos alguns trabalhos os quais até o momento geraram as publicações que estão descritas a seguir:

SILVA, A. F.; PAIVA, D. C.; Proposta de arquitetura de Agente Inteligente para Web Semântica. In: I Seminário de Tecnologia da Informação Aplicada (STIA), Chapecó. STIA, 2008. (Desenvolvido pelo doutorando juntamente com uma aluna de graduação. Foi realizada no período inicial do doutorado e é acessório em relação ao projeto que está sendo realizado.)

CARNEIRO, F. de F.; FRAGA FILHO, C. V.; PAIVA, D. C. Proposta de uso de redes sociais por instituições de ensino. 2008. (Poster). In: I Seminário de Tecnologia da Informação Aplicada (STIA), Chapecó. STIA, 2008. (Desenvolvido pelo doutorando juntamente com um aluno de graduação. Foi realizada no período inicial do doutorado e é acessório em relação ao projeto que está sendo realizado.)

RINALDI, L. C.; PAIVA, D. C.; NETTO, M. L. Uso de Realidade Virtual em Vida Artificial. In: Rosa Maria Costa; Marcos Wagner S. Ribeiro. (Org.). Aplicações de Realidade Virtual e Aumentada. Porto Alegre / RS: Sociedade Brasileira da Computação - SBC, 2009, v. , p. 30-52.

PAIVA, D. C.; SILVA, J. A. G.; NETTO, M. L. Um Simulador de Multidões em Situações de Emergência seguindo Recomendações da CIPA. In: II Congresso Tecnológico InfoBrasil, 2009, Fortaleza / CE. II Congresso Tecnológico InfoBrasil, 2009.

MUCHERONI, M. L.; PAIVA, D. C.; NETTO, M. L. As Ontologias Clássicas e a Web Semântica. In: Encontro Nacional de Ensino e Pesquisa em Informação - CINFORM, 2009, Salvador - BA. Anais do IX CINFORM. Salvador - BA: Instituto de Ciência da Informação - Edufba, 2009. v. 1. p. 1-13.

PAIVA, D. C.; SILVA, J. A. G. ; NETTO, M. L. Um Simulador de Decisão Humana em Situações de Emergência. In: CLEl, 2009, Pelotas - RS. CLEl Electronic Journal, 2009.

PAIVA, D. C.; MUCHERONI, M. L.; NETTO, M. L. Um Modelo para Rede s de Conhecimento Científico. In: I Portuguese and Multi-lingual Ontologies Workshop, 2009, São Carlos. The 7th Brazilian Symposium in Information and Human Language Technology, 2009.

MUCHERONI, M. L.; PAIVA, D. C.; NETTO, M. L. TRÊS ONTOLOGIAS CLÁSSICAS E A WEB SEMÂNTICA. Revista Ponto de Acesso (UFBA), v. 3, p. 281-298, 2009.

PAIVA, D. C.; NETTO, M. L. A Model for Social Behavior to Evaluate the Information Flow. World Congress on Communication and Arts, Guimarães, PT, 2010. 
APÊNDICE B - VERSÃO MAIOR DA FIGURA 16.

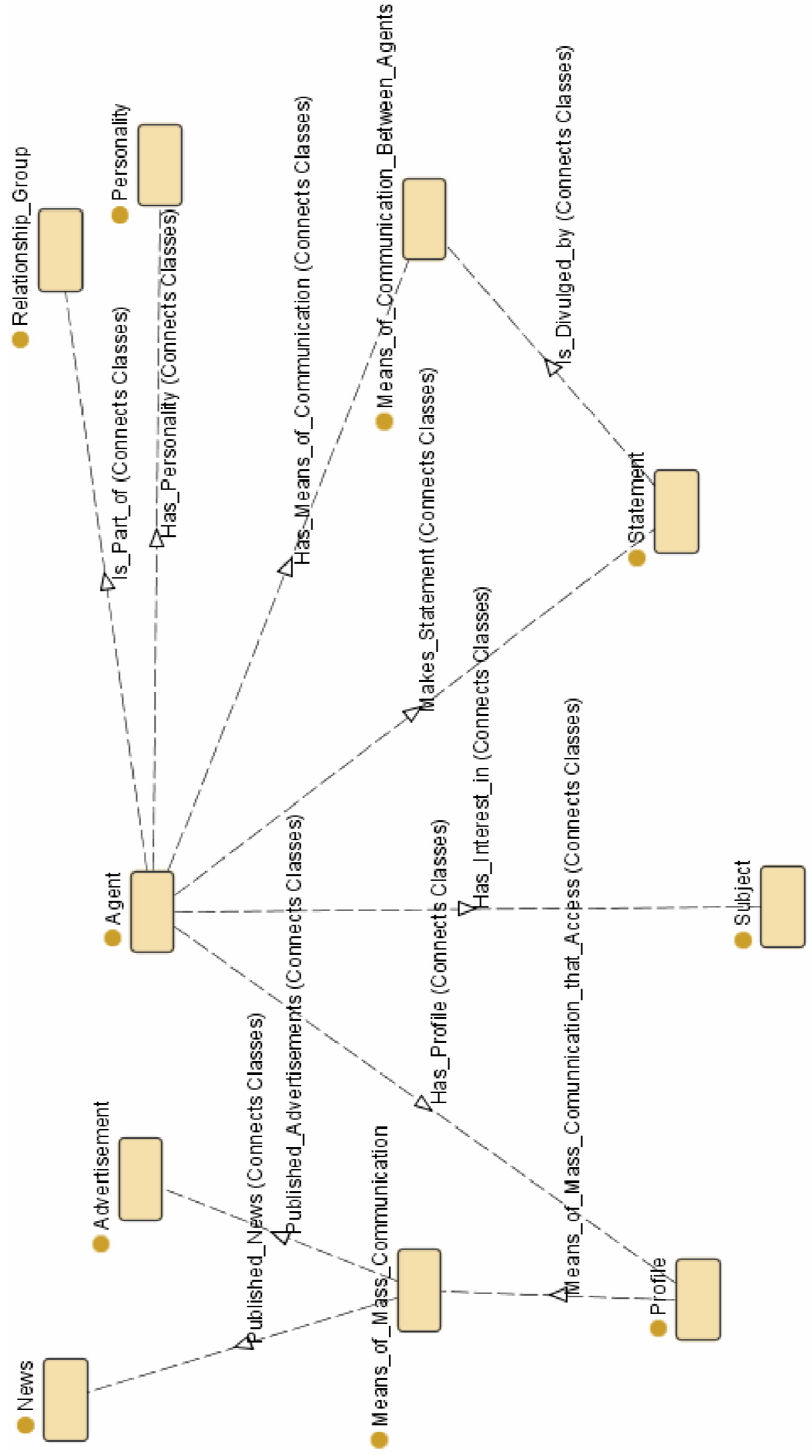


